\title{
Effects of Massage Therapy and Touch on Quality of Life Outcomes for Autologous Stem Cell Transplant Patients
}

\author{
Audrey Elizabeth Wright Snyder \\ Madison, Virginia
}

B.S.N., University of Virginia, 1989

M.S.N., University of Virginia, 1991

A Dissertation Presented to the Graduate Faculty of the University of Virginia in Candidacy for the Degree of Doctor of Philosophy

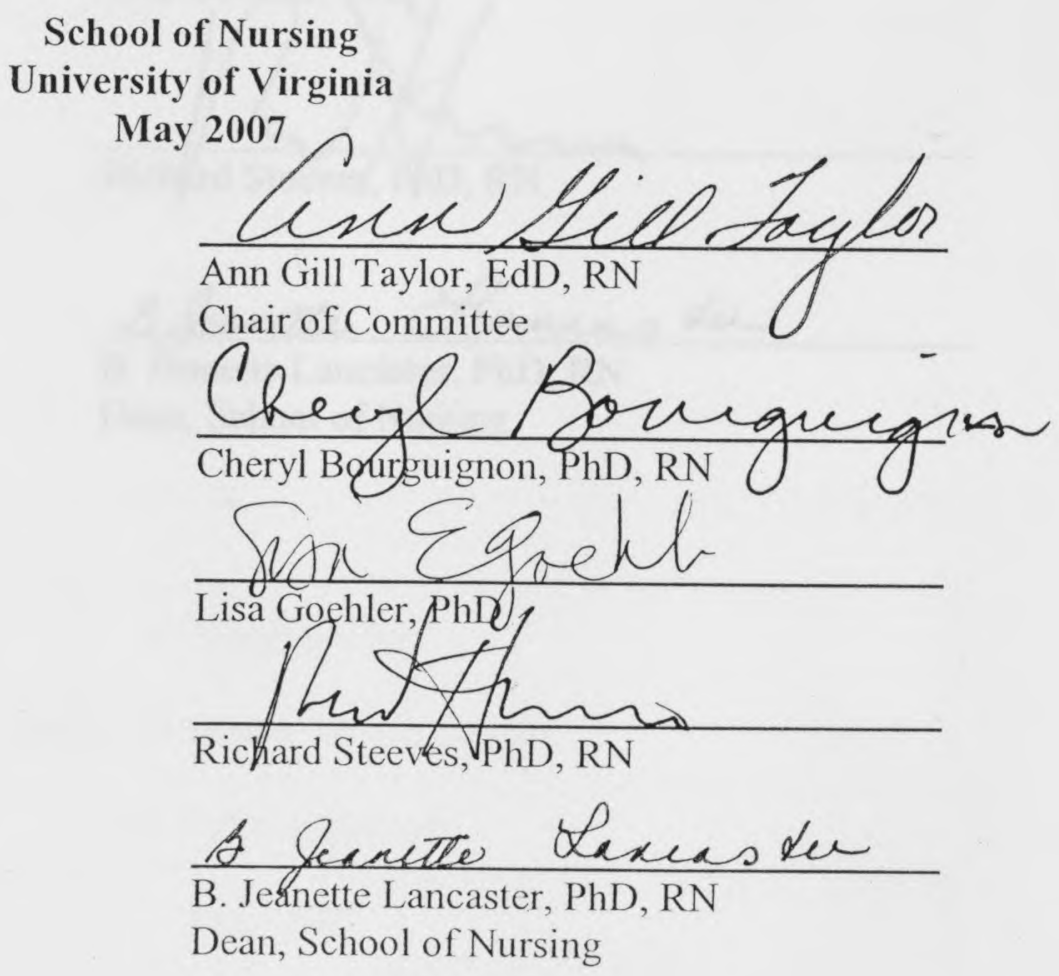




\title{
UNIVERSITY OF VIRGINIA \\ SCHOOL OF NURSING
}

\author{
Doctoral Program
}

\section{DISSERTATION APPROVAL SHEET}

Formal approval is hereby given to this submitted dissertation by Audrey Elizabeth Wright Snyder on Effects of Massage Therapy and Touch on Quality of Life Outcomes for ASCT Patients.
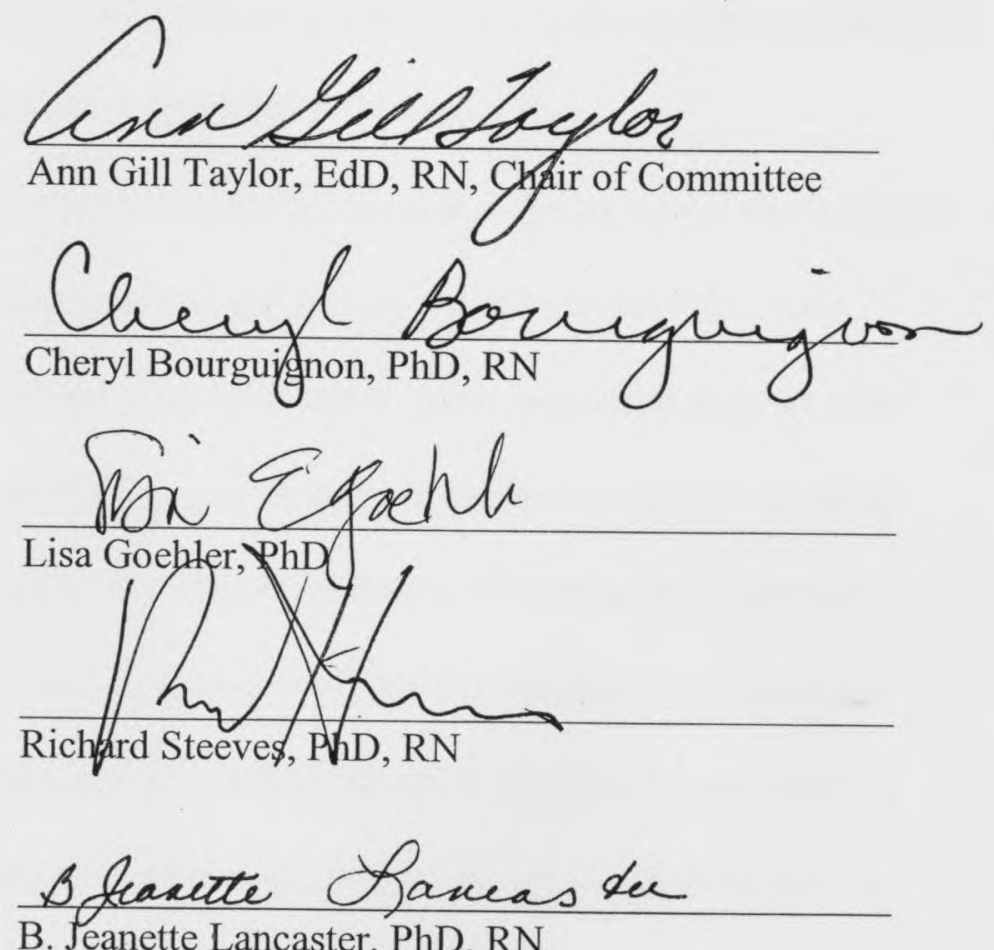

B. Jeanette Lancaster, $\mathrm{PhD}, \mathrm{RN}$

Dean, School of Nursing 


\section{(C) Copyright by}

Audrey Elizabeth Wright Snyder

All Rights Reserved

May 2007 


\begin{abstract}
:
Background: Patients with cancer undergoing autologous stem cell transplantation (ASCT) endure a series of stressors and adverse symptoms throughout treatment, resulting in greatly impaired quality of life $(\mathrm{QoL})$.
\end{abstract}

Objectives: To investigate the immediate and cumulative effects of massage on stress, relaxation, and comfort, explore effects of massage on anxiety, pain, and QoL outcomes, and identify the benefits of and barriers to patient acceptance of massage during phases of the ASCT process in individuals undergoing ASCT for cancer.

Methods: This pilot project used a mixed methods, unmasked, prospective, randomized experimental design. Baseline demographics and history, health-related QoL, state anxiety, perceived stress, comfort, and relaxation levels, pain, and social support were assessed. Descriptive statistics and graphing techniques were used to analyze the data. Results: An immediate effect in stress reduction, increased relaxation, and increased comfort were identified post massage. Cumulative effects of massage over transplant phases were not seen in the massage group. Participants in the massage group also reported lower anxiety scores across the transplant phases and lower affective and sensory pain scores during hospitalization following transplant than those in the SMC alone group. Perceived benefits of massage for the participants included improvement in symptoms that they had been experiencing prior to undergoing ASCT as well as their current treatment-related symptoms.

Conclusions: Supportive care massage can have immediate effects on stress, comfort, and relaxation and improve treatment-related symptoms for patients undergoing ASCT. 
Table of Contents

Abstract

Table of Contents

ii

Acknowledgements

viii

1. Chapter I. Introduction

a. Study purpose 8

b. Theoretical Framework 9

c. Significance

d. Hypotheses

2. Chapter II. A Review of the Literature

a. Scope of the Problem of ASCT

b. Phases of ASCT Treatment

c. Unique Needs of Patients undergoing ASCT

d. Massage Therapy: Historical Perspective

e. Modern Theories of Massage Effects

f. Health-related Quality of Life and ASCT

i. Emotional distress

ii. Pain

iii. Fatigue

iv. Nausea and vomiting 
h. Massage Effects in Relation to Stress 24

i. Massage in Critically Ill 26

j. Effects of Massage for ASCT Patients' Quality Of Life 26

$\begin{array}{ll}\text { k. Social Support and Isolation } & 28\end{array}$

1. Massage Dosage Needed for Immediate and Prolonged Effects 29

$\begin{array}{ll}\text { m. Summary } & 31\end{array}$

3. Chapter III. Methodology 33

a. The Parent Study 33

b. The Proposed Dissertation Study 34

i. Eligibility criteria $\quad 35$

ii. Sample Size $\quad 36$

iii. Procedures $\quad 36$

1. Consent Procedures 36

2. Stratified Randomization Procedures 37

$\begin{array}{ll}\text { 3. Treatment groups } & 37\end{array}$

4. Massage Protocol 40

5. Data Collection Procedure 41

6. Staff training 43

iv. Potential Risk 44

v. Source of Materials $\quad 44$

vi. Study Measures $\quad 44$

vii. Review of Instruments $\quad 45$ 
1. Demographic Form 46

2. Medical History Form 46

3. Health-related quality of life (QLQ-C30) 46

4. State anxiety (STAI Y-1) 48

5. Perceived stress, comfort and relaxation levels (NRS) 49

6. Pain (MPQ-SF) 50

7. Social support (MOS-SSS)

8. Massage Checklist 52

viii. Data Analysis $\quad 53$

ix. Summary 58

4. References

$\begin{array}{ll}\text { 5. Appendices/Instruments } & 77\end{array}$

6. Manuscript 1. Contrary to Approved Methods of Practice: Massage Therapy, Polio and Nursing, 1900-1945

a. The Social, Political, and Economic Climates 91

b. State of the Art of Medicine and Nursing, 1860-1940 94

c. Diagnosis and Medical Treatment of Infantile Paralysis 94

d. State of the Art of Nursing Related to Massage in the Early $20^{\text {th }}$ Century 96

d. The Art and Science of Massage 102

e. Massage in the Care of Psychiatric Patients 103

$\begin{array}{ll}\text { f. Massage in Obstetrical Nursing } & 104\end{array}$

g. Massage of Newborns and Premature Children 105 
h. Massage Use in Arthritis

i. Massage for Constipation

j. Massage in Neuralgia

$\mathrm{k}$. Massage in Cardiac Cases

1. Massage Use for Orthopedic Problems

m. Massage in Infantile Paralysis

n. The Kenny Massage Method

o. The Controversy Over Massage

114

p. Kenny Method in the United States

116

q. Conclusion

r. Notes

7. Manuscript 2. Use of Massage Therapy in Patients Undergoing Autologous Stem Cell Transplant: A Literature Review

a. Abstract

b. Introduction

c. ASCT Treatment

d. Unique Needs of Patients Undergoing ASCT

e. Health-Related Quality of Life and ASCT

i. Emotional Distress

ii. Pain

iii. Fatigue 
iv. Nausea and vomiting

f. Requirements for Patients Undergoing ASCT

g. Overview of Massage as a Therapy

i. Massage Therapy in Cancer

ii. Massage for Patients Undergoing ASCT

iii. Massage Effects in Relation to Stress

iv. Massage in Critically Ill Patients

h. Social Support and Isolation for Patients Undergoing ASCT

i. Conclusion

j. References

8. Manuscript 3. Effects of Massage Therapy on Quality of Life Outcomes for Autologous Stem Cell Transplant Patients

a. Abstract

b. Introduction

c. Theoretical Framework

d. Methods

i. Subjects

ii. Measurements

1. Demographic Form

2. Medical History Form

3. Health-related Quality of Life 
5. Perceived Stress, Comfort, and Relaxation

6. Pain

7. Social Support

7. Massage checklist

iii. Massage intervention

iv. Staff training

e. Data analysis

f. Results

g. Discussion

200

h. Study limitations 206

$\begin{array}{ll}\text { i. Future research } & 207\end{array}$

$\begin{array}{ll}\text { j. Conclusions } & 207\end{array}$

$\begin{array}{ll}\text { k. References } & 209\end{array}$

1. Tables 215

$\begin{array}{ll}\text { m. Box } 1 \text { Massage Protocol } & 217\end{array}$

n. Figures 219 


\section{Acknowledgements:}

\section{Funding:}

Supported by National Cancer Institute (NCI) Grant No. 5 R21 CA100627 and National Center for Complementary and Alternative Medicine (NCCAM) Grant No. K30-AT00060, and its contents are solely the responsibility of the authors and do not necessarily represent the official views of the NCI, NCCAM, or the National Institutes of Health.

A special acknowledgement and thank you to my mentor and dissertation chair, Dr. Ann Gill Taylor, for all of her encouragement, guidance and support to me over the years during my education.

Also to my committee members, Dr. Cheryl Bourguignon, Dr. Lisa Goehler, and Dr. Richard Steeves for their expertise, enthusiasm, patience and support of this project. And to Dr. Arlene Keeling, the historian who has helped me understand the present by looking at the past.

And to my husband, Evan Snyder, and daughters (Carly, Kendra and Robin) who supported me throughout this experience. 


\section{CHAPTER ONE: INTRODUCTION}

The goal of this first chapter is to guide the reader in understanding the need for this study. The rationale and expected outcomes, along with purpose, significance, and hypotheses will be presented.

\section{Autologous Stem Cell Transplant}

ASCT involves the use of aggressive, high-dose chemotherapy and/or whole-body radiation to eradicate the cancer, followed by rescue with the patient's previously harvested bone marrow or peripheral blood stem cells (Imrie et al., 2002; Jassak \& Riley, 1994) with the intent to cure the disease or prolong survival (Buchsel \& Whedon, 1995). Because treatment-related morbidity and mortality have decreased over the past decade, ASCT is becoming the therapy of choice for various hematological diseases and solid tumors (Fung, \& Nademanee, 2002; Neitzert, Ritvo, Dancey, Weiser, Murray, \& Avery, 1998). Leukemia, myeloma, lymphoma and breast cancer are treated with ASCT. Each year over 9,000 people undergo stem cell transplantation in the United States (The Leukemia and Lymphoma Society, 2002).

The ASCT process entails several distinct phases, each with unique procedures and threats to health-related QoL (Imrie et al., 2002; Rodeheaver, Taylor, \& Lyon 2003). Prior to ASCT, patients are hospitalized for mobilization of stem cells from the bone marrow. This mobilization phase involves daily chemotherapy for 3 to 5 days, often supplemented with growth factors (e.g., Neupogen), to stimulate cell proliferation. Approximately one week after hospital discharge, patients undergo several days of stem cell collection from blood and bone marrow (if necessary). Finally, patients are 
hospitalized for 1 to 3 weeks for conditioning with myeloablative chemotherapy and/or radiation (usually 2 to 5 days), followed by infusion of harvested cells during the actual transplantation. Most patients achieve engraftment (i.e., initial repopulation of the hematopoietic system) within 2 weeks, but ASCT recipients display a prolonged period of immune dysfunction and remain vulnerable to various threats to health status, including opportunistic infections and anemia that may require blood transfusions.

Patients with cancer undergoing ASCT endure a series of stressors and adverse symptoms throughout treatment, resulting in greatly impaired quality of life (QoL). In addition to adjusting to their diagnosis, these patients face life-threatening medical therapies, numerous aversive procedures, travel, unemployment, financial strain, physical isolation, and separation from social support networks (Molassiotis, van den Akker, Milligan, \& Goldman, 1997; Rodeheaver, Taylor, \& Lyon, 2003). Many patients suffer from distress, anxiety, depression, pain, nausea, and vomiting before ASCT (Cameron et al., 2001; Gaston-Johansson \& Foxall, 1996), and survivors of ASCT frequently report persistent symptoms and impaired QoL in the days, weeks, and months following ASCT (McQuellon et al., 1997; Andrykowski, et al., 2005). These symptoms are often difficult to manage by conventional medicine alone (Pico, Avila-Garavito, \& Naccache, 1998; Portenoy \& Itri, 1999). Patients receiving ASCT experience social and physical isolation due to treatment regimens and separation from family and significant others. Physical touch that is predominantly related to invasive procedures or assessments may carry a negative perspective for the patient.

Treatment-related distress may contribute to morbidity and decreased QoL 
following ASCT. Researchers have identified the need for early intervention with adjunctive therapies, such as massage, to diminish stress reactivity and treatment-related distress (Gaston-Johansson et al., 2000).

\section{Massage}

Massage is one of the oldest and most appreciated modes of sensory stimulation for alleviating pain, improving disease symptoms and promoting well-being (Churchill, 1915). Manual massage is defined as the manipulation of soft tissue by a trained massage therapist for therapeutic purposes (Frtiz, 2000). Often times this is for relaxation and pain relief. The 1999 National Health Interview Survey identified that $28.9 \%$ of the United States population used at least one complementary or alternative medicine therapy in the previous year. Of these, massage therapy was the $5^{\text {th }}$ leading complementary modality used by the United States population. The top four modalities were spiritual healing or prayer, herbal medicine, chiropractic therapy, and lifestyle-diet. Of those surveyed, 6.4\% used massage therapy (Ni, Simile, \& Hardy, 2002). A survey of primary care patients revealed $17.2 \%$ used massage therapy for the health problem for which they were seeking treatment in the medical clinic (Palinkas \& Kabongo, 2000). Massage has a long and multicultural tradition spanning centuries.

In the 1960 s, with revival of chronic disease treatment, massage became a popular therapy. During the 1970 s-80s the wide-spread health movement and pain management research brought massage to the forefront as a complementary treatment (Fritz, 2000). Massage has grown along with osteopathy, chiropractic, and physical therapy as a manual medical treatment. The Agency for Healthcare Policy and Research (1994) recommended 
massage to assist patients with cancer- and treatment-related symptoms, the recommendation paved the way for acceptance of massage use with cancer patients.

Isolation Requirements for ASCT Patients

Patients receiving ASCT experience social and physical isolation due to treatment regimens. These patients are on protective isolation for immunosuppression for seven to ten days following transplant. However, the impact of this isolation on QoL has received only limited attention in the professional literature. Physical touch that is predominantly related to invasive procedures or assessments may carry a negative perspective for the patient. Barriers to touch include severity of illness, isolation status, and glove or barrier use. The use of gloves in the routine care of patients has become commonplace over the last 10 years. There may be a difference in the receiver's perception of touch based upon the use of gloves for protective isolation versus isolation to prevent the spread of disease.

The increased incidence of antibiotic resistant organisms has influenced patients' isolation status. Patients who become colonized with Vancomycin Resistant Enteroococcus (VRE), Methacillin Resistant Staphlococcus Aureus (MRSA) or Clostridium Difficile will require contact isolation procedures beyond the usual requirements for immunosuppression for all medical and nursing care, and visitations. The incidence of opportunistic infections has increased the use of gloves for routine care such as bathing, taking vital signs, and assisting patients with activities of daily living.

Physical isolation causes stress in hospitalized patients (Ward, 2000). In one study of patients isolated for infection control of MRSA, they experienced more preventable adverse effects, expressed greater dissatisfaction with their treatment, and had less 
documented care than patients not on isolation (Stelfox, 2003). Research has shown wearing latex gloves also reduces healthcare workers' sensitivity to touch/feeling (Thompson \& Lambert, 1995). This decreased sensitivity to touch/feeling could affect procedural care. Little research has been done in the area of patient perception of touch with glove use by healthcare providers. Touch plays a large role in patients' perception of comfort. Comforting touch in nursing interventions is essential in vulnerable populations on isolation where gloves are required to provide basic care (Butts, 1995). Touch provided through massage has the potential to comfort patients and have a positive effect on patient outcomes.

\section{Massage Therapy in Cancer}

Preliminary research suggests that adjunctive massage therapy may improve adverse symptoms and QoL of patients during treatment for cancer without the side effects associated with conventional pharmacological treatments (Ahles, et al., 1999; Smith, Reeder, Daniel, Baramee \& Hagman, 2003; Field, 1998; Field, 2002; Richards, Gibson, \& Overton-McCoy, 2000; Taylor, Galper, D’Huyvetter, Bourguignon, \& Lyon, 2003; Taylor, Galper, Taylor, Rice, Andersen, Irvin, Wang, \& Harrell, 2003).

Unfortunately, few controlled studies of massage interventions have been conducted among persons with cancer, and most studies have evaluated only immediate within subjects' changes across a few brief massage sessions (Ferrell-Torry \& Glick, 1993; Grealish, Lomasney, \& Whiteman, 2000).

Massage may also increase feelings of comfort, improve sleep, and increase feelings of support in this population (Smith et al., 2003). Hospitalized cancer patients 
reported reduced pain and anxiety, increased feeling of relaxation, and had a decrease in heart rate, respiratory rate, and blood pressure (Ferry-Torry \& Glick, 1993). In hospitalized patients experiencing nausea or pain related to cancer, 10-minute foot massages by nurses had significant immediate effects on their perception of pain, nausea and relaxation (Grealish, Lomasney \& Whiteman, 2000). Cancer patients reported significant increases in QoL following four massage sessions (Grealish et al., 2000). These findings are further supported by a growing number of controlled prospective trials demonstrating positive effects of massage on anxiety (Hulme, Waterman, \& Hillier, 1999; Kim, Cho, Woo, \& Kim, 2001; Richards et al., 2000), depression (Field, Grizzle, Scafidi, \& Schanberg, 1996), pain (Cherkin et al., 2001; Felhendler \& Björn, 1996; Hernandez-Reif, Field, Krasnegor, \& Theakston, 2001; Preyde, 2000), fatigue (Field, Quintino, Henteleff, Wells-Keife \& Delvecchio-Feinberg, 1997), and QoL (Cherkin et al., 2001; Preyde, 2000) in various patient populations.

\section{Massage in ASCT}

Massage may be useful for patients undergoing ASCT. A series of massages may have a cumulative effect in these persons. Preliminary studies indicate that various types of massage can reduce distress (Smith et al., 2003; Ahles et al., 1999; Taylor, Galper, D’Huyvetter, et al., 2003; Taylor, Galper, Taylor, et al, 2003), anxiety (Ahles et al., 1999; Menard, 1995; Stephenson, Weinrich, \& Tavakoli, 2000), pain (Grealish, Lomasney, \& Whiteman, 2000; McNamara, Burnham, Smith \& Carroll, 2003; Weinrich \& Weinrich, 1990), fatigue (Ahles et al., 1999), and nausea (Ahles et al., 1999; Grealish et al., 2000) in patients undergoing conventional cancer care. 
Massage may also increase feelings of comfort, improve sleep, and increase feelings of support in this population (Smith, Reeder, Daniel, Baramee, \& Hagman, 2003). A few studies have also reported significant increases in short-term QoL of cancer patients receiving massage (Grealish et al., 2000; Wilkie, Kampbell, Cutshall, Halabisky, Harmon, Johnson, et al, 2000).

Only three studies have examined the potential benefits of massage during ASCT (Smith et al., 2003; Ahles et al., 1999, Phipps, 2002). Pediatric patients reported decreased distress with daily 15 -minute parent provided massages post-transplant (Phipps, 2002). Two studies (Ahles et al., 1999; Smith et al., 2003) reported encouraging short-term effects of massage on distress, anxiety, fatigue, nausea and ability to sleep in adults undergoing bone marrow transplantation. However, the intervention entailed only 20-30 minute treatment sessions during the acute phase of hospitalization, and the investigators called for further research to understand fully the impact of massage therapy on quality of life of these patients (Ahles et al., 1999).

Larger treatment effects may result from longer treatment sessions and cumulative effects of massage over longer intervention periods (Field, 1998; Taylor, Galper, Taylor, et al., 2003). A prior study by Taylor, Galper, Taylor and colleagues (2003) demonstrated modest effects with a less intensive (three massages a day for 3 days) massage intervention. Exploring whether or not a more intensive intervention can increase the size of the effects would be a valuable contribution. Several studies lend support for this. After having massages three times a week during hospitalization, ASCT patients had significant improvements in nausea, distress, anxiety, and mood compared to the control 
group (Ahles et al., 1999). Massage was generally most effective at the beginning of treatment, when symptoms were highest. In bone marrow transplant patients, $35 \%$ of the sample reported that benefits persisted for more than a day (Smith et al., 2003). While whole-body massages provided by professional massage therapists are generally 40 to 60 minutes in duration, clinical studies of massage have almost exclusively used massage sessions lasting 5 to 30 minutes (Field, 1998, Richards, 1998). Patients often experience considerable distress prior to ASCT, as well as during or after ASCT, and massage may produce stronger effects when introduced early in treatment and reinforced thereafter (Gaston-Johansson et al., 2000; Molassiotis, Yung, Yam, Chan, \& Mok, 2002).

\section{Study Purpose}

For her dissertation research, the student will conduct nursing research as a major component of a Center for the Study of Complementary and Alternative Therapy (CSCST) National Institutes of Health (NIH) funded Pilot Study Evaluating Massage Therapy in Cancer Patients Undergoing Autologous Stem Cell Transplantation (ASCT) with Dr. Ann Gill Taylor as the Primary Investigator. This proposed dissertation research study evaluates the effects of massage therapy and touch on quality of life outcomes for patients undergoing Autologous Stem Cell Transplant (ASCT) as part of the larger project investigating the use of massage therapy in improving QoL and reducing treatment-related morbidity of persons with cancer who are undergoing ASCT. The Parent study is a mixed methods, unmasked, prospective, randomized experimental study, that uses a standard medical care (SMC) alone control group and SMC plus massage therapy intervention group with repeated measures. The purpose of the parent study is to 
explore the feasibility of a massage intervention protocol in patients undergoing ASCT and to determine the estimation of the changes in QoL and symptoms over time in two study groups SMC alone and SMC plus massage therapy. The proposed dissertation research study will evaluate the effects of massage therapy and touch on patient comfort during isolation and quality of life outcomes for patients undergoing Autologous Stem Cell Transplant (ASCT).

\section{Theoretical Framework}

Psychoneuroimmunology is presented as a theoretical model for the interaction between psychological process, biological factors, and health behaviors impacting quality of life $(\mathrm{QoL})$ via processes involving neuroendocrine and immune mechanisms. The primary model to be used for the propose research intervention is adapted from the psychoneuroimmunology and health psychology integrative model by Lutgendorf and Costano (2003). Figure 1 on the next page depicts the model. The interaction between psychological process (Box A), biological factors (Box B), and health behaviors (Box C) impacts QoL via processes involving neuroendocrine and immune mechanisms. Effects of life stress (e.g., ASCT) are filtered through psychosocial processes (Box A) and health behaviors (Box C). Complementary therapy interventions can modulate effects of psychosocial processes and health behaviors on neuroendocrine and immune mechanisms, decreasing treatment-related symptoms and impacting resultant QoL (Box G). Complementary therapies, such as massage, can be used to alter psychosocial processes (Box A, e.g., decrease anxiety, decrease depression) or improve health behaviors (Box C) to improve treatment-related symptoms (Box F). 


\section{Significance}

Strong potential exists for this study to provide results that will enhance our understanding of factors that facilitate or impede comfort in patients on isolation during the various phases of ASCT, as well as facilitators and barriers to patient acceptance of massage interventions. This information will assist with future study designs. Data on dose of massage therapy will be used to improve future delivery of the massage intervention for enhancing QoL for patients with ASCT and other hospitalized patients. If this massage intervention, a non-invasive modalitiy is shown to benefit the study participants, it could add a much-needed adjunct to symptom management in this population.

The proposed student research study provides a basis for understanding touch and quality of life in patients undergoing isolation stressors in the acute care environment. The findings have the potential to affect not only patients with ASCT but other patients on isolation.

\section{Hypotheses}

The specific aims (hypotheses) of the proposed dissertation study are as follows:

1. Subjects receiving standard medical care (SMC) plus massage therapy for ASCT will report greater comfort, relaxation, and stress reduction with a higher massage dose than subjects receiving SMC alone.

2. Subjects receiving SMC plus massage therapy for ASCT will report improvement in QoL treatment-related symptoms with a higher massage dose over a lower massage dose. 
3. Throughout the phases of ASCT treatment, subjects receiving SMC plus massage therapy will report greater improvement in QoL treatment-related symptoms than subjects receiving SMC alone.

4. After controlling for social support, subjects receiving SMC plus massage therapy during ASCT will report greater comfort, relaxation, and stress reduction following massage sessions without gloves than massage sessions with gloves.

Secondary Aim:

To describe barriers and facilitators to ASCT patient acceptance of supportive care massage therapy in both the hospital and home settings. 
Figure 1. Psychoneuroimmunology and Health Psychology Model

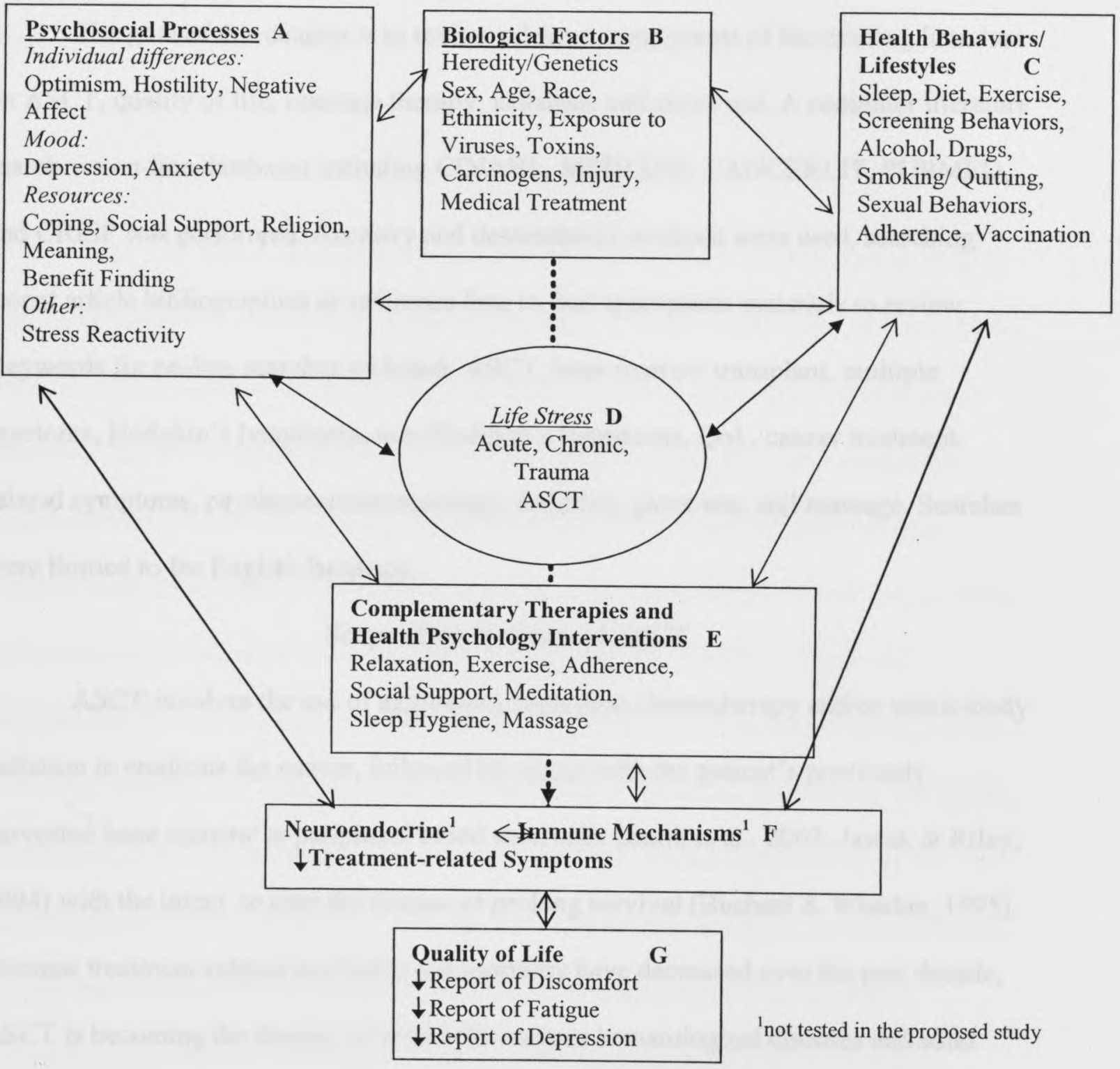




\section{CHAPTER TWO: A REVIEW OF THE LITERATURE}

The goal of this chapter is to review relevant components of the existing literature on ASCT, quality of life, massage therapy, isolation, and glove use. A computer literature search via on-line databases including CINAHL, MEDLINE, CANCERLIT, PUBMED, and CRISP was performed. Ancestry and descendancy methods were used, searching recent article bibliographies or reference lists to find appropriate materials to review. Keywords for on-line searches included: ASCT, bone marrow transplant, multiple myeloma, Hodgkin's lymphoma, non-Hodgkin's lymphoma, QoL, cancer treatmentrelated symptoms, psychoneuroimmunology, isolation, glove use, and massage. Searches were limited to the English language.

\section{Scope of the Problem of ASCT}

ASCT involves the use of aggressive, high-dose chemotherapy and/or whole-body radiation to eradicate the cancer, followed by rescue with the patient's previously harvested bone marrow or peripheral blood stem cells (Imrie et al., 2002; Jassak \& Riley, 1994) with the intent to cure the disease or prolong survival (Buchsel \& Whedon, 1995). Because treatment-related morbidity and mortality have decreased over the past decade, ASCT is becoming the therapy of choice for various hematological diseases and solid tumors (Fung, \& Nademanee, 2002; Neitzert, Ritvo, Dancey, Weiser, Murray, \& Avery, 1998). Multiple myeloma, Hodgkins lymphoma, and non-Hodgkin's lymphoma are among the types of cancer treated with ASCT. Each year over 9,000 people undergo stem cell transplantation in the United States (The Leukemia and Lymphoma Society, 2002). Patients with cancer undergoing ASCT endure a series of stressors and adverse 
symptoms throughout treatment, resulting in greatly impaired QoL. Interventions to improve patient symptoms and QoL are warranted (Podestà, 2001).

\section{Phases of ASCT Treatment}

The ASCT process entails several distinct phases, each with unique procedures and threats to health-related QoL (Imrie et al., 2002; Rodeheaver, Taylor, \& Lyon 2003). Prior to ASCT, patients are hospitalized for mobilization of stem cells from the bone marrow. This mobilization phase involves daily chemotherapy for 3 to 5 days, often supplemented with growth factors (e.g., Neupogen), to stimulate cell proliferation. Approximately one week after hospital discharge, patients undergo several days of stem cell collection from blood and bone marrow (if necessary). Finally, patients are hospitalized for 1 to 3 weeks for conditioning with myeloablative chemotherapy and/or radiation (usually 2 to 5 days), followed by infusion of harvested cells during the actual transplantation. Most patients achieve engraftment (i.e., initial repopulation of the hematopoietic system) within 2 weeks, but ASCT recipients display a prolonged period of immune dysfunction and remain vulnerable to various threats to health status, including opportunistic infections and anemia that may require blood transfusions.

\section{Unique Needs of Patients Undergoing ASCT}

Patients with cancer undergoing ASCT endure a series of stressors and adverse symptoms throughout treatment, resulting in greatly impaired QoL. In addition to adjusting to their diagnosis, these patients face life-threatening medical therapies, numerous aversive procedures, travel, unemployment, financial strain, physical isolation, 
and separation from social support networks (Molassiotis, van den Akker, Milligan, \& Goldman, 1997; Rodeheaver, Taylor, \& Lyon, 2003). Many patients suffer from distress, anxiety, depression, pain, nausea, and vomiting before ASCT (Cameron et al., 2001; Gaston-Johansson \& Foxall, 1996), and survivors of ASCT frequently report persistent symptoms and impaired QoL in the days, weeks, and months following ASCT (McQuellon et al., 1997). These symptoms are often difficult to manage by conventional medicine alone (Pico, Avila-Garavito, \& Naccache, 1998; Portenoy \& Itri, 1999). Patients receiving ASCT experience social and physical isolation due to treatment regimens. Also, the physical touch that is predominantly related to invasive procedures or assessments may carry a negative perspective for the patient.

Treatment-related distress may contribute to morbidity and decrease QoL following ASCT, and researchers have identified the need for early intervention with adjunctive therapies to diminish stress reactivity and treatment-related distress (GastonJohansson et al., 2000). Furthermore, interventions designed to improve QoL and treat adverse effects in patients with cancer should target the specific symptoms experienced by patients (Chan, Ngan, Li, Yip, Ng, Lee, et al., 2001).

Preliminary research suggests that adjunctive massage therapy may improve adverse symptoms and QoL of patients during treatment for cancer, without the side effects associated with conventional pharmacological treatments (Ahles et al., 1999; Smith et al., 2003; Field, 1998, Field, 2002; Richards, Gibson, \& Overton-McCoy, 2000; Taylor, Galper, D’Huyvetter, et al, 2003; Taylor, Galper, Taylor, et al, 2003). 
Massage Therapy: Historical Perspective

Massage as a therapy is gaining much attention as a therapeutic agent for relief of muscle spasm and pain. In fact, massage is often considered a $21^{\text {st }}$ century phenomena. However, an analysis of nursing history provides evidence that nurses have long used massage for comfort measures and for specific treatment of many orthopedic complaints and debilitating conditions (Jensen-Nelson, 1941; Rothweiler, Coulter, \& Jansey, 1935; Woolf, 1927; Macafee, 1920; Eliason, Ferguson, \& Lewis, 1936; Biermann, 1907; Barclay, 1913).

In 1901, mechano-therapy was seen as a distinct department in the science of medicine, yet no longer needing to be performed by the physician but assigned to an assistant, the nurse. Mechano-therapy was defined as "treatment by mechanical procedures as distinguished from drug therapy and surgery" (Mulliner, 1929, p.24). As early as 1900, massage was used as a treatment for polio in the United States. Massage was seen as important in the "treatment of those affections of children characterized by wasting muscles. Especially in the treatment of infantile paralysis... a measure of great value, not only in preserving the integrity of the muscles, but also in preventing the subsequent deformities which present so many difficulties in treatment" (Stanton, 1900, p.212).

The large number of men with nerve injuries and orthopedic trouble following World War I required special care. Thousands were crippled and disabled. This brought physio-therapy to medical science and created a demand for expert masseuses. In 1917 physical therapy schools were established across the county. Most were graduate 
programs requiring physical education or nurse's training as a preliminary education (Graham, 1925). Massage and Swedish movements were recognized as a branch of physical therapy in 1935. Mechanotherapy- Massage chapters appeared in nursing texts written jointly by physicians and nurses. Mechanotherapy was defined as "manipulative movements made by an operator upon the body of a patient for therapeutic purposes" (Rothweiler, Coulter \& Jansey, 1935, p.1021).

By 1941, massage was recognized as a therapeutic agent in both England and America. "The medical schools, however, especially in America, placed very little emphasis on teaching of the science and art of massage and as a result the physicians in general practice are not as cognizant of the need for massage for their patients as are the doctors training in the universities of Northern Europe" (Jensen-Nelson, 1941, p.12). Despite numerous uses, it was polio that focused nurses and physicians on the use of massage as a therapy. The polio epidemics in the early $20^{\text {th }}$ century brought heightened awareness to the uses of massage therapy in preventing long-term disability. Moreover during the polio epidemics of 1931 and 1944, some nurses, including Sister Elizabeth Kenny, used massage therapy despite early criticism of its use.

In the 1990s massage offered an additional resource to pharmacologic interventions for pain management. Nurses researched the effects on patients and began to assess the benefits of nurses receiving additional training as massage therapists, evaluating the practicality of providing massage alongside normal nursing duties (Farrow, 1990). 


\section{Modern Theories of Massage Effects}

The modern theories of massage therapy effects are autonomic or reflexive, mechanical and movement. Autonomic or reflexive approaches exert effects on the autonomic and somatic nervous system via neurohormonal actions. Mechanical approaches use force to produce mechanical changes in soft tissue. Movement approaches work to change abnormal patterns of movement and create optimal patterns. A broad spectrum of massage action is hypothesized for decreasing pain: (1) diminished pain perception from increased activity in endogenous pain modulatory systems, (2) inhibited activity in the pain-mediating neurons in the superficial layers of the spinal cord by mechanical stimulation of cutaneous and subcutaneous systems increases activity in somatosensory neurons, (3) antinociception from activation of the descending pain inhibitory system with a proposed start in the periaqueductal gray (PAG) at the brainstem level with a continuation to the dorsal horn of the spinal cord, and (4) opioid receptors activation in the PAG area (Lund, Yu, Uvnas-Moberg, Wang, Yu, Kurosaw, Agren, Rosen, Lekman, \& Lundberg, 2002).

The biological basis for massage effects is thought to be related to various hormonal responses. Much of the research in infant massage and its effects on premature infants has been based upon animal research in rats with maternal nurturing behaviors and massage-like stimulation. Oxytocinergic mechanisms have been shown to be activated and producing antinociception in response to somatosensory stimulation that is non-noxious. A single massage-like stimulation has resulted in an increased Hindpaw Withdrawal Latency (HWL) to heat stimulation, which was reversed with an oxytocin 
antagonist in rats (Ågren, Lundenberg, Unvas-Moberg \& Sato, 1995). Oxytocinergic terminals have been identified in the areas of pain modulation of the brain (Lund, et al., 2002).

Lund and colleagues (2002) investigated the antinociceptive effects of repeated massage-like stroking in rats by testing the HWL to thermal and mechanical stimulation in a time course study. The results of their study showed no short term effect in HWL in response to thermal or mechanical stimulation after 10 minutes of massage-like stroking; but, there was a cumulative effect with gradual rise in HWL response to both thermal and mechanical stimulation. Levels of oxytocin-LI in plasma and PAG were raised in the treatment group. There were significant increases in HWL in response to thermal and mechanical stimulation following intra-PAG injections of oxytocin. Dose-dependent effects were partly reversed by intraPAG injection of nonselective opioid receptor antagonist, and Oxytocin induced antinociceptive behavior was attenuated by the кopioid antagonist and $\mu$-opioid antagonist. The investigators hypothesized that heightened concentrations of endogenous oxytocin results in greater synthesis of endogenous opioids (Lund, et al, 2002). Endogenous opioids decrease pain perception.

Health-related Quality of Life and ASCT

Health-related QoL is a multidimensional construct encompassing the physical, psychological, and social domains of health status (Chan et al., 2001). QoL perceptions are shaped by personal experiences, beliefs, expectations, and perceptions, as well as threats to health and wellbeing (Testa \& Simonson, 1996). Following increased interest in the psychosocial status of patients with cancer, QoL has become an important part of 
clinical cancer research. Most patients with cancer use CAM modalities, including massage, to improve QoL (Morris, Johnson, Homer, \& Walts, 2000). Thus, QoL is also an important outcome for CAM cancer research.

Patients undergoing ASCT confront a challenging array of physical, emotional, and behavioral stressors and symptoms, resulting in impaired QoL prior to and following treatment (Gaston-Johansson et al., 2000). Many patients have difficulties with psychological/emotional adjustment in the weeks immediately after ASCT (GastonJohansson et al., 2000), and studies increasingly demonstrate deficits in physical and social/occupational QoL a year or more after ASCT (Neitzert et al., 1998). QoL prior to cancer treatment may be independently associated with response to chemotherapy and survival (Molassiotis et al., 1997). Thus, there are growing concerns regarding the QoL of patients undergoing ASCT (Gaston-Johansson et al., 2000; McQuellon et al., 1997). Emotional distress, pain, fatigue, and nausea and vomiting are frequently reported.

Patients often experience considerable distress prior to ASCT, as well as during or after ASCT, and massage may produce stronger effects when introduced early in treatment and reinforced thereafter (Gaston-Johansson et al., 2000; Molassiotis, Yung, Yam, Chan, \& Mok, 2002). Therefore, this study will pilot a 7-week massage therapy intervention initiated at the University of Virginia (UVA) Cancer Center Stem Cell Transplant Clinic 1 week prior to ASCT and continued for 6 weeks during the subsequent inpatient and outpatient phases of treatment.

\section{Emotional distress}

Patients undergoing ASCT are subjected to a wide range of psychosocial 
stressors. Anxiety, depression, and distress are prevalent prior to and following successful ASCT (Gaston-Johansson \& Foxall, 1996; Molassiotis et al., 1997; Gruber, Fegg, Buchamann, Kolb \& Hiddemann, 2003; Larsen, Nordström, Björkstrand, Ljungman \& Gardulf, 2003). In addition to coping with aversive symptoms and reduced functional status, the diagnosis of cancer can have a long-term disruptive impact on the patient and his/her family (Neitzert, 1998). Moreover, the high-dose chemotherapy given in ASCT is a life threatening medical treatment and a traumatic experience for many patients (Gaston-Johansson \& Foxall, 1996; Gaston-Johansson et al., 2000). In a recent study, $100 \%$ of patients receiving standard medical care experienced anxiety during the first week following ASCT (Gaston-Johansson et al., 2000). Longitudinal studies indicate that anxiety is often highest in the early phases of treatment (e.g., pre-ASCT) and may begin to decrease shortly after ASCT (Gaston-Johansson \& Foxall, 1996). Some patients even describe the aggressive cancer treatments as more distressing than their cancer (Molassiotis et al., 2002).

Stressors associated with ASCT include: travel for treatment, financial hardship, medical appointments, hospitalization, aversive treatments, separation from family and friends, and physical isolation (Rodeheaver, Taylor, \& Lyon, 2003). Gaston-Johansson and Foxall (1996) also found depression highest prior to transplant. Depression is a strong predictor of QoL (Gaston-Johansson \& Foxall, 1996) and may also be associated with immune function and survival in patients with cancer who receive ASCT (Herbert \& Cohen, 1993a). Because the symptoms associated with ASCT can all be exacerbated by stress, and stress has been found to reduce immune function and impair recovery 
following medical procedures (Anderson, Kiecolt-Glaser \& Glaser, 1994; Herbert \& Cohen, 1993b), stress reduction is an important objective to optimize outcomes for these patients.

\section{Pain}

Most cancer patients receiving ASCT have multiple types and sites of pain (Gaston-Johansson et al., 2000). As many as 90\% of ASCT recipients develop moderate to severe oral mucositis or throat pain that is often refractory to opioids (McGuire, Yeager, Dudley, Peterson, Owen \& Lin, 1998; Pico et al., 1998). Severe mucositis may limit the use of aggressive chemotherapy. Furthermore, opioid use may be problematic for some patients, resulting in nausea, vomiting, decreased peristalsis, respiratory depression, sedation, confusion, and dependence (Taylor, Galper, Taylor, et al., 2003; Kotani, et al, 2001). Pain is associated with depression, fatigue, and down regulation of immune function in patients with cancer (Anderson et al., 1994). Adjunctive therapies, including massage therapy, have often been recommended to optimize pain management among patients with cancer (AHCPR, 1994; NIH Technology Assessment Panel, 1996; Redd, Montgomery, \& DuHamel, 2001).

\section{Fatigue}

Fatigue is one of the most prevalent symptoms reported by ASCT recipients (Neitzert et al., 1998; Portenoy \& Itri, 1999 Gruber et al., 2003). According to GastonJohansson and Foxall (1996), fatigue is reported by $33 \%$ to $91 \%$ of patients undergoing ASCT. Fatigue impairs activities of daily living, self-esteem, and social involvement (Portenoy \& Itri, 1999), and contributes to emotional and cognitive symptoms of patients 
with cancer (Molassioitis, et al, 1997; Ahlberg, Elkman, Gaston-Johansson \& Mock, 2003). Survivors of ASCT often continue to experience fatigue relative to their premorbid functioning (Neitzert et al., 1998, Flechtner \& Bottomley, 2003).

\section{Nausea and vomiting}

Despite improvements in antiemetic drug therapy, more than half of cancer patients experience moderate to severe nausea during treatment with chemotherapy (Watson, Meyer, Thomson, \& Osofsky, 1998). Indeed, antiemetics are not universally effective, as some patients actually experience undesirable side effects from these medications (Molassiotis et al., 2002). Nausea and vomiting are significantly associated with distress and reduced QoL during chemotherapy (Cameron et al., 2001; GastonJohansson et al., 2000; Larsen, et al., 2003).

\section{Stress Associated with ASCT}

Patients undergoing ASCT are subjected to a wide range of psychosocial stressors. In addition to coping with aversive symptoms and reduced functional status, the diagnosis of cancer can have a long-term disruptive impact on the patient and his/her family (Neitzert, 1998). Moreover, the high-dose chemotherapy given in ASCT is a life threatening medical treatment and a traumatic experience for many patients (GastonJohansson, et al, 1996; Gaston-Johansson et al., 2000). Some patients even describe the aggressive cancer treatments as more distressing than their cancer (Molassiotis et al., 2002). Stressors associated with ASCT include: travel for treatment, financial hardship, medical appointments, hospitalization, aversive treatments, separation from family and friends, and physical isolation (Rodeheaver, Taylor, \& Lyon, 2003). Because the 
symptoms associated with ASCT can all be exacerbated by stress, and stress has been found to reduce immune function and impair recovery following medical procedures (Anderson et al., 1994; Herbert \& Cohen, 1993b), stress reduction is an important objective to optimize outcomes for these patients.

\section{Massage Effects in Relation to Stress}

Massage alters biochemistry immediately following massage sessions and over the course of massage treatment periods (Field, Hernandez-Reif, Diego \& Schanberg, 2005). Cortisol and cathecholamine (epinephrine and norepinephrine) release occurs in response to stress. The effects of cortisol, serotonin, and dopamine generalize across many medical conditions. Cortisol increases following experimentally-induced stress and decreases following relaxing therapies, such as massage, in the setting of job stress, depression, HIV, and cancer. Cortisol has been labeled as a culprit variable in killing immune cells, especially Natural Killer (NK) Cells. NK cells spontaneously destroy a wide variety of cancer and virus infected cells and are involved in eliminating metastases. Cortisol decreases across medical conditions following massage therapy (Field, et al., 2005). In an exploratory study of healthy humans, massage increased $\mathrm{T}$ and $\mathrm{B}$ lymphocytes proliferation (Lovas, Craig, Raison, Weston, Segal \& Markus, 2002).

There is documentation of an activation effect on serotonin and dopamine following massage. Serotonin enhances production of dopamine and hampers production of cortisol. Dopamine reduces depression and its stress effects (Field, Hernandez-Reif, 
Diego, \& Schanberg, 2005). In patients with Parkinson's disease who received 30-minute massage therapy sessions twice a week for 5 weeks, epinephrine and norepinephrine levels decreased in comparison to the progressive muscle relaxation group, suggesting the massaged patients were less stressed (Hernandez, et al., 2002).

Following 30-minute connective tissue massage provided by an occupational therapist in patients with pain syndromes there is an increase in $\beta$-endorphins, naturally occurring opioids (Kaada \& Torsteinbo, 1989). In depressed patients, lower salivary cortisol levels, epinephrine levels and urinary cortisol levels were documented immediately after 30 minute massage sessions (Field, et al., 1997). Hospitalized patients reported increased relaxation, wellbeing and mood, which led to enhanced mobility, increased energy, increased treatment participation, and shortened recovery times (Smith, Stallings, Mariner, \& Burrall, 1999).

Patients who received hand massages prior to cataract surgery under local anesthesia had decreased psychological anxiety levels, systolic and diastolic blood pressure, and pulse rates following massage therapy. Epinephrine and norepinephrine levels went down in the experimental group while they increased in the control group (Kim, Cho, Woo, \& Kim, 2001). The control group continued to have release of stress hormones while the level of stress hormones decreased in the experimental group.

In hospice patients, slow stroke back massage decreased heart rate and blood pressure and resulted in an increase in skin temperature. The changes in vital signs were indicative of relaxation (Meek, 1993). In 24 women with premenstrual Syndrome, 5week sessions of massage therapy reduced pain and water retention and overall menstrual 
distress (Hernadez-Reif, et al., 2000). In comparing the effectiveness of acupuncture, therapeutic massage, and self-care education for chronic low back pain, therapeutic massage was found more effective in providing long lasting benefits than Chinese medical acupuncture and self care (Cherkin, et al, 2001). Massage of the cranial and cervical muscles by a trained massage therapist for 30 minutes per session and eight massages provided over a four-week period resulted in a reduction in headache frequency and duration in patients with chronic tension headache. Headache intensity was not affected (Quinn, Chandler, \& Moraska, 2002).

\section{Massage in Critically Ill Patients}

Massage improved the quality of sleep in critically ill older men with 6 minute nighttime back rubs provided by nurses (Richards, 1998). Intensive care unit patients, age 19 to 81 , had significant transient decreases in heart rate, blood pressure and respirations during 5-minute foot massages (Hayes \& Cox, 1999).

\section{Effects of Massage for ASCT Patients' Quality Of Life}

Massage therapy is frequently used by patients with cancer in hopes of reducing symptoms that impair functional status and QoL (Crocetti, Crotti, Feltrin, Ponton, Geddes, \& Buiatti, 1998; Morris et al., 2000; Pan, Morrison, Ness, Fugh-Berman \& Leipzig, 2000; Fellowes, Barnes, \& Wilkinson, 2004). Similar to previous studies (Smith et al., 2003, Ahles et al., 1999), a pilot interview study conducted by the applicant's advisor and colleagues revealed that patients with cancer undergoing ASCT are very receptive to the use of massage therapy during hospitalization (Rodeheaver et al., 2003). Moreover, unlike many relaxation therapies, massage may be effective for patients with 
low imagery abilities or limited cognitive flexibility, as well as patients with reduced concentration and/or fatigue (Walker, Walker, Ostgon, Heys, Ah-See, Miller, Hutcheon, Sarkar, Eremin, 1999). Similar to acupuncture and relaxation (Gaston-Johansson et al., 2000), massage may produce stronger effects when introduced early in treatment and reinforced thereafter.

Preliminary studies indicate that various types of massage can reduce distress (Smith et al., 2003; Ahles et al., 1999; Taylor, Galper, D’Huyvetter, et al., 2003; Taylor, Galper, Taylor, et al, 2003, Phipps, 2002), anxiety (Fellowes, 2004, Ahles et al., 1999; Menard, 1995), pain (Grealish, Lomasney, \& Whiteman, 2000; Weinrich \& Weinrich, 1990), fatigue (Ahles et al., 1999), and nausea (Ahles et al., 1999; Grealish et al., 2000) in patients undergoing conventional cancer care. Grealish and colleagues (2000) reported significant increases in short-term QoL of cancer patients receiving massage. These findings are further supported by a growing number of controlled prospective trials demonstrating positive effects of massage on anxiety in various medical populations. However, controlled longitudinal studies documenting the effects of massage among patients with cancer are limited, and only three studies have examined the potential benefits of massage during ASCT (Smith et al., 2003; Ahles et al., 1999, Phipps, 2002).

In the study by Smith and colleagues (2003), patients in the treatment group reported better comfort, ability to sleep, relaxation, peacefulness and less anxiety than the "favorable visit" control group. In the Ahles (1999) study, 3 weeks of massage demonstrated modest effects on anxiety, nausea, distress, and fatigue among hospitalized cancer patients undergoing ASCT. Massage was generally most effective at the 
beginning of treatment, when symptoms were highest. In the Phipps (2002) second pilot study of pediatric BMT patients receiving massage by massage therapists or by parents, patients experienced less distress than controls.

\section{Social Support and Isolation}

Perceived social support is important in this patient population. Patients noted that one of the most important factors in going through the ASCT procedure well was having support of family and friends (Rodeheaver et al., 2003). Patients who report greater positive social support from family and friends may exhibit less treatment-related distress and better QoL, as well as superior cardiovascular and immune function (Kamarck, Peterman, \& Raynor, 1998; Uchino, Cacioppo, \& Kiecolt-Glaser, 1996).

Patients receiving ASCT experience social and physical isolation due to treatment regimens. These patients are on protective isolation for immunosuppression for seven to 10 days following transplant. The increased incidence of antibiotic resistant organisms has impacted isolation status. Patients who become colonized with Vancomycin Resistant Enteroococcus (VRE), Methacillin Resistant Staphlococcus Aureus (MRSA) or Clostridium Difficile will require contact isolation procedures beyond the usual requirements for immunosuppression for all medical and nursing care, visitations and for massage sessions. The incidence of opportunistic infections has increased the use of gloves for routine care such as bathing, taking vital signs and assisting patients with activities of daily living.

Physical isolation has caused stress in hospitalized patients (Ward, 2000). In one study of patients isolated for infection control of MRSA, patients experienced more 
preventable adverse effects, expressed greater dissatisfaction with their treatment and had less documented care (Stelfox, 2003). Physical touch in the seriously ill patient has been poorly addressed by traditional medical interventions (Lafferty, Downey, McCarty, Standish \& Patrick, 2006). Comfort touch in nursing interventions is essential in vulnerable populations on isolation where gloves are required to provide care (Butts \& Janes, 1995).

However, there has been little research on patients' perception of touch while in isolation or associated with glove use by care providers. Research has shown wearing latex gloves reduces healthcare workers' sensitivity to touch/feeling (Thompson \& Lambert, 1995). This decreased sensitivity to touch/feeling could affect procedural care. No research has been reported on massage therapists' perceptions or difficulty with massage technique while using gloves. Little research has been done in the area of patient perception of touch with glove use by healthcare providers. Comforting touch in nursing interventions is essential in vulnerable populations on isolation where gloves are required to provide basic care (Butts \& Janes, 1995). Touch provided through massage has the potential to comfort patients and have a positive impact on patient outcomes.

Massage Dosage Needed for Immediate and Prolonged Effects Massage may be useful for patients undergoing ASCT. Preliminary studies indicate that various types of massage can reduce distress, anxiety, pain, fatigue, and nausea in patients with cancer undergoing conventional care (Ahles et al., 1999; Grealish, Lomasney, \& Whiteman, 2000; Taylor, Galper, Taylor, et al., 2003). Massage may also increase feelings of comfort, improve sleep, and increase feelings of support in this 
population (Smith et al., 2003). Cancer patients reported significant increases in QoL following four massage sessions (Grealish et al., 2000). Pediatric patients reported decreased distress with daily 15 -minute parent provided massages post transplant (Phipps, 2002). Two studies (Ahles et al., 1999; Smith et al., 2003) reported encouraging short-term effects of massage on distress, anxiety, fatigue, nausea and ability to sleep in adults undergoing bone marrow transplantation. However, the intervention entailed only 20-30 minute treatment sessions during the acute phase of hospitalization, and the investigators called for further research to fully understand the impact of massage therapy on quality of life of these patients (Ahles et al., 1999). Because larger treatment effects may result from longer treatment sessions and cumulative effects of massage over longer intervention periods (Field, 1998; Taylor, Galper, Taylor, et al., 2003), the present investigation proposes to increase the duration of each massage to 50 minutes and to provide three massages per week over the 7 weeks of intervention (21 massages/patient). Because a prior study by Taylor, Galper, Taylor et al. (2003) demonstrated modest effects with a less intensive massage intervention, exploring whether or not a more intensive intervention can increase the size of the effects would be a valuable contribution. Several studies lend support for this. After having massages three times a week during hospitalization, ASCT patients had significant improvements in nausea, distress, anxiety, and mood compared to the control group (Ahles et al., 1999). In bone marrow transplant patients, $35 \%$ of the sample reported that benefits persisted for more than a day (Smith et al., 2003). While whole-body massages provided by professional massage therapists are generally 40-60 minutes in duration, clinical studies of massage have almost exclusively 
used massage sessions lasting 5 to 30 minutes (Field, 1998, Richards, 1998). In comparison, the present study will provide an intensive dose of massage therapy. Daily, weekly and over the course of the study massage doses will be analyzed in relation to QoL treatment-related symptoms.

\section{Summary}

ASCT is a highly stressful process. Individuals undergoing ASCT are likely to experience anxiety, depression, pain, nausea, vomiting, stress and impaired QoL throughout treatment. Health-related QoL is poor during the ASCT transplantation process. The impact of isolation on QoL has received limited attention. There is a great need for further research on adjunctive supportive care complementary medicine interventions with the potential to assist cancer patients undergoing ASCT. Patients with cancer undergoing ASCT experience many serious stressors during treatment, and adverse symptoms associated with ASCT, and often do not respond adequately to conventional pharmacological/medical approaches. Therefore, these patients are highly vulnerable to short-term and long-term threats to QoL.

Massage has been recommended to assist patients with cancer- and treatmentrelated symptoms (AHCPR, 1994.) This is a novel massage intervention that may significantly augment QoL and decrease stressors of isolation of cancer patients during and following ASCT. There is strong potential for this study to provide results that will enhance our understanding of facilitators and barriers to patient acceptance of massage interventions in both the home and community environments. Data on dose of massage therapy will be used to improve the delivery of the massage intervention for enhancing 
QoL for ASCT and other patient populations that endure isolation. 


\section{CHAPTER THREE: METHODOLOGY}

The Parent Study

The parent study, a mixed methods, unmasked, prospective, randomized experimental study, uses a SMC alone control group and SMC plus massage therapy intervention group with stratification by gender. The SMC plus massage therapy intervention group will receive 50 minutes Swedish massage three times a week (for intensive dose) over the seven-week period from consent and central line placement to post transplant recovery in the patient's home. The effects of massage on perceived patient comfort, relaxation, stress and QoL will be assessed by self-report and objective measures at baseline and weekly for seven weeks. The goal of this program of research is to address the need for supportive care for patients undergoing ASCT through exploring the effects of massage on patient comfort and QoL.

The primary objectives of the parent study are to:

1. Implement a novel 7-week program of massage therapy supportive care for patients with cancer undergoing ASCT and a controlled evaluation strategy to collect preliminary data needed to examine:

a. Feasibility, patient acceptance, and any potential limitations of the massage therapy and evaluation protocol; and

b. The rate of patient accrual over time using the proposed sampling criteria, as well as the percentage of eligible participants who choose to participate, participant attrition over time, and reasons for attrition. 
2. Obtain preliminary estimates (including confidence intervals) of the changes in symptoms and QoL over time in massage therapy plus SMC group and the SMC alone group.

3. Describe associations between measures of QoL, treatment-related symptoms (e.g. anxiety, stress, depression, pain, fatigue, nausea), shortterm heart rate variability (HF-HRV), medication consumption (e.g. antiemetics), and perceived social support.

The secondary objective of this study is to:

Explore the use of power spectral analysis of short-term heart rate variability (HRV) in obtaining preliminary estimates of immediate and/or cumulative changes in parasympathetic tone [high frequency component of HRV (i.e. HF-HRV)] after either massage (treatment group) or rest (SMC alone group).

The Proposed Dissertation Study

The specific aims (hypotheses) of the proposed dissertation study are as follows:

1. Subjects receiving standard medical care (SMC) plus massage therapy for ASCT will report greater comfort, relaxation, and stress reduction with a higher massage dose than subjects receiving SMC alone.

2. Subjects receiving SMC plus massage therapy for ASCT will report improvement in QoL

treatment-related symptoms with a higher massage dose over a lower massage dose. 
3. Throughout the phases of ASCT treatment, subjects receiving SMC plus massage therapy will report greater improvement in QoL treatment-related symptoms than subjects receiving SMC alone.

4. After controlling for social support, subjects receiving SMC plus massage therapy during ASCT will report greater comfort, relaxation, and stress reduction following massage sessions without gloves than massage sessions with gloves.

Secondary Aim:

To describe barriers and facilitators to ASCT patient acceptance of supportive care massage therapy in both the hospital and home settings.

\section{Eligibility Criteria}

All patients undergoing ASCT meet rigorous selection criteria (e.g., stable heart disease but no heart failure; if present, diabetes and/or hypertension must be wellcontrolled with stable medication use). Anemia is controlled prior to transplant with patients having hematocrits of 35 or greater and, if necessary, blood transfusions are given to achieve these levels.

Inclusion criteria are patients who are (1) scheduled to undergo ASCT for the treatment of cancer at UVA Stem Cell Transplant Clinic, (2) aged 18 years or older, (3) able to understand the consent form (written at 5 to 7 grade level) and complete the pencil and paper instruments, (4) platelet count $\geq 15,000 / \mathrm{mm}^{3}$, (5) could be contacted by phone, and (6) willing to abide by the proposed protocol and complete the assessments.

Criteria for exclusion include (1) regular use of massage ( $>1$ massage/month) prior to enrollment in the study, (2) current thrombosis or phlebitis because of the 
potential danger of dislodging a clot that could lead to a embolism, and (3) having been treated with medication specifically for anxiety or depression that remains uncontrolled, given that the majority of patients who have cancer requiring ASCT have a degree of depression and anxiety.

\section{Sample size}

A total of 8 of an anticipated 32 patients will be enrolled in the study due to the University of Virginia Cancer Center closure the ASCT Transplant Center during the parent study enrollment of subjects and there is no plan to reopen the center.

\section{Procedures}

Human Subject Committee and Cancer Center Protocol Committee approval will be sought prior to enrolling patients in the study. The study population will include a consecutive sample of all eligible cancer patients scheduled to undergo ASCT at the UVa Cancer Center's Stem Cell Transplant Clinic, age 18 and older, male and female, of any race or ethnic group. Potential study participants will be identified in the clinic when they present for pre-transplant evaluation. All patients will be recruited into the study 1 to 2 weeks prior to admission for mobilization chemotherapy.

At this time, potential participants identified by the Cancer Center Stem Cell Transplant team will be approached by the study coordinator, who will 1) check eligibility criteria, 2) invite patients to learn about the study; and 3) obtain informed consent of those patients interested in the study.

\section{Consent Procedures}

The investigator will review the approved Human Investigation Committee 
informed consent form with the patient and obtain the signature of the study participant once eligibility has been determined. A copy of the consent form will be given to the patient and includes the telephone number and name of the investigator who is available to answer questions.

\section{Stratified Randomization Procedures}

Following completion of the consent form and baseline assessments, study participants will be stratified by sex because of possible differences between men and women in response to massage (Altemus, Redwine, Leong, Freye, Porges, \& Carter, 2001; Labyak \& Metzger, 1997). Participants will be then randomly assigned by computer randomization, with probabilities in a ratio of $1: 1$, to one of two groups: 1 ) Standard medical care (SMC) alone group; or 2) SMC plus massage therapy.

Treatment groups. The two treatment groups are SMC alone and SMC plus massage therapy.

SMC involves mobilization chemotherapy,supplementation with growth factors to stimulate cell proliferation, collection of the stem cells from the blood (and bone marrow if needed, conditioning-high dose myoablative chemotherapy, and the transplantaation of autologous stem cells. Patients receive anti-emetics, and antacids, and electrolyte replacement using standardized protocols, as necessary. Anemia is controlled prior to transplant to achieve hematocrits of 35 or greater and, if necessary, blood transfusions are given to achieve these levels. Transplant team members monitor vital signs every 4 hours, obtain body weight twice a day, record intake and output every four hours, flush 
central lines every 8 hours, and give chlorhexidine scrubs followed by sodium

bicarbonate rinses after meals. All patients selected for the transplant program have met rigorous selection criteria (i.e., stable heart disease with no heart failure; if present, diabetes and/or hypertension must be well-controlled with stable medication use).

Participants in the SMC plus Massage therapy intervention group will receive SMC plus the massage intervention, which will entail three massages per week for each patient for 7 weeks, resulting in a total of 21 massages for each participant. The first massage will occur prior to the placement of the central line. The remaining massages will be coordinated as much as possible with the patients' scheduled appointments at the University of Virginia Stem Cell Transplant Unit, as well as other appointments at the UVA Health System. The massage coordinator will schedule massage sessions so they are not given on consecutive days if possible.

Many patients travel long distances from home for their cancer care at the University of Virginia. Therefore, during periods between phases of ASCT treatment when patients are resting at home in their communities between phases of treatment, the investigators will arrange for study participants to receive standardized "in-home" massages. Participants will receive the three weekly "in-home" massages from a from a carefully screened and selected certified massage therapist in the patient's community, who has received training and detailed instructions regarding the study protocol. The massage coordinator will plan an initial massage schedule for each enrolled participant involving her/his appointed community massage therapist. This novel aspect of the intervention has the potential to provide continuity of care during the outpatient phases of 
ASCT, while minimizing treatment barriers and unnecessary patient burdens (e.g., travel). In support of this approach, a recent study of massage for patients with chronic back pain demonstrated high adherence and significant treatment effects using massage therapists selected from providers of a large health maintenance organization (Cherkin et al., 2001). However, there is no published data on the use of professional communitybased massage therapists in research enrolling patients with cancer. Therefore, the investigator will examine factors related to the safety and efficacy of the massage protocol, including: adverse effects, treatment adherence, isolation practices and treatment integrity (e.g., length of sessions, deviations from protocol due to complications) over time.

While the majority of massages will be administered at the University of Virginia, approximately 5 of the 21 massages will be administered by a community-based massage therapist. However, the number of massages administered in each setting may vary depending upon the patient's needs and availability. Each study participant will be assigned the same massage therapist for all "at-home" massage sessions, and the same massage therapist will provide all massages at UVA. However, in the event that either massage therapist cannot administer the treatment due to illness, scheduled vacation time, or other reasons, another qualified massage therapist who has been trained to participate in the study will be contacted to provide the treatment. Massage therapists will talk weekly with the study coordinator. The clinic staff will communicate with the study coordinator if a patient has compression fractures (very rare) or shingles (very rare) that could preclude massaging affected areas of the body. Areas of sensitivity and pain will be 
assessed. Areas of concern will be avoided and other areas of the body will be massaged and documented on the massage checklist. The study coordinator will in turn communicate with the massage therapist, if these diagnoses are applicable.

\section{Massage protocol}

1. The massage table and any items brought into the patients' homes or hospital rooms will be cleaned and treated with a germicide prior to patient exposure. The massage therapist will follow infection control policies and procedures pertinent to each patient to ensure that patients are not exposed to potential pathogens. If a patient is placed on contact isolation, the massage therapist will have to wear surgical latex (or non-latex if the patient or massage therapist is allergic to latex) gloves to comply with hospital policy. 2. The therapist will enter the patient's room, greet the patient and assure patient privacy. After obtaining feedback about massage and completing hand washing, the therapist will assess the patient's skin integrity for skin breaks, lesions, or intravenous sites. Areas of sensitivity and pain will be assessed and these areas of concern will be avoided and documented on the massage checklist. If a patient reports being "too ill" to receive a scheduled massage on a given day, or has developed a complication, the massage session will be reschedule as soon as feasible.

3. Participants will be assisted in transferring to a massage table when possible. However, participants with major impediments to movement or those who prefer not to move onto the massage table will receive massages in their hospital bed.

4. Therapists will avoid initiating any conversation other than to ascertain comfort level and feedback on massage technique, but will respond to direct questions asked of them. 
This conversational behavior is considered standard for professional therapists during a massage.

5. The therapist will provide massage to the head, neck, shoulders (avoiding the central line site), back, abdomen (except on the first session because abdominal massage is initially aversive to many persons), feet, legs, hands and arms as intravenous lines permit. Patients will choose areas where the massage therapist might spend a greater proportion of time, but an effort will be made to provide each patient with a full-body massage each session. The massage protocol is based on the Swedish techniques of effleurage and petrissage, applied with very gentle pressure, and hand-over-hand continuous stroking of the back, arms and legs. No deep tissue work will be included. The massage tempo will be relatively slow. A standardized non-fragrant oil or cream will be used. The duration of massage will be standardized to 50 minutes, unless a patient requests stopping the session early.

6. At the end of each session, the therapist will complete a massage therapy checklist, to document areas that were massaged, massage duration, and any comments or feedback. Data Collection Procedures

If all inclusion criteria are met, the investigator will review each of the baseline measures (and instructions for each measure) with the participant, and the participant is instructed to complete the measures within the next several days in a quiet environment in their home. The participants will return the forms to the study coordinator by mail or at the participant's next clinic visit. Baseline questionnaires are estimated to take approximately 55 minutes to complete. Patients will be given contact information in case 
they have questions about the forms and will be telephoned and reminded to bring the completed forms to the next clinic visit if they have not returned the forms by mail.

Following informed consent and randomization, if the subject is randomized to the SMC plus massage therapy group, a local community massage therapist will be identified in the patient's home- area so that scheduling and preparations can begin for home massages. The first massage will be administered by a study massage therapist prior to central line placement for mobilization chemotherapy.

Measures of QoL, symptom questionnaires, and social support will be collected from both massage and control participants weekly throughout treatment. All SMC plus massage participants will complete the measures on specified non-massage day each week during the 7 weeks of massage intervention (or standard medical care). Weekly assessments by the patient will likely take no more than 35 to 40 minutes to complete. Every effort will be made to minimize burden on study participants. Patients will be informed that if they become tired they may put down the forms and complete the forms later in the day. A family member may help them with written responses. If it is not possible due to patient treatment plan for the assessments to be completed on a day the patient will not receive a massage, then the patient may complete the instruments prior to receiving their massage, to prevent reflection of any immediate massage effects. Participants will return the study forms to the investigator each week for the 7-weeks of the study. Patients who do not bring measures to the Stem Cell Transplant Clinic will be provided with an additional set of forms at their next visit, if needed, and asked to complete the forms and mail these to the investigator within the following two days in a 
provided self-addressed stamped envelope.

The massage therapists will complete the massage checklist before and after each massage administered during the study. Community-based massage therapists will be instructed to mail their forms on a weekly basis to the investigator who will review these measures and clarified any unclear points in a scheduled weekly telephone call with each massage therapist.

\section{Staff Training}

Massage therapists are taught from a standard curriculum. The knowledge obtained is verified with certification by the National Certification Exam for Therapeutic Massage and Bodywork. Massage therapists are trained to work with clients in a medical/hospital environment, a clinic or office setting and in the home environment. The same general guidelines for administering a massage apply to medical, clinic or home environments. A quiet environment without distractions will be maintained in all of the above settings. Using both in-hospital and community massage therapists is most reflective of how massage would be delivered and used in a large-scale study.

A packet of information and a 3-hour training session will be used to orient massage therapists to the study protocol. The investigator will be available by phone for any questions or concerns throughout the study. The massage therapists will talk weekly to the investigator. All participants living within a 30-mile radius of the Cancer Center will receive massages from a massage therapist affiliated with the CSCAT. The community massage therapists will be recruited in geographic locations throughout the state. 


\section{Potential Risk}

Potential risks from the massage intervention are minimal. No adverse events from massage therapy have been reported in patients undergoing bone marrow transplant or ASCT when administered by credentialed practitioners. However, due to low platelet count in this patient population, there is a small risk of bruising if the massage strokes are too deep and vigorous. Massages will be deferred if the patient has a platelet count less than $15,000 / \mathrm{mm}^{3}$. The massage may be rescheduled following platelet transfusion and documentation of an acceptable platelet count to minimize potential bruising or bleeding.

Exclusion criteria include current thrombosis or phlebitis (due to the potential danger of dislodging a clot that could lead to an embolism). Massage therapists will talk weekly with the study coordinator. The clinic staff will communicate with the study coordinator about the patient's health status. Compression fractures (very rare) or shingles (very rare) would preclude massaging the affected areas of the body. The massage coordinator will in turn communicate with the massage therapist, if these diagnoses are applicable.

\section{Sources of Materials}

The data analyzed will include demographics, diagnosis, and phases of transplant from the participant's medical record, participants' self report on questionnaires and instruments, participants' verbal responses to open ended questions and massage therapy checklists completed by the massage therapist.

\section{Study Measures}

Self report and objective measures to assess the effects of massage on perceived 
patient comfort and QoL will be collected from participants in both, SMC plus massage and SMC alone groups weekly throughout treatment. The assessment schedule is depicted in Table 1. Briefly, participants complete and return demographic data and medical history forms prior to treatment assignment. All measures will be completed at baseline, and QoL, symptom questionnaires, and social support will be completed weekly through the 7-week intervention. The massage therapists will complete the massage checklist before and after each massage session and assess numeric rating scales (NRS). for comfort, relaxation and anxiety prior to and immediately following each massage. All medical information provided by patients will be cross-validated against the patient's medial record or with the Stem Cell Transplant Clinic staff.

\section{Review of Instruments}

A flow chart of assessment measures by persons and measures by time points is provided (see Table 1) Measures will be collected from both massage and control participants weekly throughout treatment. Participants will complete and return baseline questionnaires prior to treatment group assignment. All measures will be conducted at baseline, and quality of life (QOL), symptom questionnaires, and social support will be completed weekly through the 7-week intervention. The massage therapists completed the massage checklist before and after each massage session and assess numeric rating scales (NRS) for comfort, relaxation and anxiety prior to and immediately following each massage. The measures are included for review (see Appendix B). The investigator anticipates that it will take approximately 55 to 60 minutes for the patient to complete measures at baseline and approximately 35 minutes for completion of measures weekly. 


\section{Demographic Form}

A one page demographic form developed by the study team will include: age, gender, racial category, years of education, and marital status. Completion time by the patient is expected to be about 5 minutes.

\section{Medical History Form}

A medical history form will document type, stage and location of cancer, prior history of cardiovascular disease, surgeries and injuries, medications, diabetes, past and current use of CAM therapies (or psychotherapy). All medical information provided by patient will be cross-validated against the patient's medial record or with the Stem Cell Transplant Clinic coordinator. Estimated time of completion is 15 minutes by the study coordinator with the patient.

\section{Health-related quality of life $(Q L Q-C 30)$}

The European Organization for Research and Treatment (EORTC) core questionnaire QLQ-C30 reflects the multidimensionality of the quality of life construct for cancer patients (Aaronson, et al., 1993). It will be administer using procedures reported in Kiebert, Curran \& Aaronson (1998). The EORTC QLQ-C30 is the most widely used and validated measure of QoL for patients with cancer (Aaronson et al, 1993). The QLQ-C30 has been translated into 49 languages and used in over 3,000 studies including cross cultural testing (Aaronson et al, 1993). The QLQ-C30 includes 30 items comprising five functional scales (physical, role, cognitive, emotional, and social), three symptom scales (fatigue, pain, and nausea/vomiting), a global QoL scale (2 items), and six single items assessing symptoms (dyspnea, insomnia, appetite loss, constipation, 
diarrhea) and financial impact (difficulties). Scoring: Responses for the functional scale are "No (1) and "Yes (2)". Higher mean scores on theses scales represent better function and higher quality of life. No time frame is referenced for these functional questions. The remaining questions ask the patient to refer to the last week. Responses for the symptom scale items are rated "Not at all (1)", "A Little Bit (2)," "Quite a Bit (3)," and "Very much (4)." Higher means on the symptoms scales represent more symptomatology and a lower quality of life. The global health status/quality of life is an 8 point scale (1-7) ranging from "Very poor (1)" to "Excellent (7)." Each scale score is calculated by averaging items within the scale and transforming the average score linearly to a 0 to 100 scale. The global QoL scale will be used as the primary measures of QoL, but other scales will also be examined as exploratory outcomes, as recommended by the developers (Curran et al., 2000). Prior to statistical analysis, the raw scores will be linearly transformed to 0 to 100 scales (Fayers, Aaronson, Bjordal, Groenvold, \& Aaronson, 1999). Mean change scores of five to 10 represent a little subjective change and a change of 10 to 20 represents a moderate change to patients (Osoba et al., 1995).

This self-report instrument takes an average of 12 minutes to complete. Reading level is rated as low. Patient and staff acceptance is high. The QLQ-C30 is acceptable to patients internationally, the scale is reliable, studies have supported clinical validity and the instruments ability to respond to change, and has been widely used to assess QOL endpoints in clinical trials including cancer patients. (Aaronson et al, 1993 ; Velikova et al, 1999; Curran, et al, 2000; Kiebert, Curran \& Aaronson, 1998). Convergent validity exceeds the .40 criterion. (Aaronson, et al., 1993). The global QOL scale correlates 
substantially with the other scales and clinical validity is supported (Aaronson, et al., 1993). Cronbach alpha reliability coefficient will be calculated for the proposed study.

Use of the QLQ-C30 in the autologous stem cell transplant (ASCT) population is feasible as it is a self report instrument, administration time is short and, reading level is low. The QLQ-C30 has been validated in male and female populations, inpatients and outpatients and patients receiving chemotherapy or undergoing surgery for cancer. In some cancer studies missing data occurs as disease progresses. Many of these studies are carried over years. The proposed study will last 7 weeks through the phases of ASCT transplant.

State Anxiety (STAI Y-1)

The State-Trait Anxiety Inventory (STAI) (Spielberger, Gorsuch, \& Lushene, 1970; Spielberger, 1989) was developed by Speilberg in 1969 and Form Y-1 was adapted in 1983. The STAI was conceptualized as a research instrument to evaluate subjective anxiety in adults. The STAI is the standard instrument to assess anxiety (Schwarzer, 1997). The State Anxiety Inventory (SAI) subscale measures feelings of apprehension, tension, nervousness and worry. The SAI scale consists of 20 items, rated on a 4-point Likert scale, ranging from 1 (Not at all) to 4 (Very much so), representing low to high anxiety for how a person "feels right at this moment" or emotionally responds to a stressful situation (Spielberger, 1983). The score ranges from 20-80 with 20-39 representing low anxiety, 40-59 moderate anxiety, and 60-80 high anxiety. Scores are reportedly higher under stress conditions (Speilberger, 1983).

This SAI is a self-report instrument and can be administered in 5-10 minutes. The 
questions are written at a $6^{\text {th }}$ grade reading level. It has been translated into more than 40 languages. There are well established psychometric properties for this instrument (Spielberger, 1983). Construct validity and test-retest reliability of this instrument are well established and support the utility of this instrument (Spielberger, 1989). The Mean alpha coefficient was .93 with construct validity established at .65 (Speilberger, 1983). Alpha for the SAI is .92 (Spielberger, 1983). High correlations (.96 and .98) are present between the STAI and other measures of anxiety (Speilberger, 1983). Internal consistency reliability estimates are satisfactory for a broad range of studies and various populations (Barnes, Harp \& Jung, 2002). In this study trait anxiety will not be measured. A Cronbach alpha reliability coefficient will be calculated for this proposed study.

Use of the SAI is feasible in the autologous stem cell transplant (ASCT) population as it is self- administered and takes only a few minutes to complete. A Metaanalytic reliability generalization of score reliability reported internal consistency at .91 (Barnes, Harp \& Jung, 2002). The longevity in use of the instrument, as well as the high correlation it has with other measures of anxiety, speaks to its validity. The SAI has demonstrated clinical significance with sensitivity to changes in anxiety following massage therapy in patients with cancer, patients receiving Autologous Bone Marrow Transplantation, and pediatric patients receiving massage therapy (Ferrell-Torry \& Glick, 1993; Taylor, Galper, Taylor, et al., 2003; Ahles et al., 1999; Field et al., 2001). Perceived Stress, Comfort and Relaxation levels (NRS)

Stress, comfort and relaxation will be measured using an 11 point numeric rating scale (NRS). Participants will rate their perceived stress, comfort and relaxation level 
prior to and after each massage. For example, the NRS for stress ranges from 0 (no stress) to 10 (extremely stressed).

The NRS takes less than 1 minute to complete. NRS is a simple, yet sensitive measure of subjective phenomena and has been used successfully in a previous study of the effects of massage (Delaney, Leong, Watkins \& Brodie, 2002). Validity and reliability of numeric rating scales as a measure of symptoms has been demonstrated with established reliability and validity (Benotsch, et al, 2000; Ahles, Ruckdeschel, \& Blanchard, 1984). Numeric rating scales for pain symptom strongly correlate $(0.85)$ with visual analog scales (VAS) in patients with cancer pain and in younger adults (Paice \& Cohen, 1997; Herr, Spratt, Mobily \& Richardson, 2004).

This simple measure of symptoms with a NRS is feasible in the ASCT population. Hospitalized patients are accustomed to symptom assessment using numeric rating scales in the hospital and clinics.

Pain (MPQ-SF)

The McGill Pain Questionnaire, Short-Form (MPQ-SF) (Melzack, 1987) measures sensory and affective aspects of pain. The MPQ-SF is a shortened version of the original McGill pain questionnaire developed by Ronald Melzack in 1975 and shortened in 1987 (Melzak, 1975, Melzak, 1987). The MPQ-SF was developed for use in research settings and when time to obtain information from the patient is short. It contains words describing both the sensory and affective components of pain. The sensory descriptors are throbbing, shooting, stabbing, sharp, cramping, gnawing, hotburning, aching, heavy, tender, and splitting. The affective descriptors are tiring- 
exhausting, sickening, fearful, and punishing-cruel. The descriptors are ranked from 0-3 (none, mild, moderate, and severe) (Melzack, 1987). The measure also contains two overall measures of pain, the Present Pain Index (0-5 rating accompanied by descriptive words: no pain, mild pain, discomforting, distressing, horrible and excruciating) and a $100 \mathrm{~mm}$ visual analogue scale (VAS) to measure pain intensity. Verbal anchors are 0 $\mathrm{mm}=$ no pain and $100 \mathrm{~mm}$ = worst pain possible). The VAS provides a graphical measure of the patient's pain response.

The MPQ-SF takes 2 to 5 minutes to complete and correlates highly (0.81-0.97) with the sensory, affective and total indices of the long form of the McGill Pain Questionnaire (Melzack, 1987). The MPQ-SF has demonstrated validity and reliability among patients with chronic cancer pain (Dugeon, Raubertas \& Rosenthal, 1993). A Cronbach alpha reliability coefficient will be calculated for the proposed study.

The MPQ-SF is feasible to assess pain in the ASCT population. The instrument consists of simple words and rankings that are easily understood by patients. The VAS is a simple robust pain management instrument which is frequently used in health care settings to assess pain severity and improvement over time of treatment. The MPQ-SF has demonstrated reliability and validity in the cancer patient population. It is well known and researched in the pain community and is quick to administer and to score.

Social Support (MOS-SSS)

The Medical Outcome Study-Social Support Survey (MOS-SSS) (Sherbourne \& Stewart, 1991) will assess social support over time. This 21-item survey has four subscales (emotional/informational support, tangible support, positive interaction, and 
affection) and an overall index of perceived social support. All but one item is rated on a 5-point Likert scale from "none of the time" to "all of the time." One item asks "About how many close friends and close relatives do you have (people you feel at ease with and can talk to about what is on your mind)?" A higher score indicates higher overall social support. High levels of internal reliability (Cronbach's alphas for all scales >.90) and convergent validity ( $r s=.69$ to .82$)$ are reported (Sherbourne \& Stewart, 1991). A Cronbach alpha reliability coefficient will be calculated for the proposed study.

The MOS-SSS is feasible in the ASCT population and has been used to measure prospective changes in social support of patients undergoing bone marrow transplants (McQuellon et al., 1998) and in patients with breast cancer (Kornblith et al., 2001). The MOS-SSS total score correlates highly with the Mental Health Inventory (Kornblith et al., 2001).

\section{Massage Checklist}

To evaluate the massage protocol, the investigator developed a checklist to be completed by all massage therapists before and after each massage administered during the study. It will document the date, time of day, and length of each massage administered, and it will be used to explore treatment adherence and integrity (deviations from the protocol, environmental barriers to massage in the hospital and home) over the course of the intervention. The massage therapist will ask the patient to evaluate the level of stress, comfort and relaxation the patient is experiencing "at this moment" using numeric rating scales prior to and immediately following each massage. On the days of the first and last massage the participant will be asked 
several open ended questions to document the participant's previous experiences with massage therapy and to evaluate the patient's perceptions of massage therapy provided during the study respectively.

The instruments selected: The European Organization for Research and Treatment core questionnaire QLQ-C30, State scale of the State Trait Anxiety Inventory, McGill Pain Questionnaire, and Medical Outcome Study-Social Support Survey evaluate the constructs of quality of life, anxiety, pain and social support respectively. Repeated measures will have to be considered in analysis of all the data represented by the instruments.

\section{Data Analysis}

The study design and data analysis have been reviewed by Cheryl Bourguignon, $\mathrm{RN}, \mathrm{PhD}$, who is the consulting statistician for the Center for the Study of Complementary and Alternative Therapies. Dr. Bourguignon will oversee the statistical analysis. All data will be entered, cleaned, and verified using Statistical package for the Social Sciences version 15.0 (or the most recent version). Data entry and cleaning will be conduced on an ongoing basis as the data are collected. A Microsoft Access database will be used to house and manage the data. Validation rules, range checks and input formats will be used to minimize data entry problems. Data files will be backed up weekly. Security procedures of all information and data collected will involve passwordprotected databases within the Center for the Study of Complementary and Alternative Therapies and all copies will be kept locked in a limited access cabinet.

Descriptive statistics will be calculated on demographic and study variables. 
Frequencies will be reported for categorical variables and means and standard deviations will be reported for continuous variables. The level of significance was set at 0.05 for all analyses, and trends will be explored.

\section{Primary Aim \#1}

Subjects receiving SMC plus massage for ASCT will report greater comfort and relaxation and reduced stress with a higher massage dose. Multi-level modeling (also called hierarchical linear modeling), will be used to analyze Aim 1. To evaluate the effect of massage dose on immediate parameters, the three outcome variables of comfort, relaxation, and stress will be assessed pre and post massage and the number of minutes of massage (massage dose) will be recorded (for each of the 21 massages). A change score (pre - post) will be calculated on every massage for each outcome variable. Patterns of change over time for each individual (within-subjects analysis) will be modeled by estimating a regression line of best fit through the participant's data points. The number of minutes of massage may vary depending upon the status of the patient and the need for other medical interventions, thus to evaluate the effect of massage dose on immediate parameters, the number of minutes of massage will be used as a time-varying covariate in the multi-level models for comfort, relaxation, and stress. To evaluate the prolonged effects of massage dose on QoL treatment-related symptoms, the multi-level models (one for each outcome variable of anxiety, stress, pain, fatigue, and nausea) will estimate the pattern of change over time using a regression line of best fit through the participant's weekly data points. The total number of minutes of massage time over the entire study will be used as a covariate in each multi-level model. Multi-level modeling is 
advantageous in that this technique permits the investigation of change over time and can be conducted if some data points are missing.

\section{Primary Aim \#2:}

Subjects receiving SMC plus massage for ASCT will report improvement in QoL treatment related symptoms with a higher massage dose. Multi-level modeling also will be used to analyze Aim 2. To evaluate the prolonged effects of massage dose on QoL treatment-related symptoms, the multi-level models (one for each outcome variable of anxiety, stress, pain, fatigue, and nausea) will estimate the pattern of change over time using a regression line of best fit through the participant's weekly data points. The total number of minutes of massage time over the entire study will be used as a covariate in each multi-level model.

\section{Primary Aim \#3}

Throughout the phases of ASCT treatment, subjects receiving SMC plus massage therapy will report greater improvement in QoL treatment-related symptoms than subjects receiving standard medical care alone. The ASCT process consists of four phases. For each outcome variable (anxiety, stress, pain, fatigue, and nausea), participant ratings will be averaged over each phase. Repeated measures ANOVAs will be used (one for each outcome variable) to evaluate differences in symptoms over the phases of the ASCT process between the standard medical care (SMC) plus massage therapy group and the SMC group alone. Each repeated measures ANOVA will consist of a betweensubject factor of group membership and a within-subject factor of phase. For significant ANOVAs, contrasts will be used to determine differences between phases in the groups. 
Primary Aim \#4

After controlling for social support, subjects receiving standard medical care (SMC) plus massage therapy during ASCT will report greater comfort, relaxation, and stress reduction following massage sessions without gloves than massage sessions with gloves.

Three multi-level models, one for each outcome variable, will be used to analyze Aim 4. The three outcome variables of comfort, relaxation, and stress will be assessed pre and post massage (for each of the 21 massages). A change score (pre-post) will be calculated on every massage for each outcome variable. Patterns of change over time for each individual (within-subjects analysis) will be modeled by estimating a regression line of best fit through the participant's data points (data points are the 21 change scores prepost massage over the study period). The use of gloves may vary depending upon infection status of patients, thus the effect of gloves will be evaluated by using glove status as a time-varying covariate in the multi-level models. Given that social support may affect the outcome variables, all models will use baseline social support as a covariate.

\section{Secondary Aim}

To describe barriers and facilitators to ASCT patient acceptance of supportive care massage therapy in both the hospital and home settings. A qualitative analysis will be conducted on open-ended questions. Open ended questions will be asked following the final massage. Content analysis will be conducted on answers to the open ended 
questions using "barriers" and "facilitators" as the two basic categories. Subcategories and descriptions based on the language used by the participants will be developed. 


\section{Summary}

In this chapter, a brief review of the methods and objectives for the parent study is presented, followed by a description of the methods to be used for the proposed dissertation study. The objective of the proposed dissertation study is to investigate the effects of massage therapy and touch on patient comfort during isolation and QoL outcomes for patients undergoing ASCT, the effect of massage dose and use of gloves with massage sessions on symptoms, and the facilitators and barriers to patient acceptance of massage during phases of the ASCT process.

Validity and reliability data is presented for the instruments proposed for this study. The instruments selected: The European Organization for Research and Treatment core questionnaire QLQ-C30, State scale of the State Trait Anxiety Inventory, McGill Pain Questionnaire, and Medical Outcome Study-Social Support Survey evaluate the constructs of quality of life, anxiety, pain and social support respectively.

Finally, the proposed procedure for data analysis using multilevel modeling is presented for Primary Aims 1-4. Qualitative analysis procedures to evaluate the secondary aim are also presented. 
Table 1

Flow Chart of Measures by Timepoints

(Bolded measures will be completed by study participants)

\begin{tabular}{|l|c|c|c|c|c|c|c|}
\hline Instruments & Baseline & Time 2 & Time 3 & Time 4 & Time 5 & Time 6 & Time 7 \\
\hline $\begin{array}{l}\text { Demographic Data } \\
\text { Form }\end{array}$ & $\mathrm{X}$ & & & & & & \\
\hline Medical History Form & $\mathrm{X}$ & & & & & & \\
\hline QLQ-C30 & $\mathrm{X}$ & $\mathrm{X}$ & $\mathrm{X}$ & $\mathrm{X}$ & $\mathrm{X}$ & $\mathrm{X}$ & $\mathrm{X}$ \\
\hline STAI Y Form & $\mathrm{X}$ & $\mathrm{X}$ & $\mathrm{X}$ & $\mathrm{X}$ & $\mathrm{X}$ & $\mathrm{X}$ & $\mathrm{X}$ \\
\hline $\begin{array}{l}\text { Perceived stress, } \\
\text { comfort and relaxation } \\
\text { NRS }\end{array}$ & $\mathrm{X}$ & $\mathrm{X}$ & $\mathrm{X}$ & $\mathrm{X}$ & $\mathrm{X}$ & $\mathrm{X}$ & $\mathrm{X}$ \\
\hline MPQ-SF & $\mathrm{X}$ & $\mathrm{X}$ & $\mathrm{X}$ & $\mathrm{X}$ & $\mathrm{X}$ & $\mathrm{X}$ & $\mathrm{X}$ \\
\hline MOS-SSS & $\mathrm{X}$ & $\mathrm{X}$ & $\mathrm{X}$ & $\mathrm{X}$ & $\mathrm{X}$ & $\mathrm{X}$ & $\mathrm{X}$ \\
\hline $\begin{array}{l}\text { Massage Therapy } \\
\begin{array}{l}\text { Checklist } \\
\text { (3 per week) }\end{array}\end{array}$ & $\mathrm{X}$ & $\mathrm{X}$ & $\mathrm{X}$ & $\mathrm{X}$ & $\mathrm{X}$ & $\mathrm{X}$ & $\mathrm{X}$ \\
\hline
\end{tabular}

'NRS completed before and after each massage in the intervention group only. 
Table 2

Analytic Methods by Study Aims

\begin{tabular}{|l|l|}
\hline Specific Aims & Analytic Methods \\
\hline $\begin{array}{l}\text { 1. Subjects receiving SMC plus massage } \\
\text { for ASCT will report greater comfort, } \\
\text { relaxation, and stress reduction with a } \\
\text { higher massage dose. }\end{array}$ & Multi-level modeling \\
\hline $\begin{array}{l}\text { 2. Subjects receiving SMC plus massage } \\
\text { for ASCT will report improvement in QoL } \\
\text { treatment related symptoms with a higher } \\
\text { massage dose. }\end{array}$ & Multi-level modeling \\
\hline $\begin{array}{l}\text { 3. Throughout the phases of ASCT } \\
\text { treatment subjects receiving SMC plus } \\
\text { massage therapy will report greater } \\
\text { improvement in QoL treatment related } \\
\text { symptoms than subjects receiving standard } \\
\text { medical care alone. }\end{array}$ & $\begin{array}{l}\text { Repeated measures ANOVAs (For } \\
\text { significant ANOVAs, contrasts will be } \\
\text { used to determine differences between } \\
\text { phases in the groups.) }\end{array}$ \\
\hline $\begin{array}{l}\text { A. After controlling for social support, } \\
\text { subjects receiving standard medical care } \\
\text { (SMC) plus massage therapy during ASCT }\end{array}$ & $\begin{array}{l}\text { ANCoscriptive statistics will be calculated on } \\
\text { demographic and study variables. }\end{array}$ \\
$\begin{array}{l}\text { Fill report greater comfort, relaxation, and } \\
\text { stress reduction following massage } \\
\text { sessions without gloves than massage } \\
\text { sessions with gloves. }\end{array}$ & $\begin{array}{l}\text { variables and means and standard } \\
\text { deviations will be reported for continuous } \\
\text { variables. } \\
\text { Three multi-level models (hierarchical } \\
\text { linear modeling) }\end{array}$ \\
\hline $\begin{array}{l}\text { Secondary Aim 1: To describe barriers and } \\
\text { facilitators to ASCT patient acceptance of } \\
\text { supportive care massage therapy in both } \\
\text { the hospital and home settings. }\end{array}$ & $\begin{array}{l}\text { Qualitative analysis: content analysis will } \\
\text { be conducted using "barriers" and } \\
\text { "facilitators" as the two basic categories. } \\
\text { Subcategories and descriptions based on } \\
\text { the language used by the participants will } \\
\text { be developed. }\end{array}$ \\
\hline
\end{tabular}




\section{References}

Aaronson, N. K., Ahmedzai, S., Bergman, B., Bullinger, M., Cull, A., Duez, N. J., et al. (1993). The European Organization for Research and Treatment of Cancer QLQC30: A quality-of-life instrument for use in international clinical trials in oncology. Journal of the National Cancer Institute, 85, 365-376.

Agency for Health Care Policy and Research [AHCPR]. (1994). Management of Cancer Pain. Clinical practice guideline No. 9. DHHS Pub. No. 94-0592. Silver Spring, MD: AHCPR Clearinghouse.

Ågren, G., Lundeberg, T., Uvnäs-Moberg, K., \& Sato, A. (1995). The oxytocin antagonist 1-deamino-2-D-Tyr-(Oet)-4-Thr-8-Orn-oxytocin reverses the increase in withdrawal response latency to thermal, but not mechanical nociceptive stimuli following oxytocin administration or massage-like stroking in rats. Neuroscience Letters, 187, 49-52.

Ahlberg, K., Elkman, T., Gaston-Johansson, F. \& Mock, V. (2003) Assessment and management of cancer-related fatigue in adults. The Lancet, 362, 640-650.

Ahles, T.A., Ruckdeschel, J.C., \& Blanchard, E.B. (1984). Cancer-related pain: II. Assessment with Visual Analogue Scales. J Psychosom Res, 28, 121-124.

Ahles, T. A., Tope, D. M., Pinkson, B., Walch, S., Hann, D., Whedon, M., et al. (1999). Massage therapy for patients undergoing autologous bone marrow transplantation. Journal of Pain and Symptom Management, 18, 157-163.

Altemus, M., Redwine, L. S., Leong, Y.-M., Freye, C. A., Porges, S. W., \& Carter, C. S. (2001). Responses to laboratory psychosocial stress in postpartum women. 
Psychosomatic Medicine, 63, 814-821.

Anderson, B. L., Kiecolt-Glaser, J. K., \& Glaser, R. (1994). A biobehavioral model of cancer stress and disease course. American Psychologist, 49, 389-404.

Andrykowski, M. A., Greiner, C. B., Altmaier, E. M., Burish, T. G., Antin, J. H., Gingrich, R., et al. (1995). Quality of life following bone marrow transplantation: Findings from a multicenter study. British Journal of Cancer, 71, 1322-1329.

Barclay, H.V. (1913). Medical Gymnastics in Locomotor Ataxia.American Journal of Nursing, 13(6), 428.

Barnes, L.L., harp, D. \& June, W.S. (2002). Reliability generalization of scores on the speilberger state-trait anxiety inventory. Educational and Psychological Measurement, 62, 603-618.

Benotsch, E. G., Lutgensorf, S.K., Watson, D., Fick, L.J., \& Lang, E.V. (2000). Rapid anxiety assessment in medical patients: Evidence for the validity of verbal anxiety ratings. Ann Behav Med, 22, 199-203.

Biermann, H. (1907). Notes on Massage. American Journal of Nursing, 7(7), 534.

Buchsel, P. C., \& Whedon, M. B. (Eds.). (1995). Bone marrow transplantation: Administration and clinical strategies. Boston: Jones \& Bartlett.

Butts, J.B. \& Janes, S. (1995). Transcending the latex barrier: the therapeutics of comfort touch in patients with acquired immunodeficiency syndrome, Holistic Nursing Practice, 10, 61-7.

Cameron, C. I., Cella, D., Herndon, J. E., Kornblith, A. B., Zuckerman, E. Henderson, E., et al. (2001). Persistent symptoms among survivers of Hodgkin's disease: An 
explanatory model based on classical conditioning. Health Psychology, 20, 71-75.

Chan, Y. M., Ngan, H. Y., Li, B. Y., Yip, A. M., Ng, T. Y., Lee, P. W., et al. (2001). A longitudinal study on quality of life after gynecological cancer treatment. Gynecologic Oncology, 83, 10-19.

Cherkin, D. C., Eisenberg, D., Sherman, K. J., Barlow, W., Kaptchuk, T. J., Street, J., et al. (2001). Randomized trial comparing traditional Chinese medical acupuncture, therapeutic massage, and self-care education for chronic low back pain. Archives of Internal Medicine, 161, 1081-1088.

Churchill, A. Q. (1915). Massage, Its Physiologic Effects. American Journal of Nursing, $15,635-636$.

Crocetti, E., Crotti, N., Feltrin, A., Ponton, P., Geddes, M., \& Buiatti, E. (1998). The use of complementary therapies by breast cancer patients attending conventional treatments. European Journal of Cancer, 34, 324-328.

Curran, D., Aaronson, N., Standaert, B., Molenberghs, G., Therasse, P., Ramirez, A., et al. (2000). Summary measures and statistics in the analysis of quality of life data: An example from an EORTC-NCIC-SAKK locally advanced breast cancer study. European Journal of Cancer, 36, 834-844.

Delaney, J. P., Leong, K. S., Watkins, A., \& Brodie, D. (2002). The short-term effects of myofascial trigger point massage therapy on cardiac autonomic tone in healthy subjects. Journal of Advanced Nursing, 37, 364-371.

Dudgeon, D., Raubertas, R. F., \& Rosenthal, S. N. (1993). The Short-Form McGill Pain 
Questionnaire in chronic cancer pain. Journal of Pain and Symptom Management, 8, 191-195.

Eliason, E.L. Ferguson, L.K. \& Lewis, E.K. (1936). Surgical Nursing. Philadelphia: J.B. Lippincott Company, 109.

Fallow, J. (1990). Massage therapy and nursing care. Nursing Standard, 4, 26-28.

Fayers, P., Aaronson, N., Bjordal, K. Groenvold, M., \& Aaronson, N.K. (1999). EORTC QLQ-C30 Scoring Manual, $2^{\text {nd }}$ ed., Brussels, Belgium: EORTC Study Group on Quality of Life Study Group.

Felhendler, D., \& Björn, L. (1996). Pressure on accupoints decreases postoperative pain. Clinical Journal of Pain, 12, 326-329.

Fellowes, D., Barnes, K., Wilkinson, S. (2004) Aromatherapy and massage for symptom relief in patients with cancer. The Cochrane Library, 2, CD002287.

Ferrell-Torry, A. T., \& Glick, O. J. (1993). The use of therapeutic massage as a nursing intervention to modify anxiety and the perception of cancer pain. Cancer Nursing, 16, 93-101.

Field, T. (2002). Massage therapy. Medical Clinics of North America, 86, 163-171.

Field, T., Cullen, C., Diego, M., Hernandez-Reif, M., Sprinz, P., Beebe, K. Kissell, B., \& Bango-Sanchez, V. (2001). Leukemia immune changes following massage therapy. Journal of Bodywork and Movement Therapies, 5, 271-274.

Field, T., Grizzle, N., Scafidi, F., \& Schanberg, S. (1996). Massage and relaxation therapies' effects on depressed adolescent mothers. Adolescence, 31, 903-911. 
Field, T., Henteleff, T., Hernandez-Reif M., Martinez, E., Mavunda, K., Kuhn C., \& Schanberg S. (1998). Children with asthma have improved pulmonary functions after massage therapy. Journal of Pediatrics, 132, 854-858.

Field, T., Hernandez-Reif, M. Diego, M. \& Schanberg, K.,C. (2005). Cortisol Decreases and Serotonin and Dopamine Increase Following Massage Therapy, Intern. J. Neuroscience, $11,1397-1413$.

Field, T, Quintino, O, Henteleff, T, Wells-Keife, L, \& Delvecchio-Feinberg, G. (1997). Job stress reduction therapies. Alternative Therapies in Health and Medicine, 3, 54-6. 11.

Field, T. M. (1998). Massage therapy effects. American Psychologist, 53, 1270-1281.

Flechtner, H. \& Bottomley, A. (2003). Fatigue and quality of life: lessons from the real world. Oncologist, 8 Suppl 1, 5-9.

Fritz, S. (2000). Mosby's fundamentals of therapeutic massage. St. Louis, MO: Mosby. Fung, H. C., \& Nademanee, A. P. (2002). Approach to Hodgkin's lymphoma in the new Millennium. Hematological Oncology, 20, 1-15.

Gaston-Johansson, F., Fall-Dickson, J. M., Nanda, J. P., Ohly, K., Stillman, S., Krumm, S., et al. (2000). The effectiveness of the Comprehensive Coping Strategy Program on clinical outcomes in breast cancer autologous bone marrow transplantation. Cancer Nursing, 23, 277-285.

Gaston-Johansson, F., \& Foxall, M. (1996). Psychological correlates of quality of life across the autologous bone marrow transplant experiences. Cancer Nursing, 19, 170-176. 
Goehler, L. E., Gaykema, R. P., Hansen, M. K., Anderson, K., Maier, S. F., \& Watkins, L. R. (2000). Vagal immune-to-brain communication: A visceral chemosensory pathway. Autonomic Neuroscience: Basic and Clinical, 85, 49-59.

Graham, L.H. (1925). Exercises for Cardiac Cases. American Journal of Nursing, 25(4), 365.

Grealish, L., Lomasney, A., \& Whiteman, B. (2000). Foot massage: A nursing intervention to modify the distressing symptoms of pain and nausea in patients hospitalized with cancer. Cancer Nursing, 23, 237-243.

Gruber, U., Fegg, M., Buchamann, M., Kolb, H.-J., \& Hiddemann, W. (2003). The longterm psychological effects of haematopoetic stem cell transplantation. European Journal of Cancer Care, 12, 249-256.

Herr, K., Spratt, K., Mobily, P.R., \& Richardson, G. (2004). Pain Intensity in older adults: Use of experimental pain to compare psychometric properties and usability of selected pain scales with younger adults. Clinical Journal of Pain, 20 (4), 207219.

Hayes, J. \& Cox, C. (1999). Immediate effects of a five-minute foot massage on patients in critical care. Intensive and Critical Care Nursing, 15, 77-82.

Herbert, T. B., \& Cohen, S. (1993a). Depression and immunity in humans: A metaanalytic review. Psychological Bulletin, 113, 472-486.

Herbert, T. B., \& Cohen, S. (1993b). Stress and immunity in humans: A meta-analytic review. Psycosomatic Medicine, 55, 364-379. 
Hernandez, M., Field, T., Largie, S., Cullen, C., Beutler, J., Sanders, C., Weiner, W., Rodriguez,-Batemen, D, Selaya, L., Schanberg, L., and Kuhn, C., (2002).

Parkinson's disease symptoms are differentially affected by massage therapy vs. progressive muscle relaxation: a pilot study. Journal of Bodywork and Movement Therapies, 6, 177-182.

Hernandez-Reif, M., Field, T., Krasnegor, J., \& Theakston, H. (2001). Low back pain is reduced and range of motion increased after massage therapy. International Journal of Neuroscience, 106, 131-145.

Hernandez-Reif, M, Martinez, A, Field, T., Quintero, O., Hart, S., \& Burman, I. (2000). Premenstrual symptoms are relieved by massage therapy. Journal of Psychosomatic Obstetrics and Gynecology, 21, 9-15.

Herr, K., Spratt, K., Mobily, P.R., \& Richardson, G. (2004). Pain Intensity in older adults: Use of experimental pain to compare psychometric properties and usability of selected pain scales with younger adults. Clinical Journal of Pain, 20 (4), $207-$ 219.

Hulme, J., Waterman, H., \& Hillier, V. F. (1999). The effect of foot massage on patients' perception of care following laparoscopic sterilization as day case patients. Journal of Advanced Nursing, 30, 460-468.

Imrie, K., Esmail, R., Meyer, R. M., et al. (2002). The role of high-dose chemotherapy and stem-cell transplantation in patients with multiple myeloma: A practice guideline of the cancer care Ontario practice guidelines initiative. Annuals of Internal Medicine, 136, 619-629. 
Jassak, P. F., \& Riley, M. B. (1994). Autologous stem cell transplant. Cancer Practice, 2, 141-145.

Jensen-Nelson,K.L. (1941). Massage in Nursing Care. New York: Macmillan Company, 12.

Kaada, B. \& Torsteinbo, , O. (1989). Increase of Plasma $\beta$-Endorphins in connective tissue massage. Gen Pharmac, 20(4), 487-489.

Kamarck, T. W., Peterman, A. H., \& Raynor, D. A. (1998). The effects of the social environment on stress-related cardiovascular activation: Current findings, prospects, and implications. Annals of Behavioral Medicine, 20, 247-256.

Kiebert, G. M., Curran, D., \& Aaronson, N. K. (1998). Quality of life as an endpoint in EORTC clinical trials. Statistics in Medicine, 17, 561-569.

Kim, M. S., Cho, K. S., Woo, H.-M., \& Kim, J. H. (2001). Effects of hand massage on anxiety in cataract surgery using local anesthetic. Journal of Cataract \& Refractive Surgery, 27, 884-890.

Kornblith, A.B. Herndon, J.E., Zuckerman, E., Viscoli, C.M., Horwitz, R.I., Cooper, M.R., Harris, L., Tkaczuk, K.H., Perry, M.C., Budman, D., Norton, L., \& Holland, J.C. (2001). Social Support as a buffer to the psychological impact of stressful life events in women with breast cancer, Cancer, 91(2), 443-454.

Kotani, N., Hashimoto, H., Sato, Y., Sessler, D. I., Yoshioka, H., Kitayama, M., et al. (2001). Preoperative intradermal acupuncture reduces postoperative pain, nausea, vomiting, analgesic requirement, and sympathoadrenal responses. Anesthesiology, 95, 349-356. 
Labyak, S. E., \& Metzger, B. L. (1997). The effects of effleurage backrub on the physiological components of relaxation: A meta-analysis. Nursing Research, 46, 59-62.

Laferty, W.E., Downey, L., McCarty, R.L., Standish, L.J. \& Patrick, D.L. (2006). Evaluating CAM treatment at the end of life: a review of clinical trials for massage and meditation. Complementary Therapies in Medicine, 14, 100-112.

Larsen,J., Nordström, G., Björkstrand, B., Ljungman, P., \& Gardulf, A. (2003).

Symptom distress, functional status andhealth-realted quality of life before highdose chemotherapy with stem-cell transplantation. European Journal of Cancer Care, 12, 71-80.

Lovas, J.M., Craig, A.R., Raison, R.L., Weston, K.M., Segal Y.D., \& Markus, M.M. (2002). The effects of massage therapy on the human immune response in healthy adults. Journal of Bodywork and Movement Therapies, 3, 143-150.

Lund, I., Yu, L. C., Uvnas-Moberg, K., Wang, J., Yu, C., Kurosaw, M., Agren, G., Rosen, A., Lekman, M., \& Lundeberg, T. (2002). Repeated massage-like stimulation induces long-term effects on nociception: contribution of oxytocinergic mechanisms. European Journal of Neuroscience, 16(2), 330-338.

Lutgendorf, S.K. and Costanzo E. S. (2003) Psychoneuroimmunology and health psychology: an integrateive model. Brain, Behavior, and Immunity 17, 225-232. Macafee, N.E. (1920). Massage: An Elementary Text-Bookfor Nurses, $2^{\text {nd }}$ Ed. Reed \& Witting Co, 5 .

McGuire, D. B., Yeager, K. A., Dudley, W. N., Peterson, D. E., Owen, D. C., Lin, L. S., 
et al. (1998). Acute oral pain and mucositis in bone marrow transplant and leukemia patients: Data from a pilot study. Cancer Nursing, 21, 385-393.

McNamara, M. E., Burnham, D. C., Smith, C., \& Carroll, D. L. (2003). The effects of back massage before diagnostic cardiac catheterization. Alternative Therapies in Health \& Medicine, 9, 50-57.

McQuellon, R. P., Russell, G. B., Cella, D. F., Craven, B. L., Brady, A., Bonomi, A., et al. (1997). Quality of life measurement in bone marrow transplantation: Development of the Functional Assessment of Cancer Therapy-Bone Marrow Transplant (FACT-BMT) scale. Bone Marrow Transplantation, 19, 357-368. McQuellon, R. P., Russell, G. B., Rambo, T. D., Craven, B. L., Radford, J., Perry, J. J., et al. (1998). Quality of life and psychological distress of bone marrow transplant recipients: The 'time trajectory' to recovery over the first year. Bone Marrow Transplantation, 21, 477-486.

Meek, S.S. (1993). Effects of slow stroke back massage on relaxation in hospice clients. IMAGE: Journal of Nursing Scholarship, 25(1), 17-21.

Melzack, R. (1975). The McGill Pain Questionnaire: Major properties and scoring methods, Pain, 1, 277-299.

Melzack, R. (1987). The Short-Form McGill Pain Questionnaire. Pain, 30, 191-197. Menard, M. (1995). The effects of therapeutic massage on post-surgical outcomes. Unpublished doctoral dissertation, University of Virginia, Charlottesville. Molassiotis, A., van den Akker, O. B., Milligan, D. W., \& Goldman, J. M. (1997). Symptom distress, coping style and biological variables as predictors of survival 
after bone marrow transplantation. Journal of Psychosomatic Research, 42, 275 285.

Molassiotis, A., Yung, H. P., Yam, B. M., Chan, F. Y., \& Mok, T. S. (2002). The effectiveness of progressive muscle relaxation training in managing chemotherapy-induced nausea and vomiting in Chinese breast cancer patients: A randomized controlled trial. Support Care Cancer, 10, 237-246.

Morris, K. T., Johnson, N., Homer, L., \& Walts, D. (2000). A comparison of complementary therapy use between breast cancer patients and patients with other primary tumor sites. The American Journal of Surgery, 179, 407-411.

Mulliner, M.R. (1929). Mechano-therapy: A Text-Book for Students. Philadelphia: Lea \& Febiger, 24.

Neitzert, C. S., Ritvo, P., Dancey, J., Weiser, K., Murray, C., \& Avery, J. (1998). The psychosocial impact of bone marrow transplantation: A review of the literature. Bone Marrow Transplantation, 22, 409-422.

NIH Technology Assessment Panel on Integration of Behavioral and Relaxation Approaches into the Treatment of Chronic Pain and Insomnia. (1996). Integration of behavioral and relaxation approaches into the treatment of chronic pain and insomnia. Journal of the American Medical Association, 276, 313-318.

Osoba, D. Rodrigues, G. Myles, J. et al (1998). Interpreting the significance of changes in health related quality of life scores, J Clin Oncol 16, 139-144.

Paice, J.A. \& Cohen, F.L. (1997). Validity of a verbally administered numeric rating scale to measure cancer pain intensity. Cancer Nurse, 20, 88-93. 
Palinkas, L. \& Kabongo, M. (2000). The use of complementary and alternative medicine by primary care patients: A SURF*NET Study. The Journal of Family Practice, $49,1121-1130$.

Pan, C. X., Morrison, S., Ness, J., Fugh-Berman, A., \& Leipzig, M. (2000).

Complementary and alternative medicine in the management of pain, dyspnea, and nausea and vomiting near the end of life: A systematic review. Journal of Pain and Symptom Management, 20, 374-382.

Phipps, S. (2002) Reduction of distress associated with paediatric bone marrow transplant: complemtary health promotion interventions. Pediatric Rehabilitation, $5,223-243$.

Pico, J-L., Avila-Garavito, A., \& Naccache, P. (1998). Mucositis: Its occurrence, consequences, and treatment in the oncology setting. The Oncologist, 3, 446-451.

Podestà, M. (2001). Transplantation hematopoiesis. Current Opinion in Hematology, 8, $331-336$.

Portenoy, R. K., \& Itri, L. M. (1999). Cancer-related fatigue: Guidelines for evaluation and management. Oncologist, 1, 1-10.

Preyde, M. (2000). Effectiveness of massage therapy for subacute low-back pain: A randomized controlled trial. Canadian Medical Association Journal, 162, 1815 1820.

Quinn, C., Chandler, C., \& Moraska, A. (2002). Massage therapy and frequency of chronic tension headaches. American Journal of Public Health, 92, 1657-1661.

Redd, W. H., Montgomery, G. H., \& DuHamel, K. N. (2001). Behavioral interventions 
for cancer treatment side effects. Journal of the National Cancer Institute, 93, 810-823.

Richards, K. (1998). Effect of a back massage and relaxation intervention on sleep in critically ill patients. American Journal of Critical Care. 7, 288-299.

Richards, K. C., Gibson, R., \& Overton-McCoy, A. L. (2000). Effects of massage in acute and critical care. Advanced Practice in Acute \& Critical Care, 11, 77-96.

Rodeheaver, P. F., Taylor, A. G., \& Lyon, D.E. (2003). Incorporating patients' perspectives in clinical trial design. Journal of Alternative and Complementary Medicine, 9, 859-967.

Rothweiler, E.L., Coulter, J.S., \& Jansey, F. (1935). The Science and Art of Nursing. Philadelphia: F.A. Davis Company.

Schwarzer, R. (1997). Psychosocial Working Group, Anxiety. Retrieved February 25, 2005 from

http://www.macses.ucsf.edu/Research/Psychosocial/notebook/anxiety.html.

Sherbourne, C. D., \& Stewart, A. L. (1991). The MOS social support survey. Social Sciences and Medicine, 32, 705-714.

Smith, M.C., Reeder, F., Daniel, L., Baramee, J. \& Hagman, J. (2003.) Outcomes of touch therapies during bone marrow transplant. Alternative Therapies in Health and Medicine, 9(1), 40-49.

Smith, M. C., Stallings, M. A., Mariner, S., \& Burrall, M. (1999). Benefits of massage therapy for hospitalized patients: A descriptive and qualitative evaluation. Alternative Therapies in Health and Medicine, 5, 64-71. 
Spielberger, C. D., Gorsuch, R. L., \& Lushene, R. E. (1970). State-Trait Anxiety Inventory. Palo Alto, CA: Consulting Psychologists Press.

Speilberger, C. (1983). Manual for the State-Trait Anxiety Inventory: STAI (Form Y).

Palo Alto, CA: Consulting Psychological Press, Inc.

Spielberger, C. (1989). State-Trait Anxiety Inventory: A comprehensive bibliography.

Palo Alto, CA: Consulting Psychologists Press, Inc.

Stanton, T.A. (1900). Massage in the Treatment of Infantile Paralysis. American Journal of Nursing, 1, 212.

Stephenson, N. L., Weinrich, S., \& Tavakoli, A. S. (2000). The effects of foot reflexology on anxiety and pain in patients with breast and lung cancer. Oncology Nursing Forum, 27, 67-72.

Stelfox, H.T., Bates, D.W. \& Redelmeier D. A. (2003) Safety of patients isolated for infection control. JAMA, 290, 1899-905.

Taylor, A. G., Galper, D. I., D’Huyvetter, K., Bourguignon, C., \& Lyon, D. E. (2003). Pain. In J. W. Spencer, \& J. J. Jacobs (Eds.), Complementary and alternative medicine: An evidence-based approach (2nd ed.), pp. 311-408. St. Louis, MO: Mosby, Inc.

Taylor, A. G., Galper, D. I., Taylor, P., Rice, L. W., Andersen, W., Irvin, W., Wang, X.G., \& Harrell, Jr., F.E. (2003). Effects of adjunctive Swedish massage and vibration therapy on short-term postoperative outcomes: A randomized, controlled trial. The Journal of Alternative and Complementary Medicine, 9(1), 77-89. 
Testa, M. A., \& Simonson, D. C. (1996). Assessment of quality-of-life outcomes. New England Journal of Medicine, 334, 835-840.

The Leukemia and Lymphoma Society (May, 2002) Bone Marrow and Stem Cell Transplantation. http://www.leukemia-lymphoma.org/all_page?item_id=5965, retrieved October 7, 2004.

Thompson, P.B. \& Lambert, J.V. (1995) Touch sensitivity through latex gloves. The Journal of General Psychology 122(1), 47-58.

Uchino, B. N., Cacioppo, J. T., \& Kiecolt-Glaser, J. K. (1996). The relationship between social support and physiological processes: A review with emphasis on underlying mechanisms and implications for health. Psychological Bulletin, 119, 488-531.

Velikova, G., Wright E.P., Smoth, A.B., et al. (1999). Self reported quality of life of individual cancer patients: Concordance of results with clinical course and medical records. Eur J Cancer 35, 998-1107.

Walker, L. G., Walker, K., Ogston, K., Heys, S. D., Ah-See, A. K., Miller, I. D., Hutcheon, A.W., Sarkar, T.K., Eremin, O. (1999). Psychological, clinical and pathological effects of relaxation training and guided imagery during primary chemotherapy. British Journal of Cancer, 80, 262-268.

Watson, M., Meyer, L., Thomson, L., \& Osofsky, S. (1998). Psychological factors predicting nausea and vomiting in breast cancer patients on chemotherapy. European Journal of Cancer, 34, 831-837.

Ward, D. (2000). Infection control: reducing the psychological effects of isolation. 
British Journal of Nursing, 9(3), 162-70.

Weinrich, S. P., \& Weinrich, M. C. (1990). The effect of massage on pain in cancer patient. Applied Nursing Research, 3, 140-145.

Wilkie, D. J., Kampbell, J., Cutshall, S., Halabisky, H., Harmon, H., Johnson, L. P., et al. (2000). Effects of massage on pain intensity, analgesics and quality of life in patients with cancer pain: A pilot study of a randomized clinical trial conducted within hospice care delivery. Hospice Journal, 15, 31-53.

Woolf, M.S. (1927). Principles of Surgery for Nurses. Philadelphia: W.B. Saunders, Co., 303-304. 
Appendix A Instruments

$$
\text { QLQ-C30 }
$$

We are interested in some things about you and your health. Please answer all of the questions yourself by circling the number that best applies to you even though some of the questions may seem not to apply to you at a given point in time. There are no "right" or "wrong" answers. The information that you provide will remain strictly confidential.

\section{Please fill in:}

Today's date:

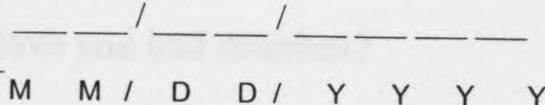

Your initials:

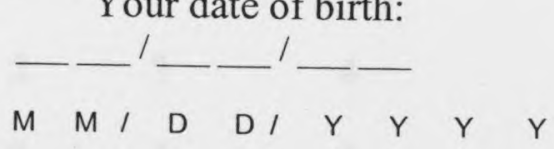

1. Do you have any trouble doing strenuous activities, like carrying a

No Yes heavy shopping bag or a suitcase?

2. Do you have any trouble taking a long walk?

3. Do you have any trouble taking a short walk outside of the house?

4. Do you have to stay in a bed or a chair for most of the day?

5. Do you need help with eating, dressing, washing yourself or using the toilet?

During the past week:

$\begin{array}{cccc}\begin{array}{c}\text { Not at } \\ \text { all }\end{array} & \text { A } & \text { Quite } & \begin{array}{c}\text { Very } \\ \text { much }\end{array}\end{array}$

6. Were you limited in doing either your work or other daily activities.

7. Were you limited in pursuing your hobbies or other leisure time activities?

8. Were you short of breath?

$$
1
$$

2

3

4

9. Have you had pain?

1

2

3

4

10. Did you need to rest?

\section{1}

2

3

4

11. Have you had trouble sleeping?

1

2

3

4

12. Have you felt weak?

1

2

3 
13. Have you lacked appetite?

14. Have you felt nauseated?

15. Have you vomited?

16. Have you been constipated?

17. Have you had diarrhea?

18. Were you tired?

19. Did pain interfere with your daily activities?

20. Have you had difficulty in concentrating on things, like reading a newspaper or watching television?

21. Did you feel tense?

22. Did you worry?

23. Did you feel irritable?

24. Did you feel depressed?

25. Have you had difficulty remembering things?

26. Has your physical condition or medical treatment interfered with your family life?

27. Has your physical condition or medical treatment interfered with your social life?

28. Has your physical condition or medical treatment caused you financial difficulties?

\begin{tabular}{|c|c|c|c|}
\hline $\begin{array}{c}\text { Not at } \\
\text { All }\end{array}$ & $\underset{\text { little }}{\mathbf{A}}$ & $\begin{array}{l}\text { Quite } \\
\text { a bit }\end{array}$ & $\begin{array}{l}\text { Very } \\
\text { much }\end{array}$ \\
\hline 1 & 2 & 3 & 4 \\
\hline 1 & 2 & 3 & 4 \\
\hline 1 & 2 & 3 & 4 \\
\hline 1 & 2 & 3 & 4 \\
\hline 1 & 2 & 3 & 4 \\
\hline 1 & 2 & 3 & 4 \\
\hline 1 & 2 & 3 & 4 \\
\hline 1 & 2 & 3 & 4 \\
\hline 1 & 2 & 3 & 4 \\
\hline 1 & 2 & 3 & 4 \\
\hline 1 & 2 & 3 & 4 \\
\hline 1 & 2 & 3 & 4 \\
\hline 1 & 2 & 3 & 4 \\
\hline 1 & 2 & 3 & 4 \\
\hline
\end{tabular}

For the following questions, please circle the number between 1 and 7 that best applies to you:

29. How would you rate your overall health during the past week?

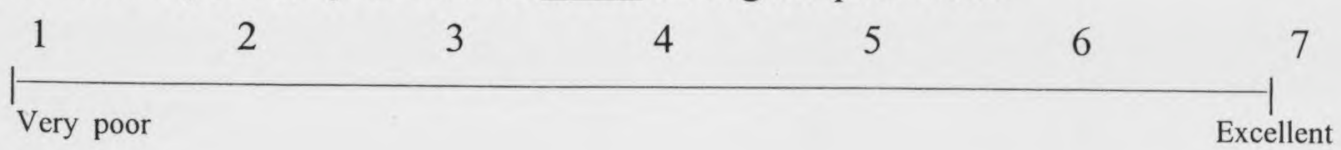


30. How would you rate your overall quality of life during the past week?

\begin{tabular}{|lllllll}
1 & 2 & 3 & 4 & 5 & 6 & 7 \\
\hline Very poor & & & &
\end{tabular}




\section{STAI - FORM Y-1}

DATE:

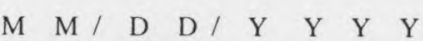

A number of statements that people have used to describe themselves are given below. Read each statement and then circle the number to the right of the statement to indicate how you feel RIGHT NOW, that is, AT THIS MOMENT. There is no right or wrong answer. Do not spend too much time on any one statement. Circle the number across from each statement that describes best your present feelings.

\begin{tabular}{|c|c|c|c|c|c|}
\hline & & $\begin{array}{l}\text { Not at } \\
\text { all }\end{array}$ & Somewhat & $\begin{array}{l}\text { Moderately } \\
\text { so }\end{array}$ & $\begin{array}{c}\text { Very } \\
\text { much so }\end{array}$ \\
\hline 1. & I feel calm & 1 & 2 & 3 & 4 \\
\hline 2. & I feel secure & 1 & 2 & 3 & 4 \\
\hline 3. & I am tense & 1 & 2 & 3 & 4 \\
\hline 4. & I feel strained & 1 & 2 & 3 & 4 \\
\hline 5. & I feel at ease & 1 & 2 & 3 & 4 \\
\hline 6. & I feel upset & 1 & 2 & 3 & 4 \\
\hline 7. & $\begin{array}{l}\text { I am presently worrying over } \\
\text { possible misfortunes }\end{array}$ & 1 & 2 & 3 & 4 \\
\hline 8. & I feel satisfied & 1 & 2 & 3 & 4 \\
\hline 9. & I feel frightened & 1 & 2 & 3 & 4 \\
\hline 10. & I feel comfortable & 1 & 2 & 3 & 4 \\
\hline 11. & I feel self-confident & 1 & 2 & 3 & 4 \\
\hline 12. & I am nervous & 1 & 2 & 3 & 4 \\
\hline 13. & I am jittery & 1 & 2 & 3 & 4 \\
\hline 14. & I feel indecisive & 1 & 2 & 3 & 4 \\
\hline 15. & I am relaxed. & 1 & 2 & 3 & 4 \\
\hline 16. & I feel content & 1 & 2 & 3 & 4 \\
\hline 17. & I am worried & 1 & 2 & 3 & 4 \\
\hline 18. & I feel confused & 1 & 2 & 3 & 4 \\
\hline 19. & I feel steady & 1 & 2 & 3 & 4 \\
\hline 20 . & I feel pleasant & 1 & 2 & 3 & 4 \\
\hline
\end{tabular}




\section{MCGILL PAIN QUESTIONNAIRE}

DATE:

$\bar{M} \bar{M} / \bar{D} \bar{D} / \bar{Y}-\bar{Y} \bar{Y} \bar{Y}$

Below are words that may describe your pain. Check the box for each word that represents the degree to which you feel that type of pain, on average, or in general in the past week.

Be sure to check one box for each word.

Throbbing

\section{None}

Shooting

Stabbing

Sharp

Gnawing

Hot-Burning

Aching

Heavy

Tender

Splitting

Tiring/Exhausting

Sickening

Fearful

Punishing/Cruel

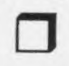

$\square$

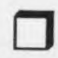

$\square$

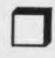

$\square$

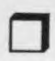

$\square$

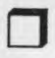

$\square$
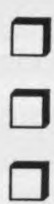

Mild

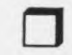

$\square$

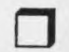

$\square$
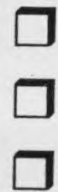

$\square$
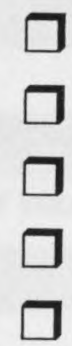

Moderate

Severe
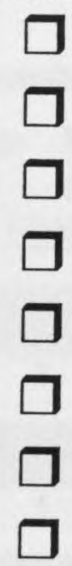

$\square$

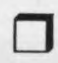

$\square$

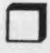

$\square$

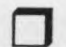

Circle the number below that indicates how much pain you have NOW.

$\begin{array}{cccccccccc}0 & 1 & 2 & 3 & 4 & \begin{array}{c}5 \\ \text { mo pain }\end{array} & 6 & 7 & \begin{array}{c}8 \\ \text { mild }\end{array} & \end{array}$

Check the box beside the word that best describes your PRESENT pain intensity now (how much it hurts).

$\square$ No pain

$\square$ Distressing $\square$ Mild

$\square$ Horrible $\square$ Discomforting

$\square$ Excruciating 


\section{MEDICAL OUTCOME STUDY-SOCIAL SUPPORT SURVEY}

Below are some questions about the support that is available to you.

1. About how many close friends and close relatives do you have (people you feel at ease with and can talk to about what is on your mind)?

Write in number of close friends and close relatives:

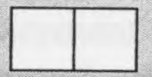

People sometimes look to others for companionship, assistance, or other types of support. How often is each of the following kinds of support available to you if you need it?

(Circle one number on each line)

DATE:

$\mathrm{M} M / \overline{\mathrm{D}} \mathrm{D} / \mathrm{Y} / \overline{\mathrm{Y}} \overline{\mathrm{Y}}$
A Little Some Most All None of the of the of the of the of the Time Time Time

Time

2. Someone to help you if you were confined to bed $\begin{array}{lll}1 & 2 & 3\end{array}$

3. Someone you can count on to listen to you when you need to talk $1 \quad 3$

4. Someone to give you good advice about a crisis $2 \quad 3$

5. Someone to take you to the doctor if you needed it 1

6. Someone who shows you love and affection

23

7. Someone to have a good time with 2 3

8. Someone to give you information to help you understand a situation 1

9. Someone to confide in or talk to about yourself or your problem 1

10. Someone who hugs you

11. Someone to get together with for relaxation

$\begin{array}{lll}1 & 2 & 3 \\ 1 & 2 & 3\end{array}$

12. Someone to prepare your meals if you were unable to do it yourself 1

13. Someone whose advice you really want

14. Someone to do things with to help you get your mind off things

15. Someone to help with daily chores if you were sick

16. Someone to share your most private worries and fears with

17. Someone to turn to for suggestions about how to deal with a personal problem

18. Someone to do something enjoyable with

19. Someone who understands your problems

20. Someone to love and make you feel wanted

$\begin{array}{lll}1 & 2 & 3 \\ 1 & 2 & 3 \\ 1 & 2 & 3 \\ 1 & 2 & 3 \\ 1 & 2 & 3 \\ 1 & 2 & 3\end{array}$




\section{ASCT Massage Study \\ Massage Therapy Documentation Sheet \\ INITIAL Massage}

ID Number

Date Time

Massage Therapist AM/PM Study Day

Massage \#

ASCT phase:

Prior to Central Line Placement $\square$ Central line placement day

$\square$ Awaiting cell collection $\square$ Cell collection $\square$ Chemotherapy

$\square$ Rest Day $\square$ Transplant $\square$ Post transplant in hospital $\square$ Post transplant in Charlottesville area $\square$ Post transplant at home

Location of Massage:

$\square$ UVA outpatient setting

Charlottesville area

$\square$ UVA inpatient setting

$\square$ Home

Prior to the very first massage in this study, ask the patient the following questions: Have you ever had a massage by a professional massage therapist before? $\square$ Yes $\square$ No If yes, approximately how many times?

Was it a comfortable experience for you? $\square$ Yes $\square$ No If not, why not?

Does the patient have compression fractures? $\square$ Yes $\square$ No

Does the patient have shingles? $\square$ Yes $\square$ No

Does the patient have evidence of a DVT? $\square$ Yes $\square$ No If yes, location

Gloves: $\square$ Required $\square$ Not required

Isolation status: $\square$ None $\square$ Protective Contact isolation for $\square$ VRE $\square$ MRSA $\square$ C. diff

"Please rate how comforted you feel right now."

\begin{tabular}{|cccccccccccc}
0 & 1 & 2 & 3 & 4 & 5 & 6 & 7 & 8 & 9 & 10 \\
\hline $\begin{array}{c}\text { Not comforted } \\
\text { at all }\end{array}$ & & & & & & & & & & &
\end{tabular}

"Please rate the level of stress you feel right now."

\begin{tabular}{|cccccccccccc}
0 & 1 & 2 & 3 & 4 & 5 & 6 & 7 & 8 & 9 & 10 \\
\hline $\begin{array}{c}\text { No stress } \\
\text { at all }\end{array}$ & & & & & & & & & & &
\end{tabular}

"Please rate the level of relaxation you feel right now."

$\begin{array}{lllllllllllc}0 & 1 & 2 & 3 & 4 & 5 & 6 & 7 & 8 & 9 & 10 \\ \begin{array}{c}\text { Not relaxed } \\ \text { at all }\end{array} & & & & & & & & & & & \end{array}$


Massage Therapy Documentation Sheet, page 2

Swedish massage can be completed in any order. Avoid IV sites or central line site at shoulders.

\begin{tabular}{|c|c|c|c|c|c|c|}
\hline \multirow{2}{*}{$\begin{array}{l}\text { Body area to be } \\
\text { massaged/ } \\
\text { Check if area was } \\
\text { massaged today }\end{array}$} & \multicolumn{5}{|c|}{$\begin{array}{c}\text { Skin or IV access limitations } \\
\text { (check at appropriate body part) }\end{array}$} & \multirow{2}{*}{$\begin{array}{c}\text { Comments } \\
\text { (check } \square \text { if patient requests } \\
\text { area not to be massaged) }\end{array}$} \\
\hline & $\begin{array}{c}\text { Central } \\
\text { line }\end{array}$ & IV & Shingles & $\begin{array}{l}\text { Skin } \\
\text { tears }\end{array}$ & $\begin{array}{c}\text { Pain or } \\
\text { sensitivity }\end{array}$ & \\
\hline$\square \mathrm{R}$ foot & & & & & & $\square$ \\
\hline$\square \mathrm{L}$ foot & & & & & & $\square$ \\
\hline R leg & & & & & & $\square$ \\
\hline$\square \mathrm{L} \mathrm{leg}$ & & & & & & $\square$ \\
\hline$\square \mathrm{R}$ hand & & & & & & $\square$ \\
\hline$\square$ L hand & & & & & & $\square$ \\
\hline$\square \mathrm{R}$ arm & & & & & & $\square$ \\
\hline$\square \mathrm{L}$ arm & & & & & & $\square$ \\
\hline$\square$ Abdomen & & & & & & $\square$ \\
\hline$\square$ Neck & & & & & & $\square$ \\
\hline$\square \mathrm{Head}$ & & & & & & $\square$ \\
\hline$\square$ Shoulders & & & & & & $\square$ \\
\hline$\square$ Back & & & & & & $\square$ \\
\hline
\end{tabular}

All attempts should be made to complete a minimum of 10 of the 13 identified areas during the 50-minute massage, unless patient requests the area be avoided.

Immediately after the massage, ask the patient:

"Please rate how comforted you feel right now."

$\begin{array}{ccccccccccc}0 & 1 & 2 & 3 & 4 & 5 & 6 & 7 & 8 & 9 & 10 \\ \begin{array}{c}\text { Not comforted } \\ \text { at all }\end{array} & & & & & & & & & & \end{array}$

"Please rate the level of stress you feel right now."

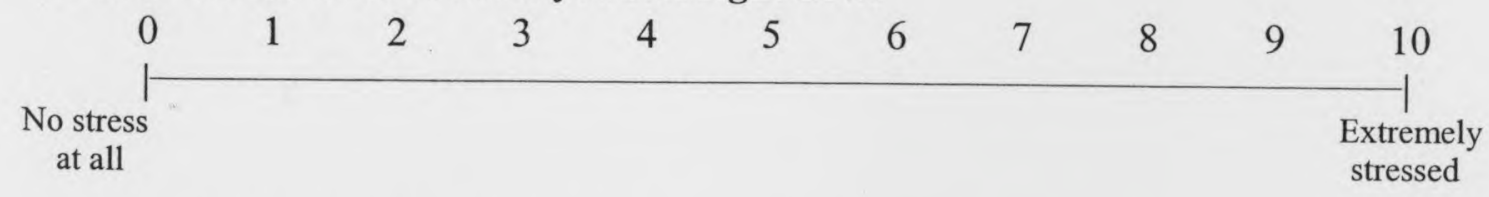

"Please rate the level of relaxation you feel right now."

Not relaxed

\begin{tabular}{llllllllllll}
0 & 1 & 2 & 3 & 4 & 5 & 6 & 7 & 8 & 9 & 10 \\
\hline axed & & & & & & & & & & &
\end{tabular}

Length of Massage: $\square 50$ minutes $\square$ Other___ minutes (specify time)

Document reason if massage is less than 50 minutes:

Deviations from protocol? $\square$ No $\square$ Yes If yes, explain: 
Skin integrity concerns? $\square$ No $\square$ Yes If yes, explain: 


\section{Massage Therapy Documentation Sheet \\ ASCT Massage Study \\ FINAL Massage}

ID Number Massage Therapist

Date Time am/pm Study Day Massage \#

ASCT phase: $\square$ Central line placement day $\square$ Awaiting cell collection $\square$ Cell collection $\square$ Chemotherapy $\square$ Rest Day $\square$ Transplant $\square$ Post transplant in hospital $\square$ Post transplant in Charlottesville area $\square$ Post transplant at home

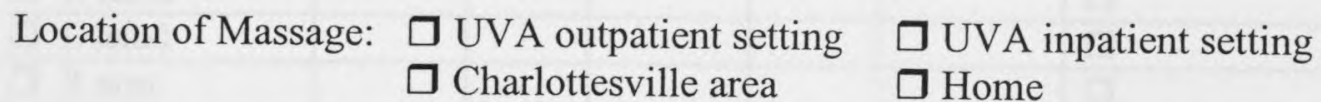

Does the patient have compression fractures? $\square$ Yes $\square$ No

Does the patient have shingles? $\square$ Yes $\square$ No

Does the patient have evidence of a DVT? $\square$ Yes $\square$ No If yes, location

Gloves are $\square$ Required $\square$ Not required

Isolation status: $\square$ None $\square$ Protective Contact isolation for $\square$ VRE $\square$ MRSA

$\square$ C. diff

Prior to the massage, ask the patient:

"Please rate how comforted you feel right now."

$\begin{array}{lllllllllll}0 & 1 & 2 & 3 & 4 & 5 & 6 & 7 & 8 & 9 & 10 \\ \begin{array}{l}\text { Not comforted } \\ \text { at all }\end{array} & & & & & & & & & & \end{array}$

"Please rate the level of stress you feel right now."

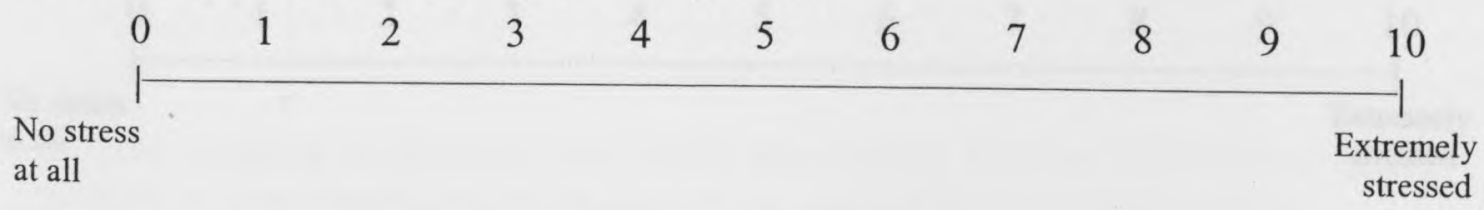

"Please rate the level of relaxation you feel right now."

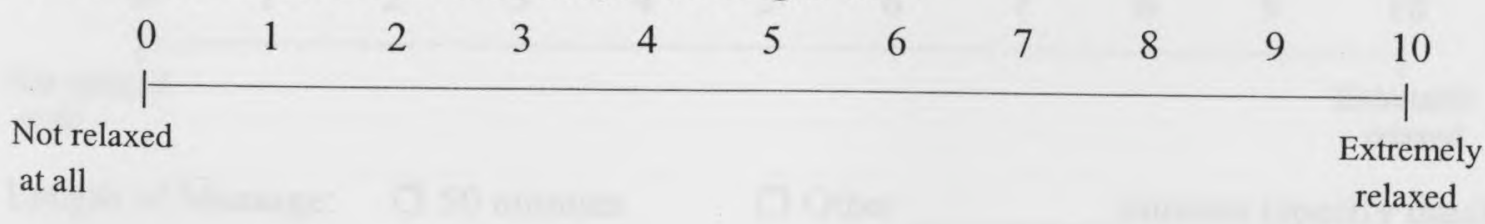


Swedish massage can be completed in any order. Avoid IV sites or central line site at shoulders.

\begin{tabular}{|c|c|c|c|c|c|c|}
\hline \multirow{2}{*}{$\begin{array}{l}\text { Body area to be } \\
\text { massaged/ } \\
\text { Check if area was } \\
\text { massaged today }\end{array}$} & \multicolumn{5}{|c|}{$\begin{array}{c}\text { Skin or IV access limitations } \\
\text { (check at appropriate body part) }\end{array}$} & \multirow{2}{*}{$\begin{array}{c}\text { Comments } \\
\text { (check } \stackrel{\omega}{ } \text { if patient requests } \\
\text { area not to be massaged) }\end{array}$} \\
\hline & $\begin{array}{c}\text { Central } \\
\text { line }\end{array}$ & IV & Shingles & $\begin{array}{l}\text { Skin } \\
\text { tears }\end{array}$ & $\begin{array}{c}\text { Pain or } \\
\text { sensitivity }\end{array}$ & \\
\hline$\square \mathrm{R}$ foot & & & & & & $\square$ \\
\hline$\square \mathrm{L}$ foot & & & & & & $\square$ \\
\hline$\square \mathrm{R}$ leg & & & & & & $\square$ \\
\hline$\square \mathrm{L} \mathrm{leg}$ & & & & & & $\square$ \\
\hline$\square \mathrm{R}$ hand & & & & & & $\square$ \\
\hline$\square$ L hand & & & & & & $\square$ \\
\hline$\square \mathrm{R}$ arm & & & & & & $\square$ \\
\hline$\square \mathrm{L}$ arm & & & & & & $\square$ \\
\hline$\square$ Abdomen & & & & & & $\square$ \\
\hline$\square$ Neck & & & & & & $\square$ \\
\hline$\square$ Head & & & & & & $\square$ \\
\hline$\square$ Shoulders & & & & & & $\square$ \\
\hline Back & & & & & & $\square$ \\
\hline
\end{tabular}

All attempts should be made to complete a minimum of 10 of the 13 identified areas during the 50 -minute massage, unless patient requests the area be avoided.

Immediately after the massage, ask the patient:

"Please rate how comforted you feel right now."

Not comforted at all

$4 \quad 5$

\begin{tabular}{lllll}
6 & 7 & 8 & 9 & 10 \\
\hline & & $\begin{array}{l}\text { Extremely } \\
\text { comforted }\end{array}$
\end{tabular}

"Please rate the level of stress you feel right now."

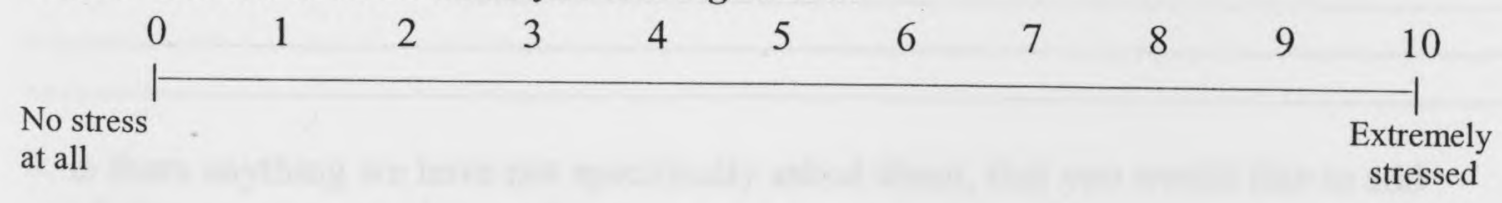

"Please rate the level of relaxation you feel right now."

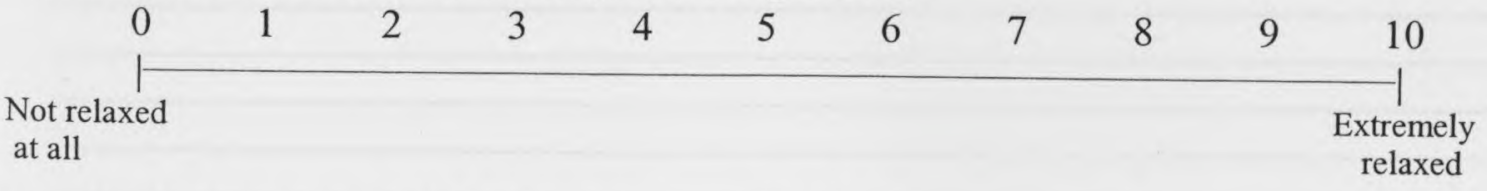

Length of Massage: $\square 50$ minutes $\quad \square$ Other__ minutes (specify time)

Document reason if massage is less than 50 minutes:

Deviations from protocol (explain):

Skin integrity concerns (specify): 
After the last massage in the study, ask the patient the following questions:

1. Has participating in this study benefited you? $\square$ Yes $\square$ No If yes, how

2. Has massage benefited you? $\square$ not at all $\square$ stress reduction $\square$ increased comfort $\square$ increased relaxation $\square$

other

3. Is there a difference in the way you experienced the massages when gloves were used by the massage therapist? $\square$ Yes $\square$ No If yes, how would you describe the difference you felt when gloves were used?

If yes, do you feel gloves interfered?

4. Did you experience any difficulties receiving massages in the hospital? $\square$ Yes No If yes, what were the difficulties?

5. Did you experience any difficulties receiving massage at home? $\square$ Yes $\square$ No If yes, what were the difficulties?

6. "Is there anything that would have improved the massage experience for you? $\square$ Yes $\square$ No If yes, what?"

7. Is there anything we have not specifically asked about, that you would like to add relative to your experience of massage or any suggestions for future studies? 
Manuscript 1

Contrary to Approved Methods of Practice: Massage Therapy, Polio and Nursing, 1900-1945

Proposed submission to:

Nursing History Review 
Contrary to Approved Methods of Practice: Massage Therapy, Polio and Nursing, 1900-1945

Audrey Snyder, PhD(c), RN, ACNP-CS, FAANP, CMT

The University of Virginia Doctoral Program

School of Nursing

P.O. Box 800782

Charlottesville, Virginia 22908

Phone 434-924-0094

e-mail: aew3e@virginia.edu

Arlene W. Keeling, PhD, RN

The Centennial Distinguished Professor of Nursing and

Director, The Center for Nursing Historical Inquiry

McLeod Hall, UVA School of Nursing

The University of Virginia

P.O. Box 800782

Charlottesville, Virginia 22908

If trained in skillful ways

And married to your mind and heart, your hands

Can execute enduring artistries and soothe,

If bred to serve, a restless world to rest.

- Josephine Hammond ${ }^{1}$

Key words: Massage, mechanotherapy, physiotherapy, back rubs, polio, infantile paralysis

The authors wish to thank Joan Echtenkamp Klein, M.S.L.S., and Andrew Sallans, Digital Projects Specialist, of the The Claude Moore Health Sciences Library Historical Collections for their archival assistance. 
Contrary to Approved Methods of Practice: Massage Therapy, Polio and Nursing, 1900-1945

Massage as a therapy is gaining much attention as a therapeutic agent for relief of muscle spasm and pain. In fact, massage is often considered a $21^{\text {st }}$ century phenomenon. However, an analysis of nursing history provides evidence that nurses have long used massage for comfort measures and for specific treatment of many orthopedic complaints and debilitating conditions. ${ }^{2}$ In the first decade of the $20^{\text {th }}$ century, massage was used in general conditions of weakness. ${ }^{3}$

The polio epidemics in the early $20^{\text {th }}$ century brought heightened awareness to the usefulness of massage therapy in preventing long-term disability from the devastating disease. Moreover, during the polio epidemics of 1931 and 1944 some nurses, including Sister Elizabeth Kenny, used massage therapy despite early criticism of its use. ${ }^{4}$

The purpose of this paper is to examine the use of massage therapy in nursing during the early years of the $20^{\text {th }}$ century. Research questions included: (1) For what purpose did nurses use massage therapy? (2) What knowledge did nurses have about massage? and, (3) Did physicians support the use of massage? The use of massage in the history of polio treatment is highlighted.

\section{The Social, Political, and Economic Climates}

The first half of the $20^{\text {th }}$ century was one of enormous change as America dealt with the social problems of urbanization and industrialization, followed in rapid succession by World War I, the Roaring Twenties, the Great Depression, and the Second 
World War. During this time common themes emerged, including the growing strength of the country, the spirit of progress, and the idea that science could solve problems.

Urbanization and industrialization brought overcrowded living conditions, filthy streets, polluted air, and an increase in infectious diseases. Indeed a plethora of ills, including tuberculosis, polio, measles, mumps, chicken pox, and typhoid fever were common. Of these, polio was particularly devastating. During the first half of the $20^{\text {th }}$ century, major polio epidemics occurred in 1916, 1931, and 1944 in the United States. ${ }^{5}$ These epidemics were almost exclusively among young children and the effects were often devastating. ${ }^{6}$

Infantile paralysis, or acute anterior poliomyelitis, was identified as a virus by Viennese physician Karl Landsteiner in $1908 .^{7}$ In 1909, William Flexner at the Rockefeller Institute demonstrated polio was an infectious disease. ${ }^{8}$ Several days into the disease process the virus attacked the cells in the anterior horn of the spinal cord. Once deprived of nervous impulses, muscles became paralyzed. Damaged cells could recover but dead cells could not, leaving muscles permanently paralyzed. Therefore, some paralysis cleared with time, some did not.

Mortality from infantile paralysis was high, in some epidemics as high as 25 percent. ${ }^{9}$ In comparison to other common childhood illnesses - diphtheria, whooping cough, measles, mumps, and chicken pox — infantile paralysis carried the highest death rate. ${ }^{10}$ It also crippled more children than any other disease. ${ }^{11}$ Some patients escaped paralysis completely and $50 \%$ of all polio patients recovered on their own. ${ }^{12}$ This led some people to believe there were two strains of the infantile paralysis virus. ${ }^{13}$ Some 
patients who were seriously paralyzed recovered with no treatment. Others recovered although they had bad treatment. Meanwhile, even with the best treatment, others remained crippled because of the extensive destruction to nerve cells. ${ }^{14}$ As new developments in medicine and surgery came to the forefront of science, historically accepted medical therapies of heat, light, exercise, and massage faded into the background.

Because infantile paralysis transmission was associated with poor slum areas, numerous people, mostly those in the upper middle class, fled the cities for the countryside each summer. ${ }^{15}$ After a long train ride and exhaustion from an abrupt change in routine, children would occasionally develop the disease. ${ }^{16}$ There was no way to predict who would be affected and by $1921,200,000$ children were crippled in 48 states, ${ }^{17}$ the majority due to infantile paralysis. What was certain was that in severe cases the crippling effects were devastating. ${ }^{18}$ In this era before a vaccine or cure for polio, symptom management was the only recourse. As a result, it would be the polio epidemics in the first half of the century that would once again focus the medical and nursing communities on massage.

It was not until 1938 that the National Institute for Infantile Paralysis, a nonprofit organization, was established "to forward action on all fronts of the attack on infantile paralysis, including the cause, prevention and treatment of disease. ${ }^{\prime 19}$ Rapid progress in research began with the Institute's support paving the way for growth in the application of massage therapy. 
By 1941, massage was recognized as a therapeutic agent for polio in both England and America. "The medical schools, however, especially in America, placed very little emphasis on teaching of the science and art of massage and as a result the physicians in general practice are [were] not as cognizant of the need for massage for their patients as are [were] the doctors training in the universities of Northern Europe. ${ }^{20}$

\section{State of the Art of Medicine and Nursing, 1860-1940}

In the 1860s, Gustav Zander founded an Institution of Mechanicotherapy in Stockholm. According to Zander "the healing principle lies in part in exercising the muscles, and in part in certain mechanical operations upon special organs or parts of the body." Mechanicotherapeutics were taught in medical schools at the time. ${ }^{21}$ By 1901 , mechano-therapy was seen as a distinct department in the science of medicine, assigned to an assistant, the nurse, rather than a physician. ${ }^{22}$ Mechano-therapy was defined as "treatment by mechanical procedures as distinguished from drug therapy and surgery."23 By 1911, many large hospitals had Zander rooms equipped with machines that massaged the various parts of the body.

Mechanotherapy-massage chapters were in nursing texts written jointly by physicians and nurses. Mechanotherapy was defined as "manipulative movements made by an operator upon the body of a patient for therapeutic purposes." Massage and Swedish movements were recognized as a branch of physical therapy in $1935 .^{24}$

\section{Diagnosis and Medical Treatment of Infantile Paralysis}

As was the case with other diseases, in the early years of the $20^{\text {th }}$ century the treatment of polio was based on the latest scientific medicine. Moreover, treatment 
approaches varied by institution. During 1916, New York City hospitals' infantile paralysis treatments ranged from symptomatic treatment to the use of such innovative treatments as lumbar puncture, horse serum, immune serum, citrated blood, and convalescent serum. ${ }^{25}$ To be effective, treatment with serum from children who had had the disease needed to occur prior to the onset of paralysis. So critical was the need that it was not uncommon for medical personnel to send a plea to Rotary Clubs to spread the word, educate the public, and provide transportation to children who could give blood (convalescent serum) to patients with the disease. ${ }^{26}$

Treatment was aimed at reducing inflammation, keeping muscle tone, and preventing atrophy or wasting of muscle fibers. ${ }^{27}$ Medical treatment of the era was complete rest in the acute phase with the application of external mechanical supports. ${ }^{28}$ Treatment during the convalescent period consisted of rest, orthopedic appliances, and heat to relieve muscle soreness. ${ }^{29}$ Hot packs were changed every $30-45$ minutes in the early stages of the disease. Muscles were splinted in a neutral resting position. ${ }^{30}$ Recovery from infantile paralysis occurred usually within four to six months and orthopedic surgery on deformed limbs, joints, or spine was performed later. ${ }^{31}$ Indeed, surgery corrected many of the disabling deformities resulting from polio, transplanting the tendon of a healthy muscle in place of a nonfunctioning one. ${ }^{32}$ Polio could cause a condition similar to talipes (clubfoot). If paralyzed and no contracture existed, splinting was necessary to avoid the pull of the sound muscles, and, if the paralysis persisted, a tendon transplant was performed. ${ }^{33}$ 
During this period there was also a concerted effort by physicians away from folk medicine and plant medicines as treatments for disease. With the discovery of penicillin and insulin in the 1920s, drugs and new surgical techniques in the early 1900 s, medications and surgery were increasingly valued. Moreover, the traditionally used therapies such as hotpacks, mustard poultices, ${ }^{34}$ and massage were often seen as providing comfort rather than cure.

\section{State of the Art of Nursing Related to Massage in the Early $20^{\text {th }}$ Century}

Despite this focus on new scientific therapies and the turning away from oldfashioned physical treatments, nurses used massage in the care of the sick in the early $20^{\text {th }}$ century. As students, they were taught the art and science of massage as a part of the nursing curriculum. Kurre Ostrom's book, Massage and the Original Swedish Movements, was frequently used in nursing curricula and was written for physicians, nurses, and professional masseurs. The $5^{\text {th }}$ edition, published in 1902 , focused on massage as a therapeutic agent, discussing massage techniques for treatment of specific body parts and for specific diseases. ${ }^{35}$ A 1907 American Journal of Nursing article defined massage as "systematic rubbing and manipulation of the soft tissues of the body, which is often combined with passive, active, and resistive movements ...oldest means of relieving bodily infirmities." According to that article, massage was recommended for use "in constitutional ailments as an auxiliary agent to the recuperative power of the body." 36 If used in this manner, its effects were noted:

The function of the skin is improved; the flow of the blood and lymph is accelerated; blood is attracted to the surface from internal parts; nerves are stimulated 
or soothed, as the case may be; effete matter is evacuated; adhesions of soft parts are broken down; swelling and thickening of the tissues are reduced; nutrition is improved. Disorders of digestive, circulatory organs, the nervous system, diseases or injuries affecting muscles, bones, or joints receive benefit from massage. ${ }^{37}$

The publication of Dr. Böhm's Massage: Its Principles and Technic in 1913 provided an American edition of his text, which demonstrated the massage techniques with illustrations of its use in the Hoffa Clinic in Austria. ${ }^{38}$ By 1915 massage was broadly defined as "any scientific manipulation executed on the human body with a curative, palliative, or hygienic objective in view." Massage manipulations were based upon physician Albert Hoffa's system of "stroking, or effleurage; kneading, or petrissage; rubbing, or friction; and striking, or tapotement; and shaking, or vibration." Massage affected the skin, circulatory system, respiratory system, nervous system, lymph stream, muscles, removal of waste in the body, and stimulated digestion. ${ }^{39}$

In addition to specific massage books, general textbooks for nurses included information on massage. One, a 1916 text titled, Practical Points in Nursing: For Nurses in Private Practice, describes massage as "the scientific rubbing and manipulation of the body; strengthens tissues and restores tone generally, acting as mild and thorough exercise for the patient. All movements are from the extremities toward the heart, and consist of kneading, rolling, beating, and rubbing movements. Effleurage, tapotement, and pétrissage are the terms used for the chief movements, though each school of massage has its own terms and methods." 40 
Another text, Macafee's Massage: An Elementary Text-Book for Nurses, also included information on massage. According to that text, "Massage is not a cure all for all disease, but is one of the remedial agents used in connection with other treatments for nervous or chronic disease, in orthopaedic work and to take the place of exercise." Macafee's book included the history of massage, physiologic effects, general treatment, indications, contraindications, and formulas for general massage, head and face massage, treatment of lower and upper extremities after removal of casts or splints, treatment for lumbago, stiff necks, sciatica, sprains, chronic constipation, breast massage, and corrective massage. $^{41}$

A popular pocket reference for nurses included a chapter on massagemechanotherapy. The 1919 edition notes, "It not being possible for all nurses to become proficient in the art of massage while doing general nursing (as it requires time, patience, and a great deal of experience to succeed), massage has become somewhat specialized, and we find many nurses who devote their time and attention exclusively to this work. Yet all nurses should have a general knowledge of the physiologic effects of massage and how to give it." 42

Sometimes nurses took specific massage courses that required one year of concentrated study. In 1925 a distinction was made between the massage by nurse and by a specialist:

Possibly the most definite rule is to restrict the former to routine work, i.e., to treatment that has not from time to time to be variously amended, or in 
complicated cases, to such treatment as may intervene between the visits of the specialist, and may therefore be supervised and regulated as needed. ${ }^{43}$

The curriculum included stroking, kneading, passive and resistive exercises, and percussion. Instruction in the classroom and practical work were encouraged. Those nurses who fulfilled the requirements were recognized by the American Physiotherapy Association. $^{44}$

A 1932 curriculum for schools of nursing prepared by the National League of Nursing Education Committee recommended a supplementary course in physiotherapy consisting of 15 hours divided into lectures, demonstration, and laboratory practice. The curriculum included massage, therapeutic exercise, hydrotherapy, and thermotherapy (light and heat). According to an outline of the three-hour massage class: "Meaning of term massage. Classification of movements: stroking, friction, vibration, kneading, [and] percussion. Physiological effects of each. Therapeutic effects of each. Some indications for massage. Contraindications for massage." ${ }^{\text {45 }}$ A three-hour laboratory session outline included the following:

Practice in the five manipulations with special reference to the following: massage to head and neck to relieve insomnia; massage around pressure points for increased circulation to prevent pressure sores; massage following the removal of casts in fracture, especially to reduce edema; massage to prevent muscle atrophy in bedridden patients, especially lower extremities; massage in lumbago, myalgias, etc; massage in subacute and chronic stages of arthritis, neuritis, synovitis, etc. ${ }^{46}$ 
Because skin care and comfort have been two major nursing disciplinary foci, nursing textbooks of the 1930s and 1940s commonly instructed nurses in bed-making, baths and care of the back. According to one: "After washing the back, rub with alcohol." ${ }^{47}$ Clear instructions were provided for the procedure for rubbing the back. A simple alcohol rub was provided at least once a day in addition to the morning and evening bath for bed-patients. "Do not ask a patient if she desires a rub, she may think it is too much trouble and will answer accordingly. Just bring a bottle of alcohol, and say that you think a rub will make her feel better." Daily care of the back was provided for "all bed-patients who lie in the same position, who are very thin or who suffer from disease such as tuberculosis, paralysis, certain forms of kidney and heart disease, fractured (broken) hips, back, legs, etc. ${ }^{, 48}$ Back massages stimulated circulation and provided general relief of fatigue. $^{49}$

Massage or rubbing was used as a preventative measure for bedsores. According to Dakin and Thompson:

Rubbing stimulates the circulation and brings blood to the surface. This relieves the congested condition and allows the blood to flow more freely. To aid in the stimulating process, alcohol is usually employed, followed by dusting with powder to prevent chafing and to assist in keeping the parts thoroughly dry. Rub away from the part with a circular motion. ${ }^{50}$

A 1930 Principles and Practices of Nursing text dedicated four pages to the bed bath and massage, noting: 
Any doubts that one may have as to the beneficial effects of the bath are dispelled by observing the effects on a very sick patient. The patient's chart and his exhausted appearance may indicate a very restless, sleepless night, and a generally poor condition. After a warm bath, massage, change of linen and remaking of the bed, if skillfully done, the patient will often doze off into a peaceful, restful slumber from which he will waken refreshed - his pulse, breathing, and whole appearance will show improvement. When the doctor arrives he does not see the patient at his worst — does not see the symptoms that may indicate his real condition. This is a tribute to nursing and explains why the doctor sometimes wishes to see the patient before the morning bath. This also further emphasizes the importance of close observation and accurate recoding by the nurse of all symptoms previous to the bath, together with the results achieved. $^{51}$

By 1935-1940, nursing texts included chapters on physical therapy with massage as a subheading. "The particular type of massage should be specified by the physician ordering the treatment." 52 Types of massage were described as deep stroking, compression, and percussion. The 1941 edition of the popular pocket handbook dropped mechanotherapy from the title of the massage chapter and devoted seven pages to effects, indication, general rules, order and length of massage, the five movements, effects of massage, and a detailed protocol for massage of arms, legs, feet, and back. ${ }^{53}$

In the introduction to her 1941, second edition of Massage in Nursing Care, Jensen-Nelson, RN, identified massage as both a supportive and remedial measure and 
increasingly important in both hospital and public health nursing. Her book was written for instructors and students of massage. Lectures and laboratory work consisting of at least eight class periods two hours in length were recommended. In the laboratory sections students were to practice on each other. ${ }^{54}$

Thus, from a review of nursing textbooks, it is clear that by 1920 nurses valued massage. Indeed, at a time when physicians were increasingly concerned with finding a scientific cure for various diseases and focusing on surgery, nurses were using supportive approaches to promote patient comfort.

\section{The Art and Science of Massage}

While early nursing texts of the $20^{\text {th }}$ century provided chapters dedicated to massage, covering the history, nursing requirements, and procedures to be followed, nurses were to use massage only with physician order. ${ }^{55}$ Massage required training and knowledge of the movement cure and the nature and course of the disease being treated. "To be an expert masseuse requires a thorough knowledge of anatomy, and constant practice." ${ }^{, 56}$

Massage could be applied generally or locally to a particular body part. Duration of massage ranged from 10 to 20 minutes for local treatments or 20 minutes to one hour for general treatment. ${ }^{57}$ According to one text, massage of the back associated with morning and evening baths "should consume from three to five minutes." 58

If the skin was dry, lubricants could be used. Lubricants included oils such as olive oil, cocoa butter, and pure Vaseline. Talcum powder and alcohol were used as a drying agent. Alcohol was also often used for its "refreshing effect." ${ }^{, 59}$ Rubs and frictions 
were common in the second decade of the $20^{\text {th }}$ century. Alcohol, witch hazel, menthol, and oils were common agents used. The chief effect was friction with the bare hands and was designed to hasten the circulation in the peripheral veins. ${ }^{60}$

Instructions to nurses included: "In general massage, the patient should wear a loose gown. Never expose your patient." 61 "If patients complain of pain or discomfort at any time during the course of the treatment, massage should be discontinued at once and not attempted again without further advice from the attending physician."62

Contraindications to massage included acute inflammation, fever, pus, skin diseases associated with rash or parasitic diseases, and carcinoma. In some instances, the directions were clear: the limbs of postoperative patients "should never be massaged on account of the danger of embolism. ${ }^{\circ 3}$ Despite these limitations on the use of massage, there were many conditions in which massage was used as a therapeutic agent and comfort measure.

\section{Massage in the Care of Psychiatric Patients}

Psychiatric nursing texts of the 1930s also included chapters on physical therapy and massage. "Massage and manual Swedish movements are probably the most generally employed in treating nervous states. We prescribe light massage during the 'rest cure'; and sometimes in acute neurasthenic states, we order it three times a week ..." ${ }^{64}$ Deep abdominal massage with a "small cannon ball over the abdomen when lying down ... tend to raise blood pressure, thus indirectly relieving neurasthenic fatigue." 65 "In the sick, the normal reaction of release from tension does not always appear upon removal of 
the emotional stimuli. It may be induced by various nursing measures such as a sponge bath, alcohol rub, massage, etc." ${ }^{66}$ Massage was used as treatment for prolonged insomnia, "The muscles of their backs and necks 'feel like iron bands' under the nurse's fingers and it may take an hour's manipulation to restore them to normal, but when this is accomplished the patient will sleep."67 "Except for the back in routine nursing care, massage should not be given to mental patients without the doctor's order."

\section{Massage in Obstetrical Nursing}

In obstetrical and gynecologic nursing, massage was used in several ways: during pregnancy, in routine care of the newborn, for prematurely born children, to relieve constipation in infancy and, in the gynecologic patient, to stimulate milk production in the breast or to relieve breast engorgement, and in puerperal care including fundal massage.

Massage and gymnastics were considered beneficial during pregnancy if out-ofdoor activities were contraindicated. ${ }^{69}$ For example, an expectant mother with heart trouble or a mother placed on bed rest to prevent an abortion may have benefited from massage. $^{70}$

Breast massage was performed if the woman was breastfeeding. ${ }^{71}$ Engorged breast massage was practiced only under the order of a physician. A 1908 obstetric text provides clear instructions, pictures, and diagrams for massage of the breast for both engorgement and to stimulate formation of milk. ${ }^{72}$ Massage of the breast and the abdomen from below upward was a measure to increase blood supply to the breast, thus 
increasing milk supply. Massage was prohibited in the presence of inflammation and nurses used care to distinguish engorgement from mastitis. ${ }^{73}$

Massage was used during the latter portion of the puerperal period; it "should be given very gently at first, the back and limbs only being treated. Later on, the entire body, including the abdomen, may be subjected to massage with great benefit." ${ }^{, 74}$ If tardy involution of the uterus was a complication, "massage in the form of gentle friction over the fundus for ten minutes twice daily" promoted involution. ${ }^{75}$

\section{Massage of Newborns and Premature Children}

Care of the newborn child included a massage following the morning bath for 10 to 15 minutes. Abdominal massage following the morning bath or at night was also used for the treatment of constipation in infants, and "will sometimes cause an attack of colic to cease." 76

Massage was given for the purpose of preventing disability following fractures and removal of casts for the treatment of congenital hip dislocations. ${ }^{77}$ According to one text:

Massage is one of the best means of stimulating repair, of preventing atrophy of muscles and stiffness of joints and tendons. It stimulates an inflammatory reaction, producing a constant supply of healing blood and a prompt withdrawal of waste products. It is often given regularly every day, as soon as union is secured and there is no danger of displacement. $^{78}$

According to another medical text, massage could also be used for premature children: 
Much can be done to aid the development and nutrition of premature children by thorough, gentle, general massage with inunctions with various easily absorbed fats. ... The child's entire body should be gone over thoroughly, not omitting the head and face. ${ }^{79}$

A popular obstetrician of this era, Joseph DeLee, also advocated massage for preemies, noting:

If the child is very premature, these attentions are given every other day. They are not omitted, because the infant needs some stimulation to bring it out of the torpid state in which it usually lies, and which disposes it to stagnation of the blood in the extremities and the lungs. ${ }^{80}$

\section{Massage Use in Arthritis}

In addition to the use of massage for comfort, skin care, and the care of obstetric patients and infants, massage was used on the extremities and abdomen of patients with arthritis. As patients were frequently bedridden, bony prominences reddened and "rubbing of bony prominences" in arthritis patients is reported. ${ }^{81}$

Massage is very valuable in the rheumatoid syndrome, depending on whether an effect is desired locally or in a more remote locality. It has an effect on both the finer and deeper circulation. Massage has a great value as a form of exercise for arthritis with the fatigue factor at a minimum. This valuable form of therapy may be used to prevent atrophy of muscles; improve local and general metabolism; increase local circulation; and finally help to remove edema from the dependent parts in the arthritic. Massage may 
produce as well as relieve pain in the muscles of arthritics. Thus the advisability of individualizing its application is evident. ${ }^{82}$

\section{Massage for Constipation}

Massage was also recommended for the treatment of constipation as colonic irrigation with massage was thought to improve muscle tone of the colon. According to one textbook:

Colonic massage is given for ten minutes before the irrigation is commenced. This massage begins in the left iliac fossa, and is directed downward toward the colon ... a circular motion with moderate pressure is used. Each succeeding motion begins at a point farther from the rectum, following the colon. ... After twelve distinct massage motions have been executed, the kneading type of abdominal massage is given. ${ }^{83}$

The text went on to note that massage was contraindicated in some cases of constipation, stating:

The nurse must therefore trust the wisdom of the physician as to the desirability of employing it at all. ... When fecal impaction is present colonic flushing with normal-salt solution as described above may be given in addition to massage. Daily abdominal massage lasting 10-30 minutes for two to three weeks showed improvement. $^{84}$

A textbook for first-year students also instructed nurses on the benefits of massage for the treatment of constipation, noting: "Massage of the abdomen is used with especial benefit in children, where natural simple measures are not sufficient to produce a normal action 
of the bowels. Begin at the right groin and follow the course of the colon around the abdomen." 85

\section{Massage in Neuralgia}

Massage was also used for pain syndromes. According to Williams:

Neuralgia in the back part of the head is often caused by infiltrations in the trapezius and sterno-cleido-mastoid muscles because of the pressure exerted by theses infiltrations upon the nerve endings enervating the back part of the scalp. These infiltrations removed by kneading and friction, the pain very often decreases. $^{86}$

Improvement was often seen with five to six treatments but could last for months, initially given every day for 5-15 minutes, decreasing to two to three times a week. ${ }^{87}$

A textbook of surgical nursing instructs: "If surgery was performed for neuritis, the patient was splinted for 7 to 10 days and then active and passive motions, massage and electrical stimulation were begun. Patients were taught to massage the involved muscles to prevent atrophy." 88

\section{Massage in Cardiac Cases}

Treatment of all types of heart cases, except for pericarditis, with massage and graduated exercises was attempted in Children's Hospital of Los Angeles beginning in 1923. Hospitalization of these patients decreased 50 percent. Massage was performed daily in the acute stage and then 2-3 times a week. The system of treatment was worked out by physician Edith Bronson of San Francisco: 
As soon as pain has subsided, the gentle effleurage of arms, legs, and back is begun and following this, breathing is taught. The treatment lasts only about ten minutes but it should be repeated at some later hour in the day. The pulse is taken before and after the treatment and an accurate record is kept. If there has been a change either up or down of more than 20 points it is considered too strenuous and is accordingly reduced the following day. If, however, all has gone well up to the end of the first week, we consider our patient ready for the second stage and more severe work is started. The treatment is increased to 20 or 25 minutes daily and consists of effleurage and light petrissage of the extremities and back, followed by passive arm exercises with breathing and passive leg movement. ... Having successfully completed the second week, the time of treatment is increased to 30 or 40 minutes. Twenty minutes of this is filled with vigorous massage to the extremities, abdomen and back, the remainder is taken up with exercises. ${ }^{89}$

Clearly massage was used repeatedly by nurses for a variety of illnesses.

Massage was consistently used with psychiatric patients, obstetrical patients, in the care of newborns and premature children, and for patients with arthritis, constipation, or neuralgia.

\section{Massage Use for Orthopedic Problems}

Some of the most immediate effects were seen in the treatment of orthopedic patients. Compound fractures from shrapnel and machine gun bullets during the First World War were complicated by osteomyelitis. Muscles of limbs affected by ostomyelitis were massaged daily. ${ }^{90}$ Following amputations, the healed stump was massaged to restore tone to the muscles. ${ }^{91}$ Massage and active motion were started early 
after burn wounds healed to restore normal function to areas of contracture of scar tissue. A 1929 text described the use of massage and passive movements supervised by a nurse for the treatment of sprains. ${ }^{92}$

By 1935 to 1940, surgical nursing texts provided more detailed instructions on the use of massage in the treatment of sprains, dislocations, fractures and "other surgical affections." ${ }^{93}$ A 1935 text provides more information on effect: "We cannot heal torn fibres by massage, but we can assist in restoring the circulation on which the repair depends, and not only the repair of these fibres, but all various injuries that have been sustained. ... [M] assage aims to restore vasomotor tone to prevent further effusion," 94 On the use of massage in fractures: "It is to be noted that massage and immobilization are not methods of treatment of fractures, but are adjuncts to be used in combination with proper reduction and fixation." 95 Massage was "of the greatest value in relieving pain, hastening the absorption of exudates and the early restoration of function. ${ }^{, 96}$ Nurses were cautioned about the harm that could be done with improper use of massage. Massage was given to reduce swelling and limit effusions with sprains, to alleviate pain and promote absorption of inflammatory products in dislocations, and to relieve pain and restore function following fractures. ${ }^{97}$ Parts to be massaged were prepared with heat for fractures and whirlpool baths for amputation-stumps. ${ }^{98}$

\section{Massage in Infantile Paralysis}

Despite widespread acceptance of massage as a therapeutic agent and a comfort measure, it was polio that focused nurses and physicians on the use of massage as a specific treatment for a specific disease. As early as 1900, massage was used as a 
treatment for polio in the United States. Massage was seen as important in the "treatment of those affections of children characterized by wasting muscles. Especially in the treatment of infantile paralysis it is found to be a measure of great value, not only in preserving the integrity of the muscles, but also in preventing the subsequent deformities which present so many difficulties in treatment." ${ }^{, 99}$ Massage of affected muscles was recommended as soon as the child could bear friction. Cocoa-butter and cod-liver oil or the bare hand could be used:

The mildest form is what is termed 'friction massage;' in this method the part is rubbed in a circular manner with two or three fingers of one hand; following this, the part is grasped with the whole hand and firmly but gently squeezed in an upward direction; this movement is known as 'effleurage,' its object being to promote the circulation in the lymphatic and other vessels, Pétrissage, or kneading of the muscle, is a movement of much value as tending to promote capillary circulation and to stimulate nervous force. Tapotement, or tapping of the muscle, is also employed, these movements being followed by effleurage. At first massage should be very gentle, but as the child becomes more accustomed to it the more forcible measures may be employed. ${ }^{100}$ Massage may need to be performed for months for gradual improvement. Treatment for infantile paralysis consisted of massage for 15 minutes morning and night, warm baths and gentle passive movements to prevent deformity. Reeducation of muscles was a cornerstone of treatment. ${ }^{101}$ According to a 1915 medical text, "flushing 
the muscle with blood, as is done by massage, we can increase both in size and power the muscle or parts of muscles whose representation in the cord has not been destroyed." 102

With advanced surgical techniques and splinting, for a period of time massage was recommended only after a convalescent period of about five to eight weeks. During the 1920 s to 1940 s in the United States, massage was contraindicated in the acute treatment of polio; in fact, immobilization and splinting of the extremities was routinely performed. "Proper splinting must be instituted and kept up as long as necessary." ${ }^{103}$ One 1940 s text states, "At the end of that time, if no pain is present, systematic daily massage and passive movements of the muscles not entirely paralyzed will ultimately make them stronger." ${ }^{\prime 104}$ Other texts of the 1940 s still advised that any movement was detrimental: "Absolute rest in bed is prescribed, and attempts to move paralyzed limbs are avoided." 105 In the 1941 Massage in Nursing text, one of the principal duties of the nurse during the acute phase was to protect muscles with rest. After the acute phase, when muscles directly affected were identified, specific treatment was commenced. ${ }^{106}$ Just a few years earlier, in the 1930s, Sister Kenny, an Australian nurse, publicly recommended the controversial therapy - a recommendation that caused her work to be scrutinized by physicians around the world.

\section{The Kenny Massage Method}

A native of Australia, Elizabeth Kenny recounted her experience in working with victims of infantile paralysis in her 1943 autobiography, noting that she began working as a nurse in the Australian bush after completion of her vocational training. There, in 1911, Kenny encountered her first case of infantile paralysis in a child and sent a telegram to 
Dr. McDonnell, 100 miles away, asking him how to treat the symptoms. McDonnell's reply was terse: "Infantile Paralysis. No known treatment. Do the best you can with the symptoms presenting themselves." 107

Left to her own devices, Kenny experimented with several treatments including fried salt in a bag, and then linseed meal poultice applied to the spasming muscles. The first did not work and the last was too heavy and increased the pain. Subsequently, Kenny tore an Australian wool blanket into strips, soaked the strips in boiling water, wrang the strips out and applied each to the spasming muscles as she had seen aborigines use hot clothes on involved extremities. Kenny's mechanical-focused mind helped her view the musculoskeletal system as a system of levers and pulleys. The spasming muscles produced severe pain. The soaks helped to decrease the spasms and pain. Once the pain subsided she worked on the muscles. Kenny later told a nurse she used blankets, heat, water, and her hands. Her treatment worked and, in fact, Kenny treated several cases in this manner with the outcome of no residual paralysis of muscles. Later she learned from McDonnell that her treatments were counter to orthodox medical care of the day for infantile paralysis. Her treatment of infantile paralysis victims was placed on hold when she joined the Australian medical corps in 1932 in preparation for the possibility of a war in Europe. ${ }^{108}$

That year Australia experienced a severe polio epidemic, giving Kenny an opportunity to demonstrate her method of treatment. The Kenny method consisted of heat application with wool cloths, massage, and physical therapy (passive range of motion) during the acute phase of spasms, whereas conventional treatment was immobilization 
with splinting and casting to prevent deformities which often left the patients crippled.

Opposition of strong and weakened muscles, paralyzed weaker muscles or spasms caused the deformities. This was exacerbated by the muscles' inability to relax. ${ }^{109}$ The method focused on massage, muscle retraining, and reeducating muscles.

\section{The Controversy Over Massage}

Sister Kenny was "unprepared for the extraordinary attitude of the medical world in its readiness to condemn anything that smacked of reform or that ran contrary to approved methods of practice." ${ }^{110}$ She was opposed by the medical community in Australia and later in Europe and much of the United States. She found antagonism by female massage therapists in Australia. The Australian Trained Nurses' Journal reported the Australian Massage Association passed a resolution petitioning the government to prevent Sister Kenny's use of muscle re-education because she had not been registered to practice the technique. A report to the National Foundation for Infantile Paralysis stated that Kenny should not be permitted to teach her treatment method. ${ }^{111}$

Sister Kenny met the most conflict with her belief in infantile paralysis as a peripheral muscle disease versus a central nervous system disease. Clearly, Kenny had developed a theory that did not fit in with the accepted pathology of the disease. Physicians believed infantile paralysis was a disease of the spinal cord and central nervous system and left muscles flaccid, which needed support. ${ }^{112}$ She met subtle opposition and was investigated by the Board of Government Medical Investigation in Australia. Dr. Cilento's report for the State Health Department investigation stated: 
As a result of these observations, it was reported that Sister Kenny undoubtedly had produced results remarkable enough to attract the surprise and inspire the confidence of both lay and medical witnesses, and that she had in several cases brought these results about where competent men had declared the case irresponsive further to the ordinary routine methods of physical therapy and where only the life of an invalid was to be anticipated by the patient. ${ }^{113}$

Because Kenny did not wish to alienate members of the medical staff, she tried to establish harmony. Her philosophy was, "If I undertook treatment, the patient must be periodically examined in the presence of the same physician and a history of the case recorded." 114 She wanted her work to be evaluated and reported by the medical community, not herself. ${ }^{115}$ Scientific evaluation of massage therapy effects was needed. In Australia, Kenny was not permitted to work on patients with recent or acute stages of disease. A second report for the State Health Department stated "the same results could not be obtained by any other method in any other institution."116 An official medical investigation announced "that all recent cases were totally and permanently cured and that some of the seemingly hopeless cripples had been restored to comparatively normal activity." 117 These claims were made by medical professionals and were not Kenny's words. ${ }^{118}$ Yet, these words describing a nurse's technique of curing a patient of paralysis created much controversy and conflict for the Kenny method.

A commission was appointed in 1935 to compare the Kenny method with orthodox treatment. The 130-page commission report condemned her work and ideas. It 
was later determined to be a mistake, but the accusations took years for Kenny to live down. ${ }^{119}$

In Australia her technique was considered "revolutionary methods." Once in England, she was permitted to treat patients as early as one month following the onset of illness with excellent results. Kenny opposed splinting of extremities. An English report on infantile paralysis treatment supported her view and documented immobilization had bad effects. ${ }^{120}$

Sister Kenny made an effort to prepare talks, collect evidence, and present cases to the medical world reflecting the Kenny method of treatment for infantile paralysis. ${ }^{121}$

\section{Kenny Method in the United States}

Prior to Sister Kenny's arrival in the United States, some of her methods were used but frequently not early in the disease process. One 1927 case study reports the use of removable splints four weeks after diagnosis, and "treatment was begun, consisting of the application of heat, very gentle movements and skillful massage." No one was trained in the methods in the child's home area so she stayed at a distant hospital for care. ${ }^{122}$

In 1938, two years prior to Kenny's arrival in the United States, the National Foundation for Infantile Paralysis made a grant of $\$ 6,000$ to the University of Indiana to study four treatment methods, one of which was the Kenny method. ${ }^{123}$

When Kenny first came to the United States in 1940 she tried to share her methods with the Department of Physical Therapy in the Ruptured and Crippled Hospital in New York without acceptance. In May 1940, Kenny went to the Mayo Clinic, in Rochester, Minnesota, and Shriners' Hospital, where the Kenny method produced 
dramatic results quickly. It was clear; the Kenny method of treating persons with infantile paralysis became accepted practice. ${ }^{124}$ Splints were quickly relegated to recycling heaps. By 1942 the use of splints, frames, and plaster casts in the early treatment of infantile paralysis were replaced with the Kenny method of treatment, which was recommended to be initiated on the first day of illness. ${ }^{125}$

When Kenny sustained a Coles' fracture of her arm, others had to demonstrate her techniques. ${ }^{126}$ When the same results were obtained by others using her techniques, there was more acceptance for Sister Kenny's work. The National Foundation for Infantile Paralysis (NFIP) supported a program of study by Kenny at the University of Minnesota. ${ }^{127}$ Preliminary evaluation of the Kenny Method of treatment was published in the June 1941 issue of the Journal of the American Medical Association demonstrating acceptance by the scientific community. ${ }^{128}$ According to that article, treatment of polio began to shift from focusing on "the paralysis to the treatment and care of spasms, alienation, and incoordination, which in themselves are capable of producing damaging and crippling deformities." 129 The Kenny method was quickly adopted by the medical community in the United States. Sister Kenny had spent 30 years trying to convince medical communities in other countries to support her work.

The results of this program of study at the University of Minnesota recommended further study, which the NFIP supported with a second grant in $1941 .{ }^{130}$ Following the second study, the medical advisory committee of the foundation reported "the early stage of the disease is reduced and the contractures prevented with the Kenny method."131 Based on this report, a plan was developed for dissemination of the Kenny method to 
nurses and physical therapy technicians. Courses in the Kenny method for nurses, physicians, and physical therapists were conducted in 1942 under the supervision of Miland E. Knapp, MD, in Minneapolis. ${ }^{132}$

In 1940 to 1941 Sister Kenny published two books on the treatment of infantile paralysis. The NFIP funded research investigating the symptoms described by Sister Kenny, which proved they existed. Muscles that were unable to move were not paralyzed but in spasm. In December 1941, the NFIP board met and accepted the Kenny concept of disease causing spasm. With the Kenny method, the documented 85 percent residual deformity from infantile paralysis decreased to 20 percent. ${ }^{133}$ In 1942, the content for orthopedic nursing recommended by the National League for Nursing included demonstrations in the Kenny method of care for poliomyelitis patients if the Kenny method was approved by the medical staff. ${ }^{134}$

Philip Lewin wrote a book, Infantile Paralysis, in 1941 that included a brief but informative overview of the Kenny method of treatment. ${ }^{135}$ At this time the NFIP was still advertising free Toronto splints and Bradford frames from the central supply depot in New York City for patients in the acute stage of infantile paralysis. ${ }^{136}$

In 1942 Stevenson published "The Kenny Method" in the American Journal of Nursing to educate nurses about the Kenny theory of disease. She described concepts of spasm, mental alienation, and incoordination, the terms Kenny used. At this time treatment recommendations to begin immediately upon diagnosis included: natural rest position, muscle analysis to determine which areas of the body required packs, general care to include freedom of movement as soon as coordination was present, hot packs 12 
hours a day, no splints, and massage and muscle re-education. Stevenson compared the Kenny method to the previous methods of disease treatment using a scientific approach.

By 1942, the NFIP revised its pamphlet, "Facts about Infantile Paralysis," because of "the method of treatment introduced by Miss Elizabeth Kenny, the Australian nurse, in which early physical therapy replaces splinting." There were no new advances in prevention or cure but in the method of treatment. ${ }^{137}$ The pamphlet was made available for free upon writing the foundation. ${ }^{138}$ Nursing Care in the Kenny Method of Treatment for Infantile Paralysis was also made available free of charge to any nurse or nursing agency. ${ }^{139}$

There was a great need for nurses, physicians, and therapists to be trained in the Kenny method in the United States. The first Sister Kenny Institute opened to train therapists in 1942. In the 1943 epidemic there were over 15,000 cases of infantile paralysis reported. ${ }^{140}$ The large numbers of patients diagnosed with infantile paralysis opened the doors for more training centers. By the spring of 1947 there were centers in Memphis, Little Rock, New Orleans, Louisville, St Louis, and Indianapolis. ${ }^{141}$ Reader's Digest scholarships supported 10 nurses from Latin American countries to study the Kenny method of treating infantile paralysis at the University of Minnesota Medical Center in Minneapolis. ${ }^{142}$ New York University offered courses for nurses in the Kenny technique and the NFIP provided scholarships for nurses to attend. ${ }^{143}$

By 1944 the Guide for Nurses in the Nursing Care of Patients with Infantile Paralysis included nursing aspects of the Kenny Method with patterns for making hot packs and instructions in their application. ${ }^{144}$ In 1944 there were more than 50 centers 
supported by the NFIP. ${ }^{145}$ The aim of the foundation was to have the "Kenny method a part of the curriculum in every medical, nursing, and physical therapy school in the country."146

Kenny received long-awaited recognition for her proven methods in the treatment of infantile paralysis in the United States. In 1942, Kenny received the Gold Key Service award from the American Congress of Physical Therapy. Her most distinguished award was an Honorary Doctorate of Humane Letters from the University of Rochester. ${ }^{147}$

In the United States, Kenny presented before many medical meetings. She used motion pictures to show before-and-after results. ${ }^{148}$ Case studies documented patients' conditions before and after treatment.

Kenny was accepted at the University of Minnesota medical center as a guest faculty member. By April 1944, more than 900 people were trained at the University of Minnesota in the Kenny method. The NFIP opened other centers in California, Georgia, Illinois, Indiana, Pennsylvania, and New York. More than $\$ 500,000$ was spent in four years for the study of, and treatment with, the Kenny method. Treatment by the Kenny method was more costly in money and personnel. Cost to society's economic burden for education, vocational training, facilities for surgical hospitals, and convalescent care for victims of infantile paralysis was also great at this time. ${ }^{149}$ The immediate identified outcomes made the expense worthwhile. 


\section{Conclusion}

While nurses have long used massage as part of the treatment for arthritis, constipation, orthopedic complaints, as a part of baths and evening nursing care, in obstetrics, pediatrics, and cardiac care, and for pain relief in neuralgias, its use in the treatment of a major illness such as polio was met with great controversy. The medical community was focused on new scientific methods of cure, not on something as basic as nurse-provided massage. Particularly in Australia and Europe, there was much resistance to the massage techniques advocated by Sister Kenny, an Austrailian nurse who practiced in the Outback. By the 1940s, however, when polio was better understood, American physicians accepted the practice. Its scientific merit had been established; simply put, it worked. Moreover, Kenny accepted the scientific method and actually conducted de facto "pre-post trials," having physicians evaluate the patients she treated. Her work with massage as a therapeutic agent should not be overlooked today as massage is re-evaluated as a treatment for symptoms associated with numerous medical and surgical conditions. 


\section{Notes}

1. Quoted in Anna Quincy Churchhill, "Massage, Its Physiological effects," American Journal of Nursing no. 8 (1915): 635 (hereafter cited as $A J N$ ).

2. Kathryn L. Jensen-Nelson, Massage in Nursing Care, (New York: Macmillan Company, 1941), 12; Ella L. Rothweiler, John S. Coulter, and Felix Jansey, The Science and Art of Nursing (Philadelphia: F.A. Davis, 1935), 1021. Nurse Rothweiler was Instructor of Nurses, American Hospital, Chicago and Dr. Coulter the Associate Professor and Head of the Physical Therapy Department Northwestern University Medical School, Dr. Jansey, Instructor in Surgery, Northwestern University Medical School; M.S. Woolf, Principles of Surgery for Nurses (Philadelphia: W.B. Saunders, 1927), 303-4; Nellie Elizabeth Macafee, Massage: An Elementary Text-Book for Nurses, $2^{\text {nd }}$ ed. (Reed \& Witting, 1920), 5. This text was intended as a study guide to meet the requirements of the Pennsylvania State Board of Registration of Nurses; E. L. Eliason, L. Kraeer Ferguson, and Elizabeth Keller Lewis, Surgical Nursing (Philadelphia: J.B. Lippincott, 1936):109; Helene Biermann, "Notes on Massage," AJN 7, no. 7 (April, 1907): 534; H.V. Barclay, "Medical Gymnastics in Locomotor Ataxia," AJN 1, no. 6 (March, 1913): 428.

3. Biermann, "Notes on Massage," 534; Eliason et al., Surgical Nursing, 109; Charlotte Talley, "Tracing the Sources and Limiting the Spread of Infantile Paralysis," AJN 17, no. 3 (October,1916): 216; Anna Caroline Maxwell and Amy Elizabeth Pope, Practical Nursing: A Text-Book for Nurses, (New York: G.P. Putnam's Sons, 1914), 858. 
4. National Foundation for Infantile Paralysis, The Story of the Kenny Method, no. 50 (New York: The National Foundation for Infantile Paralysis, 1944): 6 (hereafter cited as NFIP).

5. NFIP, Facts and Figures about Infantile Paralysis, no. 59 (New York: NFIP, 1946).

6. Robert S. McCombs, Diseases of Children for Nurses (Philadelphia: W. B. Saunders, 1923), 228. During widespread epidemics, mothers were encouraged to take their children's temperature every evening for early identification of the disease. Charles $\mathrm{H}$. Mayo, “Infantile Paralysis (Poliomyelitis),” The Crippled Child 5, no. 5 (February, 1928): 101 (hereafter cited as TCC).

7. C.E. Irwin, "Infantile paralysis," TCC 29, no. 3 (October, 1941): 63.

8. Daniel Wilson, "A Crippling Fear: Experiencing Polio in the Era of FDR," Bulletin of the History of Medicine 72 (1998): 469; R. I. Harris, "Crippled Children: How May Their Deformities Be Prevented," TCC 9, no. 3 (October, 1931): 80, details the commonly held medical belief that permanent partial paralysis caused unequal pull on the extremities resulting in deformity. Mary Rees Mulliner, Mechano-therapy: A Text-Bookfor Students, (Philadelphia: Lea \& Febiger, 1929): 209, notes, “The good muscles pull the parts out of shape, as in lateral curvature, flail foot, flexion of various joints, etc." Dr. Mulliner was formerly Instructor in Mechano-therapy in the summer school of Harvard University; in the Sargent School for Physical Education; in the Department of Hygiene, Wellesley College; in the American School of Physical Education, and in Classes for PhysioTherapy Aids at the Request of and Under the Sanction of the Surgeon-General, U.S. Army. Irwin, "Infantile Paralysis," 63, theorizes that the lack of nerve energy to the 
muscles lead to paralysis. Mayo, "Infantile Paralysis," 100, describes that once paralysis of a portion of the body occurred, death could follow. Elizabeth Kenny and Martha Ostenso, And They Shall Walk: The Life Story of Sister Elizabeth Kenny, (New York: Dodd, Mead, 1943), 253, found that paralysis only existed in $20 \%$ of severe cases. Henry Keller, "Care of Crippled Children in Some Parts of the Near East," TCC 9, no 1 (June, 1931): 11. In the Near East there was the belief that deformity associated with infantile paralysis was actually due to fright. If bulbar paralysis occurred, affecting the respiratory muscles, the patient was more likely to die.

9. Edgar Hull, Christine Wright, and Ann B. Eyl, Medical Nursing, (Philadelphia: F.A. Davis, 1943), 609. Dr. Hull was the Professor of Medicine and Director of the Department of Medicine, Louisiana State University School of Medicine, Visiting Physician, Charity Hospital of Louisiana at New Orleans, Nurse Wright was a Graduate of Davis-Fischer Sanatorium, Atlanta Georgia, Instructor in Nursing Arts, Charity Hospital School of Nursing, New Orleans, Louisiana 1928-1939, Public Health nursing, St. Mary Parish Health Unit and Experience Center, Franklin Louisiana, 1939; Graduate Work at Columbia University, 1940-1941; Educational Director, Division of Nursing, Louisiana State Board of Health 1941-, Ms. Eyl was a Dietitian, $155^{\text {th }}$ Service Unit, Medical Section, Fort Knox, KY.

10. NFIP, Facts and Figures about Infantile Paralysis, no.59 (New York: NFIP, 1946), composed of reports from the United States Bureau of the Census, "Vital Statistics, Special Reports," "Mortality Statistics," and from the United States Public Health Service, "Notifiable Diseases, Prevalence by States" 1915-1945. Also see NFIP, When 
Polio Strikes... Helpful Hints for Everyone, no. 51 (New York: NFIP, 1944); NFIP, The Story of the National Foundation for Infantile Paralysis, no.36 (New York: NFIP, 1931), 11. The diagnosis of infantile paralysis was suspected during epidemic periods when acute febrile illness occurred, but a spinal tap was needed for diagnosis. Early identification of IP was suspected if the patient had flu-like symptoms. Unless there was an epidemic, diagnosis might not occur until a child could not walk or stand.

11. Mayo, "Infantile Paralysis," 101; NFIP, Facts and Figures, 27.

12. NFIP, Story of the Kenny Method, 6.

13. Wilson, Bulletin of the History of Medicine, 471.

14. LeRoy W. Hubbard, "The Treatment of Infantile Paralysis By Exercises in a Natural Warm Water," TCC 5, no. 2 (July-August, 1927): 37; Edgar F. Allen, "Finish What We Start," TCC 9, no. 1 (June, 1931): 9, notes that 25,000 additional children were crippled in the U. S. in 1931 alone. See also Jessie Lulu Stevenson, The Nursing Care of Patients with Infantile Paralysis, no. 22 (New York: NFIP, 1940): 15, that describes treatment of infantile paralysis epidemics by public health methods of isolation and quarantine, hospitalization, cleanliness, and anti-fly campaigns. Suspected and known cases were reported to local health officials. It was recommended that patients be treated in hospitals especially if quarantine in the home could not be maintained. Also see NFIP, Doctor... What Can I Do?: Facts about Infantile Paralysis, no. 34A, $2^{\text {nd }}$ ed. (New York: NFIP, 1942), 12; and Joseph C. Regan, MD and Della M. DeGraw, "The Treatment of the Acute Stage of Poliomyelitis from the Nurses' Standpoint," AJN 18, no. 1 (October, 1917): 6. Quarantine during the 1916 epidemic was 8 weeks, later it was shortened to 6 
weeks. Parents were permitted one visit for identification of the child. Visitors were forbidden to touch patients and had to wear gowns while in the wards. All care providers and maids wore gowns and used a nose and throat spray of 1 part hydrogen peroxide to 4 parts water parts water before going off duty. Della McGraw was the Supervisor of Nurses and Dr. Regan an Assistant Resident Physician at Kingston Avenue Hospital, Brooklyn, New York. As noted in Edna Moynihan, "Acute Poliomyelitis," AJN 16, no. 12 (September, 1916): 1183, all bodily secretions had to be disinfected prior to disposal. Lillian D. Wald, "The Care of Sick Children in the Home," (paper presented at the Academy of Medicine 10 May, 1917), published in Section on Pediatrics, New York Public Library, Lillian Wald Collection, Reel 25, p.1-2; "Editorial Comment," AJN 16, no. 12 (September, 1916): 1170. Lillian D. Wald was instrumental in establishing convalescent hospitals for the treatment of infantile paralysis victims in New York City. Specially trained orthopedic nurses cared for patients in their homes. Children were referred to the Henry Street Settlement in New York from many sources.

\section{Refer to}

http://www.hyperhistory.com/online_n2/people_n2/persons6_n2/roosevelt.html. Franklin D. Roosevelt suffered from a crippling attack of infantile paralysis in 1921. This did not keep him from aspiring to the office of President of the United States. He served four terms from 1932-1948. He concealed many of the effects of polio on his own body, yet served as an inspiration to many who had the disease or had family members with the disease. 
16. NFIP, When Polio Strikes. There was much fear associated with the lack of medical knowledge about infantile paralysis and disease transmission. NFIP, Story of the National Foundation, 12. Theories about disease spread varied. One theory was that the virus enters "through nose and throat and passes to the spinal cord along certain nerve trunks which end in the roof of the nose." Irwin, "Infantile Paralysis," 63, presents another theory: that the virus enters by way of the gastrointestinal tract. A third theory is found in Stevenson, The Nursing Care of Patients with Infantile Paralysis, 12: in 1912 it was believed the virus was transmitted person to person via mucous membranes. It was not until the 1940s that it was well known that the invisible virus attaches to anterior horn cells of gray matter of spinal cord in the cells of origin of motor neurons. The result, of course, is difficulty with movement, paralysis and spasms. As described in Carrie Webster, "Infantile Paralysis: After Effects and Treatment," AJN 20, no. 9 (June, 1920): 695, and in Regan and DeGraw, "Treatment of the Acute Stage," 6, it was believed that the incubation period for polio was short, only one to three days. State Medical Institute of Sweden, "Investigation on Epidemic Infantile Paralysis," Report from the State Medical Institute of Sweden to the XV International Congress on Hygiene and Demography (Washington, Stockholm:, 1912): 212. Degeneration of nerve cells occurred and varied by individual.

17. Allen, "Finish What We Start," 8. In 1921, Edgar F. Allen founded The National Society for Crippled Children. In 1931 the suggested charter for Crippled Children was "for every crippled child, everywhere, such measure as will early discover and diagnose 
his handicap, provide care and treatment, and so train him that he may become an asset to society and not a liability."

Refer also to The National Society for Crippled Children, "Story of the Easter Seal," TCC 21, no.6 (April, 1944): 152.

18. Hubbard, "Natural Warm Water," 38. Franklin D. Roosevelt spent several weeks at Warm Springs in the summer of 1924 and spring of 1925 exercising in the pools. He purchased the property in Georgia and turned it into a hydrotherapeutic rehabilitation center for cases of infantile paralysis, creating the Warm Springs Foundation. Once a prominent politician was diagnosed with polio, common views on the disease changed. 19. NFIP, Story of the National Foundation, 6; NFIP, Story of the Kenny Method, 3. 20. Jensen-Nelson, Massage in Nursing Care, 12.

21. Helen Parks, "Medico-mechanical Treatment," AJN 11, no. 5 (February, 1911): 428430.

22. Helen Conkling Bartlett, "The Teaching of Massage to Pupils in Hospital Training Schools," AJN 1, no. 10 (July, 1901): 718-20. Ms. Bartlett was an Instructor in Massage, Johns Hopkins Hospital Training-School for Nurses and Graduates of the Training School.

23. Mulliner, Mechano-therapy, 24.

24. Rothweiler et al., The Science and Art of Nursing, 1021.

25. Naomi Rogers, Dirt and Disease: Polio Before FDR, (New Jersey: Rutgers University Press, 1992), p. 97; Alfred H. Freilberg, "The Story of Two Children," TCC 5, no.1 (May-June, 1927): 16. Physicians found it difficult to help laymen "realize that what 
is destroyed by the infection in the spinal cord cannot be replaced; that what is merely damaged becomes repaired by nature's own processes and little influenced by anything which we can do clinically."

26. Harris, "Crippled Children," 80-81.

27. Hubbard, "Natural Warm Water," 37.

28. Irwin, "Infantile Paralysis," 63-64.

29. Stevenson, Nursing Care of Patients, 24.

30. Harris, "Crippled Children," 81.

31. Irwin, "Infantile Paralysis," 63; Hubbard, "Natural Warm Water," 38. Patients diagnosed with infantile paralysis had acute sensitivity to touch. Following the epidemic of 1916 hot salt water baths were used to stimulate circulation, and relieve pain and tenderness. YMCA swimming pools and other swimming tanks were used for muscle exercises for children under 12 years of age.

32. Charles Phillips Emerson and Jane Elizabeth Taylor, Essentials of Medicine (Philadelphia: J.B. Lippincott, 1940), 1799-800. Dr. Emerson was a research fellow in Medicine, Harvard Medical School, Resident Physician, Thorndike Memorial Laboratory and Assistant in Medicine, Boston City Hospital. Nurse Taylor was an Assistant Professor of Medical Nursing, Yale University of School of Nursing, Assistant in Charge of Medical Nursing, New Haven Hospital.

33. M. S. Woolf, Principles of Surgery for Nurses (Philadelphia: W. B. Saunders, 1927), 303-304. 
34. For more on traditional therapies, see Arlene W. Keeling, Nursing and the Privilege of Prescription (Columbus, OH: Ohio State University Press, 2007).

35. Kurre Ostrom, Massage and the Original Swedish Movements: Their Application to Various Diseases of the Body (Philadelphia: P. Blakiston's Son, 1902). Kurre Ostrom was from the Royal University of Upsala, Sweden. He lectured before the Training Schools of Nurses connected with the Hospital of the University of Pennsylvania, German Hospital, Woman's Hospital, Philadelphia Lying-In Charity Hospital, Philadelphia Polyclinic and College for Graduate in Medicine and Kensington Hospital for Women, of Philadelphia.

36. Biermann, “Notes on Massage," 534.

37. Ibid.

38. Max Böhm, Massage: Its Principles and Technic, ed. Charles F. Painter (Philadelphia: W. B. Saunders, 1913).

39. Churchill, "Massage," 635-36.

40. Emily A. M. Stoney and Lucy Cornelia Catlin, Practical Points in Nursing, $5^{\text {th }}$ ed. (Philadelphia: W. B. Saunders, 1916), 457.

41. Macafee, Massage, 5.

42. Amanda K. Beck, A Reference Hand-Bookfor Nurses, $4^{\text {th }}$ ed. (Philadelphia: W. B. Saunders Company, 1919), 132.

43. Bartlett, "Teaching of Massage," 718-20; Also see Lily H. Graham, "Exercises for Cardiac Cases," AJN, 25, no.4 (April, 1925): 365. 
44. Bartlett, "Teaching of Massage," 718-20. Graham, "Exercises for Cardiac Cases," 365.

45. Committee on Education of the National League of Nursing Education, "A Curriculum for Schools of Nursing," 7th ed. (New York: National League of Nursing Education, 1932), 187-88.

46. Ibid.

47. Florence Dakin and Ella M. Thompson, Simplified Nursing (Philadelphia: J. B. Lippincott, 1941), 165

48. Ibid.

49. Bertha Harmer and Virginia Henderson, Textbook of Principles and Practice of Nursing, $4^{\text {th }}$ ed. (New York: MacMillan, 1939) 288. Martha Ruth Smith and Jean Broadhurst, An Introduction to the Principles of Nursing Care (Philadelphia: J. B. Lippincott, 1937), 163.

50. Dakin and Thompson, Simplified Nursing, 165.

51. Harmer and Henderson, Textbook of Principles and Practice, 286-87. A cold wet hand rub combining cold with mechanical friction was "used in febrile conditions where the tub-bath is too vigorous a treatment." Amanda K. Beck, A Reference Hand-Book for Nurses, $4^{\text {th }}$ ed. (Philadelphia: W. B. Saunders, 1919), 132-33, notes that massage given "one to two hours before the patient quiets down for the night frequently results in improved sleep."

52. Henry S. Brooks, Jr. and Pearl Castile, A Textbook of Surgical Nursing, $2^{\text {nd }}$ ed. (St. Louis: C.V. Mosby, 1940), 589. Dr. Brooks was an Instructor in Clinical Surgery at 
Washington University School of Medicine, Surgeon to Outpatients, Washington University Dispensary, Assistant Surgeon to Barnes Hospital and Visiting Surgeon to Home G. Philips Hospital. Nurse Castile was Assistant Director of the School of Nursing, University of California, Former Instructor in Nursing, University of California. See also Rothweiler et al., The Science and Art of Nursing, 1021; and Philip Lewin, Orthopedic Surgery for Nurses including Nursing Care (Philadelphia: W. B. Saunders (1940), 34557.

53. Amanda K. Beck and Lyla Olson, A Reference Hand-Bookfor Nurses, $9^{\text {th }}$ ed. (Philadelphia: W. B. Saunders, 1941), 122-31. Ms. Beck was a graduate of the Illinois Training School for Nurses and Ms. Olson the Superintendent of Nurses, Kahler Hospital, Rochester Minnesota.

54. Jensen-Nelson, Massage in Nursing Care, xiv.

55. For further reading on the legal aspects of nursing care during this time, see Keeling, Nursing and the Privilege of Prescription, 1893-2000.

56. Maxwell and Pope, Practical Nursing, 856; Eliason et al., Surgical Nursing, 109. Movement Cure refers to the Swedish Movement Cure, based upon the work of Per Henrick Ling, a Swedish Poet and philosopher, that included gymnastics and therapeutic massage. Movement Cure was brought to the United States around 1868 by physicians George Taylor and Robert Taylor. Also discussed in Biermann, "Notes on Massage," 534; Barclay, "Medical Gymnastics," 428.

57. Eliason et al., Surgical Nursing, 109: Biermann, "Notes on Massage," 534; Maxwell and Pope, Practical Nursing, 858. 
58. Harmer and Henderson, Textbook of Principles and Practice, 289.

59. Biermann, "Notes on Massage," 534; Churchill, "Massage," 635; Harmer and Henderson, Textbook of Principles and Practice, 288; Maxwell and Pope, Practical Nursing, 858; Philip Lewin, Orthopedic Surgery for Nurses Including Nursing Care (Philadelphia: W.B. Saunders, 1940), 346; Eliason et al, Surgical Nursing, 169. 60. George Knapp Abbott, Elements of Hydrotherapy for Nurses (Tacoma Park, MD: Review and Herald, 1912), 198-99. Dr. Abbott was the Professor of Clinical Medicine in the College of Medical Evangelists, Loma Linda, California.

61. Maxwell and Pope, Practical Nursing, 858.

62. Eliason et al., Surgical Nursing, 170.

63. Ibid., 109.

64. William S. Sadler, Lena Sadler, and Anna Kellogg, Psychiatric Nursing (St. Louis: C. V. Mosby, 1937), 370.

65. Ibid., 372 .

66. Maude Muse, A Textbook of Psychology (Philadelphia: W. B. Saunders, 1939), 15455.

67. Ibid., 155 .

68. W. Earl Biddle, Mildred Van Sickel, and William Sandy, Introduction to Psychiatry (Philadelphia: W.B. Saunders, 1943), 115.

69. Carolyn Conant Van Blarcom, Obstetrical Nursing (New York: Macmillan, 1922), 130. 
70. Carolyn Conant Van Blarcom, J. Clifton Edgar, and Frederick Rice, Getting Ready to Be a Mother (New York: Macmillan, 1922), 64-65.

71. Biermann, “Notes on Massage,” 537.

72. Joseph B. De Lee, Obstetrics for Nurses, $3^{\text {rd }}$ ed. (Philadelphia: W. B. Saunders, 1911), 310-27.

73. John Osborn Polak, Manual of Obstetrics, $2^{\text {nd }}$ ed. (Brooklyn, New York: Physicians and Surgeons Book, 1922), 211-12; Ralph Colp, and Manelva Wylie Keller, Textbook of Surgical Nursing, (New York: Macmillan, 1929), 52, describes massage being used after the excision of the breast for carcinoma to decrease swelling of the arm. Dr. Colp was an Instructor in Surgery, Columbia University, Lecturer in Surgical nursing, Mt. Sinai Hospital training School for Nurses, Attending Surgeon, Beekman Street Hospital, New York, Adjunct Surgeon, Mt. Sinai Hospital, New York, and Former lecturer in Nursing and Health, Teachers College, Columbia University. Nurse Keller was former Chief Operating Room Nurse, St. Luke's Hospital, New York and Anesthetist, St. Luke's Hospital, New York.

74. Edward P. Davis, Obstetric and Gynecologic Nursing, $5^{\text {th }}$ ed. (Philadelphia: W. B. Saunders, 1917), 97; De Lee, Obstetrics for Nurses, 215.

75. Polak, Manual of Obstetrics, 209.

76. Davis, Obstetric and Gynecologic Nursing, 253-4; Van Blarcom et al., Getting Ready to Be a Mother, 216-17.

77. Manelva Wylie Keller, Textbook of Surgical Nursing (New York: Macmillan, 1936), 206 and 210. 
78. Harmer and Henderson, Textbook of Principles and Practice, 957.

79. Davis, Obstetric and Gynecologic Nursing, 252.

80. De Lee, Obstetrics for Nurses, 506.

81. Dorothy MacLeod and Dora Mathis, "The Nursing Care of Arthritic Patients," AJN 32, no. 6 (June, 1932): 631.

82. Theodore Franklin Back, “Arthritis," AJN 32, no. 6 (June, 1932): 628.

83. MacLeod \& Mathis, “Arthritic Patients," 633-4.

84. Kate T. Williams and Isabel McIsaac, "Massage for Constipation," AJN 1, no.10 (July, 1901): 713-14.

85. Charlotte A. Aikens, Primary Studies for Nurses (Philadelphia: W. B. Saunders, 1916), 250.

86. Kate W. Williams, "Method of Massage of the Scalp," AJN 2, no. 1 (October, 1901), 27-9. Ms. Williams was at the Illinois Training School for Nurses, Chicago.

87. Ibid.

88. Colp and Keller, Textbook of Surgical Nursing, 192-3.

89. Graham, "Exercise for Cardiac Cases," 366-7.

90. Colp and Keller, Textbook of Surgical Nursing, 180.

91. Manelva Wylie Keller, Textbook of Surgical Nursing, $3^{\text {rd }}$ ed. (New York: MacMillan, 1936), 213.

92. Colp and Keller, Textbook of Surgical Nursing, 52 \& 183.

93. Eliason et al., Surgical Nursing, 170; Rothweiler et al, Science and Art of Nursing, 1021-27. 
94. Rothweiler et al., The Science and Art of Nursing, 1024.

95. Ibid.

96. Charles D. Lockwood, John Wolfer, and Mildred Newton, The Principles and Practice of Surgical Nursing (New York: Macmillan, 1935), 317.

97. Eliason et al., Surgical Nursing, 172; Keller, Textbook of Surgical Nursing, 206.

98. Rothweiler et al., Science and Art of Nursing, 1026-27.

99. T. Ambrose Stanton, "Massage in the Treatment of Infantile Paralysis," AJN 1, no. 3

(December, 1900), 211-12. Dr. Stanton practiced in Toronto, Ontario, Canada. 100. Ibid., 212.

101. Francis Fraser, "Infantile Paralysis," part 1, $A J N 13$, no. 4 (January, 1913): 255; part 2, AJN 13, no.5 (February, 1913): 345, (paper presented at the eleventh annual meeting of the New York State Nurses' Association, Utica, NY, 16 October 1912).

Eliason et al., Surgical Nursing, 109.

102. George Frederic Still, Common Disorders and Disease of Childhood, $3^{\text {rd }}$ ed. (London: Oxford University Press, 1915), 699.

103. Richard Kovács, Physical Therapy for Nurses (Philadelphia: Lea \& Febiger, 1940), 281.

104. Emerson and Taylor, Essentials of Medicine, 1799-800.

105. Hull et al, Medical Nursing, 609.

106. Jensen-Nelson, Massage in Nursing Care, 135. "The deltoid, anterior tibial, quadriceps, opponens, pollicis, and abdominals, are those most frequently involved." 107. Kenny and Ostenso, And They Shall Walk, 23. 
108. Don W. Gudakunst, MS, The Importance of Research, no 42 (NFIP, 1942), 19-20; Kenny and Ostenso, And They Shall Walk, 29 and 90. In December 1916, Elizabeth Kenny was promoted from rank of staff nurse (equivalent to $2^{\text {nd }}$ Lieutenant) to Sister (equivalent to First Lieutenant) in the military rank for nurses in the Australian Medical Corps. She served in the medical corps during WWI as a nurse on hospital ships between Europe and Australia from 1915-1918. She made 12 round trips. She was wounded in the left knee and leg from enemy shrapnel, and developed a heart condition that was not clear in diagnosis. Following the war she transferred from the Australian Imperial Forces to the Commonwealth Military Force. She invented the Sylvia stretcher for transportation of shock patients, naming it after one of her patients. Kenny obtained a patent and used the royalty monies to open her first clinic in 1913 in Townsville, Queensland, Australia to care for children with infantile paralysis. Later clinics were named Elizabeth Kenny clinics.

109. Kenny and Ostenso, And They Shall Walk, 161. Infantile paralysis was a dreaded disease. Sister Kenny reported a 10 to 20 per hundred death rate when an epidemic was severe.

110. Ibid., 231.

111. NFIP, The Story of the National Foundation for Infantile Paralysis; 11. Kenny and Ostenso, And They Shall Walk, 174.

112. Kenny and Ostenso, And They Shall Walk, 97.

113. Ibid., 196

114. Ibid. 
115. Ibid., 102.

116. Ibid., 103.

117. Ibid., 177.

118. Ibid., 161.

119. Ibid., 224. Sister Kenny opposed muscle testing as it agitated the reflexes and exaggerated the spasm.

120. Ibid., 194.

121. Freilberg, "Story of Two Children," 15.

122. NFIP, The Story of the Kenny Method, 4.

123. Kenny and Ostenso, And They Shall Walk, 158; The Story of the Kenny Method, 3.

124. NFIP, Doctor... What Can I Do? 12-15.

125. Kenny and Ostenso, And They Shall Walk, 228.

126. NFIP, Story of the Kenny Method, 4; Gudakunst, The Importance of Research, 21.

127. W. H. Cole and M. E. Knapp, “The Kenny Method of Treatment of Infantile

Paralysis: A Preliminary Report," Journal of the American Medical Association 116 (7

June 1941): 2577-80.

128. George Knapp Abbott, Fred B. Moore and Kathryn L. Jensen-Nelson, Physical

Therapy in Nursing Care (Tacoma Park, MD: Review and Herald, 1945), 484.

129. NFIP, Story of the Kenny Method, 5.

130. Ibid., 6.

131. "Kenny Method Course for Nurses," AJN 42, no. 5 (May, 1942), 583-84.

132. Kenny and Ostenso, And They Shall Walk, 248. 
133. Carmelita Calderwood, Orthopedic Nursing: Content and Method of the Teaching Program in Schools of Nursing (New York: Joint Orthopedic Nursing Advisory Service of the National Organization for Public Health Nursing and the National League of Nursing Education, 1942), 24.

134. Carmelita Calderwood, review of Infantile Paralysis by Philip Lewin, AJN 41, no. 10 (October, 1941): 1243.

135. The $A J N$ has many examples of resources, books, and courses offered to educate nurses and other healthcare providers about infantile paralysis and massage. "Editorial Comment," AJN 43, no. 6 (June, 1943). The Joint Orthopedic Nursing Advisory Council advertised the availability of educational materials on poliomyelitis (available for loan with postage charge only), that included slides on the care of patients in casts. Other advertisements: "Splints for Infantile Paralysis Patients," AJN 41, no. 7 (July, 1941): 771; and "Health Education for the Community" sessions, AJN 43, no 5 (June, 1943): 604. The NFIP also announced the availability of both English and Spanish translations of its pamphlet by Stevenson, The Nursing Care of Patients with Infantile Paralysis, "Editorial Comment," AJN 41, no. 7 (July, 1941), 876.

136. NFIP, Doctor... What Can I Do?

137. Unsigned review of Nursing Care of Patients with Infantile Paralysis, including Nursing Aspects of the Kenny Method, by Joint Orthopedic Nursing Advisory Service, AJN 43, no. 10 (October, 1943): 969. 
138. Unsigned review of Nursing Care in the Kenny Method of Treatment for Infantile Paralysis, by Division of Services for Crippled Children, AJN 43, no. 5 (May, 1943): 520.

139. NFIP, The Story of the Kenny Method, 6; NFIP, Facts and Figures about Infantile Paralysis.

140. Kenny and Ostenso, And They Shall Walk, 266.

141. "Latin-American Nurses Study Kenny Treatment," AJN 43, no. 11 (November, 1943):1051.

142. "Kenny Technic Courses at New York University," AJN 43, no. 7 (July, 1943): 690; “Sister Kenny at New York University,” AJN 43, no. 3 (March, 1943): 314.

143. Joint Orthopedic Nursing Advisory Service of the National Organization for Public Health Nursing and the National League of Nursing Education, A Guide for Nurses in the Nursing Care of Patients with Infantile Paralysis, including Nursing Aspects of the Kenny Method, no. 45, $2^{\text {nd }}$ ed. (New York: NFIP, 1943).

144. NFIP, Story of the Kenny Method, 10.

145. Ibid.

146. Kenny and Ostenso, And They Shall Walk, 266.

147. Ibid., 276.

148. Allen, "Finish What We Start," 9; NFIP, Story of the Kenny Method, 9-10. 
Manuscript 2

Use of Massage Therapy in Patients Undergoing Autologous Stem Cell Transplant:

A Literature Review

Proposed submission to:

Journal of Clinical Oncology

Impact factor for this journal is 11.810 
Use of Massage Therapy in Patients Undergoing Autologous Stem Cell Transplant:

A Literature Review

Audrey Snyder, Ann Gill Taylor, and Cheryl Bourguignon

From the Center for the Study of Complementary and Alternative Therapies, School of Nursing, University of Virginia, Charlottesville, Virginia. 


\section{Abstract}

The autologous stem cell transplant (ASCT) treatment process involves the use of aggressive, high-dose chemotherapy and/or whole-body radiation to eradicate the cancer, followed by rescue with the patient's previously harvested bone marrow or peripheral blood stem cells with the intent to cure the disease or prolong patient survival. Because treatment-related morbidity and death have decreased over the past decade, ASCT is becoming the therapy of choice for selected hematological diseases and solid tumors. Patients with cancer undergoing ASCT endure a series of stressors and adverse symptoms throughout treatment, resulting in a greatly impaired quality of life (QoL). This article reviews what is known about QoL, treatment-related symptoms, and the use of massage therapy in patients undergoing ASCT.

Key Words: stem cell transplantation, bone marrow transplantation, quality of life, isolation, protective gloves, massage 
Introduction

The autologous stem cell transplant (ASCT) treatment process involves the use of aggressive, high-dose chemotherapy and/or whole-body radiation to eradicate the cancer, followed by rescue with the patient's previously harvested bone marrow or peripheral blood stem cells ${ }^{34,35}$ with the intent to cure the disease or prolong survival. ${ }^{5}$ Because treatment-related morbidity and death have decreased over the past decade, ASCT is becoming the therapy of choice for selected hematological diseases and solid tumors. ${ }^{22,52}$ Leukemia, multiple myeloma, Hodgkin's lymphoma, non-Hodgkin's lymphoma, and breast cancer are among the types of cancer treated with ASCT. Each year more than 9,000 people undergo stem cell transplantation in the United States (US). ${ }^{42}$

\section{ASCT Treatment}

The ASCT process entails several distinct phases, each with unique procedures and threats to health-related quality of life (QoL). ${ }^{34,65}$ Prior to ASCT, patients are hospitalized or treated as daily outpatients for mobilization of stem cells from the bone marrow. This mobilization phase involves daily chemotherapy for 3 to 5 days, often supplemented with growth factors (e.g., Neupogen ${ }^{\circledR}$ ), to stimulate cell proliferation. Approximately 1 week after mobilization, patients undergo several days of stem cell collection from blood and, if necessary, bone marrow. Finally, patients are hospitalized for 1 to 3 weeks for conditioning with myeloablative chemotherapy and/or radiation (usually 2 to 5 days), followed by an infusion of harvested cells during the actual transplantation. Most patients achieve engraftment (i.e., initial repopulation of the hematopoietic system) within 2 weeks, but ASCT recipients display a prolonged period 
of immune dysfunction and remain vulnerable to various threats to health status, including opportunistic infections and anemia that can require blood transfusions.

\section{Unique Needs of Patients Undergoing ASCT}

Patients with cancer who undergo ASCT endure a series of stressors and adverse symptoms throughout treatment, resulting in greatly impaired QoL. In addition to adjusting to their diagnosis, these patients face life-threatening medical therapies, invasive procedures, travel demands, unemployment, financial strain, physical isolation, and separation from social support networks. ${ }^{48,65}$ Many patients suffer from distress, anxiety, depression, pain, nausea, and vomiting before ASCT, ${ }^{7,24}$ and survivors of the process frequently report persistent symptoms and impaired QoL in the days, weeks, and months following. ${ }^{46}$ These symptoms are often difficult to manage by conventional medicine alone ${ }^{57,59}$ Patients receiving ASCT also experience social and physical isolation because of treatment regimens.

The physical touch that is predominantly related to invasive procedures or assessments can create a negative tactile perception. Thus, some patients begin to associate touch with painful procedures. The treatment-related distress that patients experience can contribute to morbidity and decreased QoL following ASCT.

Interventions to improve patient symptoms and QoL are warranted. ${ }^{58}$ Researchers have identified the need for early intervention with adjunctive therapies such as massage to diminish stress reactivity and treatment-related distress. ${ }^{23}$ Interventions designed to improve QoL and treat adverse effects in patients with cancer should target any symptoms experienced. ${ }^{8}$ 
Preliminary research suggests that adjunctive massage therapy improves adverse symptoms and QoL for patients during cancer treatment without the side effects associated with conventional pharmacological therapies. ${ }^{3,15,19,64,66,70,71}$

\section{Health-Related Quality of Life and ASCT}

Health-related QoL is a multidimensional construct encompassing the physical, psychological, and social domains of health status. ${ }^{8}$ Quality of life perceptions are shaped by personal experiences, beliefs, expectations, and perceptions as well as by threats to health and well-being. ${ }^{72}$ Increased interest in the psychosocial status of patients with cancer and their QoL has become an important part of clinical cancer research. Most patients with cancer use complementary and alternative medicine modalities, including massage, to improve QoL. ${ }^{50}$

Patients undergoing ASCT confront a challenging array of physical, emotional, and behavioral stressors and symptoms resulting in impaired QoL before and after treatment. ${ }^{23}$ Many have difficulties with psychological/emotional adjustment in the weeks immediately after ASCT, ${ }^{23}$ and studies have increasingly demonstrated deficits in physical and social/occupational QoL 1 year or more after ASCT ${ }^{52}$ Quality of life before cancer treatment may be independently associated with response to chemotherapy and survival; ${ }^{48}$ thus, there are growing concerns regarding the QoL of patients undergoing ASCT. Such patients frequently report emotional distress, pain, fatigue, nausea, and vomiting that affect QoL. ${ }^{23,46}$

\section{Emotional Distress}

Patients undergoing ASCT are subjected to a wide range of psychosocial 
stressors. Anxiety, depression, and distress are prevalent prior to and following successful ASCT. ${ }^{24,26,41,48}$ In addition to coping with adverse symptoms and reduced functional status, the diagnosis of cancer can have a long-term disruptive affect on the patient and his or her family. ${ }^{52}$ Moreover, the administration of high-dose chemotherapy during ASCT is life-threatening and a traumatic experience for many patients. ${ }^{23,24}$ In a recent study, $100 \%$ of patients receiving standard medical care experienced anxiety during the first week after ASCT. ${ }^{23}$ Longitudinal studies indicate that anxiety is often highest in the early phases of treatment (e.g., pre-ASCT) and may begin to decrease shortly after ASCT. ${ }^{24}$ Some patients even describe the aggressive cancer treatments as more distressing than the cancer. ${ }^{49}$

Stressors associated with ASCT include travel for treatment, financial hardship, medical appointments, hospitalization, invasive treatments, separation from family and friends, and physical isolation. ${ }^{65}$ Gaston-Johansson and Foxall ${ }^{24}$ also found depression to be highest prior to transplant. Depression is a strong predictor of QoL and may be associated with immune function and survival in patients with cancer who receive ASCT. ${ }^{28}$ Because the symptoms associated with ASCT can be exacerbated by stress and because stress can reduce immune function and impair recovery following medical procedures, ${ }^{4,29}$ stress reduction is an important objective to optimize outcomes for these patients.

\section{Pain}

Most patients with cancer who receive ASCT have multiple types and sites of pain. ${ }^{23}$ As many as $90 \%$ of ASCT recipients develop moderate to severe oral mucositis or 
throat pain that is often refractory to opioids. ${ }^{44,57}$ Severe mucositis may limit the use of aggressive chemotherapy. Furthermore, opioid use may be problematic for some patients, resulting in nausea, vomiting, decreased peristalsis, respiratory depression, sedation, confusion, and dependence. ${ }^{39,71}$ Pain is associated with depression, fatigue, and downregulation of immune function in patients with cancer. ${ }^{4}$ Adjunctive therapies, including massage therapy, have often been recommended to optimize pain management among patients with cancer. ${ }^{1,51,62}$

\section{Fatigue}

Fatigue is one of the most prevalent symptoms reported by ASCT recipients. ${ }^{26,52,59}$ According to Gaston-Johansson and Foxall, ${ }^{24}$ fatigue is reported by $33 \%$ to $91 \%$ of patients undergoing ASCT. Fatigue impairs activities of daily living, selfesteem, and social involvement ${ }^{59}$ and contributes to emotional and cognitive symptoms in patients with cancer. ${ }^{2,48}$ Survivors of ASCT often continue to experience fatigue after treatment. $^{20,52}$

\section{Nausea and Vomiting}

Despite improvements in antiemetic drug therapy, more than half of cancer patients experience moderate to severe nausea during treatment with chemotherapy. ${ }^{77}$ Indeed, antiemetics are not universally effective, as some patients actually experience undesirable side effects from these medications. ${ }^{49}$ Nausea and vomiting are significantly associated with distress and reduced QoL during chemotherapy. ${ }^{7,23,41}$ 
Isolation Requirements for Patients Undergoing ASCT

Patients undergoing ASCT experience social and physical isolation associated with the treatment regimens. They are on protective isolation for immunosuppression for 7 to 10 days following transplant; however, the affect of this isolation on QoL has received only limited attention in the professional literature. Barriers to touch include severity of illness, isolation status, and glove or barrier use. The use of gloves in the routine care of patients has become commonplace over the last 10 years. There may be a difference in the receiver's perception of touch based on whether the gloves are used to prevent additional infection in the patient or to prevent the spread of opportunistic infections to others.

The increased incidence of antibiotic-resistant organisms has influenced patients' isolation status. Patients who become colonized with vancomycin-resistant Enterococcus, methicillin-resistant Staphylococcus aureus (MRSA), or Clostridium difficile will require contact isolation procedures beyond the usual requirements for immunosuppression for all medical and nursing care, and visitations. The incidence of opportunistic infections has increased the use of gloves for routine nursing care such as taking vital signs, bathing, and assisting patients with other activities of daily living.

Physical isolation causes stress in hospitalized patients. ${ }^{76}$ In a study of patients isolated for infection control of MRSA, they experienced more preventable adverse effects, expressed greater dissatisfaction with their treatment, and had less documented care $^{68}$ than similar patients who had not been isolated. Research has shown that wearing latex gloves also reduces healthcare workers' sensitivity to touch, ${ }^{73}$ which could affect 
procedural medical and nursing care. Little research has been done on patient perception of touch from healthcare provided with gloves, although touch plays a large role in a patient's perception of comfort. Comforting touch during nursing interventions is essential in vulnerable populations on isolation when gloves are required to provide basic care. ${ }^{6}$ Touch provided through massage has the potential to comfort patients and create a positive effect on patient outcomes.

Patients often experience considerable distress prior to ASCT as well as during or after ASCT, and massage may produce stronger effects when introduced early in treatment and reinforced thereafter. ${ }^{23,49}$

\section{Overview of Massage as a Therapy}

Massage is one of the oldest and most appreciated modes of sensory stimulation for alleviating pain, improving disease symptoms, and promoting well-being. ${ }^{10}$ Often massage is used for relaxation and pain relief. Manual massage is defined as the manipulation of soft tissue by a trained massage therapist for therapeutic purposes. ${ }^{21}$

The 1999 National Health Interview Survey revealed that $28.9 \%$ of the US population had used at least one complementary or alternative medicine therapy in the previous year. Among these treatments, massage therapy was the 5th leading complementary modality used by the US population. The top four modalities were spiritual healing or prayer, herbal medicine, chiropractic therapy, and lifestyle diet. Of those patients surveyed, $6.4 \%$ had used massage therapy during the previous year. ${ }^{53} \mathrm{~A}$ survey of primary care patients revealed that $17.2 \%$ used massage therapy for a health problem for which they were also seeking treatment in a medical clinic. ${ }^{54}$ 
Massage has a long and multicultural tradition spanning centuries. In the 1960s, with the revival of chronic disease treatment, massage became a popular therapy. During the 1970 s and 1980 s, the widespread health movement and pain management research brought massage to the forefront as a complementary treatment. ${ }^{21}$ Massage has grown along with osteopathy, chiropractic, and physical therapy as a manual medical treatment. The Agency for Health Care Policy and Research ${ }^{1}$ recommended massage to assist patients with cancer- and treatment-related symptoms, which paved the way for greater acceptance of this treatment modality in patients with cancer.

\section{Massage Therapy in Cancer}

Preliminary research suggests that adjunctive massage therapy improves adverse symptoms and the QoL of patients during cancer treatment without the side effects associated with conventional pharmacological treatments. ${ }^{3,15,19,64,66,70,71}$ Unfortunately, few controlled studies of massage interventions have been conducted in persons with cancer, and authors of most studies have evaluated only the immediate changes in patients that occurred across a few brief massage sessions. ${ }^{14,25,40}$

Massage may increase feelings of comfort, improve sleep, and promote feelings of support in patients with cancer. ${ }^{66}$ Hospitalized male cancer patients who were experiencing cancer-related pain reported reduced pain and anxiety, increased feelings of relaxation, and decreased heart rate, respiratory rate, and blood pressure after 30-minute massages on two consecutive evenings. ${ }^{14}$ In hospitalized patients experiencing nausea or pain related to cancer, 10-minute foot massages by nurses had significant immediate effects on perceptions of pain, nausea, and relaxation. ${ }^{25}$ Cancer patients reported 
significant increases in QoL following four massage sessions. These findings are further supported by data from a growing number of controlled prospective trials demonstrating the positive effects of massage on anxiety, ${ }^{33,38,64}$ depression, ${ }^{16}$ pain,,${ }^{9,12,31,60}$ fatigue, ${ }^{18}$ and QoL $L^{9,60}$ in various patient populations.

\section{Massage for Patients Undergoing ASCT}

Preliminary studies have indicated that various types of massage can reduce distress, ${ }^{3,56,66,70,71}$ anxiety (Menard M, unpublished data), ${ }^{3,13,69}$ pain, ${ }^{25,45,78}$ fatigue, and nausea $^{3,25}$ in patients undergoing conventional cancer care. Massage can also increase feelings of comfort, improve sleep, and promote feelings of support in this population. ${ }^{66}$ Authors of a few studies have reported significant increases in short-term QoL for patients with cancer who received massage..$^{29,79}$

Massage therapy is frequently used by patients with cancer in hopes of reducing symptoms that impair functional status and QoL; ${ }^{11,13,50,55}$ therefore, massage may be useful for patients undergoing ASCT. Similar to previous study data, ${ }^{3,66}$ a structured interview study conducted with 10 patients who had received ASCT over the previous year revealed that those with cancer were very receptive to the use of massage therapy during hospitalization. ${ }^{65}$ The patients ( 5 women and 5 men) had a variety of cancers (six different types) and had undergone transplantation an average of 3.8 months earlier. The focus of this formative study was the exploration of patient attitudes toward the use of massage and other relaxation therapies during the inpatient and outpatient phases of 
ASCT treatment. Patients interviewed were very receptive to the use of massage during ASCT: all 10 patients $(100 \%)$ reported a favorable view of massage use during ASCT, although 2 patients $(20 \%)$ indicated that they may have refused massage immediately after transplantation given the severity of their symptoms. Five patients $(50 \%)$ had used massage in the past for relaxation, stress reduction, pain, anxiety, and other symptoms. ${ }^{65}$

Unlike many relaxation therapies, massage can be effective for patients with low imagery abilities or limited cognitive ability as well as for those with reduced concentration and/or fatigue. ${ }^{75}$ Similar to acupuncture and relaxation, ${ }^{23}$ massage can produce stronger effects when introduced early in disease treatment and reinforced thereafter. A series of massages may have a cumulative effect in patients with cancer.

These findings are further supported by results from a growing number of controlled prospective trials demonstrating positive effects of massage on anxiety in various medical populations. However, controlled longitudinal studies documenting the effects of massage among patients with cancer are limited, and only four studies have been focused on the potential benefits of massage during bone marrow transplant or ASCT treatment regimens. ${ }^{3,56,66}$ A summary of the four studies follows.

In the study by Ahles and colleagues, ${ }^{3} 31$ adult patients were randomized to receive nine 20- to 30 -minute massages (three massages a week over the 3 weeks of the acute admission phase) or standard medical treatment. Assessments were made before and after the initial, fifth, and final (prior to discharge) massages. Measures included the State-Trait Anxiety Inventory, Beck Depression Inventory, Profile of Mood States-Short Form, and numeric rating scales of distress, fatigue, nausea, and pain. Massages were 
provided by the same experienced massage therapist for all participants in the intervention group. The areas massaged included the head, face, neck, and shoulders. Participants receiving the massages reported an immediate reduction in distress, fatigue, nausea, and state anxiety with the first massage, a decrease in state anxiety at midtreatment, and less fatigue at pre-discharge compared with the standard care group. Both groups showed significant declines over time on the Profile of Mood States and StateTrait Anxiety Inventory.

Smith and colleagues ${ }^{66}$ conducted a randomized control study of adult patients receiving a bone marrow transplant. Patients were randomized to one of three study arms: therapeutic touch, massage therapy, or friendly visit (control) groups. Eighty-eight participants were enrolled in the study. Participants were stratified based on the type of transplant (autologous or allogenic). A standardized protocol began the day of chemotherapy and was administered every third day through discharge from the program for each arm of the study. In the massage study arm, nurse-massage therapists provided 30-minute massages. Variables evaluated were time for engraftment, complications during treatment, and a patient's perceptions of therapy benefit. There were no differences in the time to engraftment. A significantly lower score for neurological complications was noted for the massage therapy group compared with the friendly visit/control group. Perceived benefit was statistically significant for the massage therapy group compared with the friendly visit/control group. Massage was generally most effective at the beginning of treatment when symptom discomfort scores were highest. The mean comfort score scales were higher for both massage and therapeutic touch 
groups compared with the friendly visit/control group. There was a $50 \%$ dropout rate in the study.

Phipps ${ }^{56}$ evaluated pediatric patients (ages 1-20) undergoing autologous and allogeneic bone marrow transplants using multiple interventions that included imagery, humor therapy, emotional expression therapy, and massage therapy (taught to and administered by the parents). Behavioral, Affective, and Somatic Experiences Scales (BASES) developed by the investigator were obtained at baseline and weekly through week 6 posttransplant and then monthly until 6 months posttransplant from parents, from patients 5 years and older, and from nurses during the in-hospital phase. Massage was taught to the parents by massage therapists, and the parents provided 15-minute daily massages. The first pilot study $(N=21)$ examined the feasibility and logistics of implementing the four interventions with each participant. The patients and parents rated the benefits of the four interventions from highest to lowest as follows: massage, humor therapy, imagery, and self expression. The authors did not report the results of the BASES.

In a second pilot study conducted to evaluate modes of massage delivery for pediatric patients undergoing bone marrow transplantation, researchers randomized participants to receive professional massage, parent massage, or no massage. Childreported somatic distress was less in both massage intervention groups than in the control group. $^{57}$

Authors of two studies ${ }^{3,66}$ reported encouraging short-term effects of massage on distress, anxiety, fatigue, nausea, and ability to sleep in adults undergoing bone marrow 
transplantation. In the study by Smith and colleagues, ${ }^{66}$ patients in the massage treatment group reported greater comfort, ability to sleep, relaxation, and peacefulness and less anxiety than those in the friendly visit/control group.

Longer treatment sessions over extended intervention periods offer greater treatment effects and contribute to the cumulative benefits of massage. ${ }^{19,71}$ A study by Taylor and colleagues ${ }^{71}$ demonstrated modest outcomes with a less intensive (50 minute massages once a day for 3 days) massage intervention. Data from several studies lend support to this finding. After receiving massages 3 times a week during hospitalization, patients who had been treated with ASCT had significant improvements in nausea, distress, anxiety, and mood compared with the control group. ${ }^{3}$ In a convenience sample of 113 hospitalized patients who received from one to four massages over the course of their hospitalization, 25 (35\% of the 70 patients completing a questionnaire) reported that benefits of massage persisted for more than 1 day. ${ }^{67}$

Whereas whole-body massages provided by professional massage therapists generally last 40 to 60 minutes in duration, clinical studies of massage have almost exclusively involved the use of massage sessions lasting 5 to 30 minutes. ${ }^{19,63}$ There is a need for researchers to mirror practice regimens with massage sessions longer than 30 minutes in duration. Patients often experience considerable distress prior to ASCT as well as during and after transplantation. ${ }^{23,49}$ Longer massage sessions may produce stronger effects, especially when the sessions are introduced early in treatment and reinforced thereafter. 


\section{Massage Effects in Relation to Stress}

Massage alters the body's biochemistry immediately after massage sessions and over the course of massage treatment periods. ${ }^{17}$ Cortisol and catecholamine (epinephrine and norepinephrine) release occurs in response to stress. Cortisol increases following experimentally induced stress and decreases after relaxing therapies such as massage in the setting of job stress, depression, human immunodeficiency virus, and cancer. Cortisol has been labeled as a culprit variable in killing immune cells, especially natural killer (NK) cells. The NK cells spontaneously destroy a wide variety of cancer and virusinfected cells and are involved in eliminating metastases. Cortisol decreases across medical conditions following massage therapy. ${ }^{17}$ In an exploratory study of healthy humans, massage increased both $\mathrm{T}$ and $\mathrm{B}$ lymphocyte proliferation. ${ }^{43}$

Massage can activate the release of serotonin and dopamine. Serotonin enhances the production of dopamine and hampers the production of cortisol. Dopamine reduces depression and its stress-related effects. ${ }^{17}$ In parkinsonian patients who received 30 minute massages twice a week for 5 weeks, epinephrine and norepinephrine levels decreased in comparison with levels in patients in the progressive muscle relaxation group, suggesting that those who received the massages were less stressed. ${ }^{31}$

Following 30-minute connective tissue massages provided by an occupational therapist in patients with pain syndromes, there was an increase in $\beta$-endorphins, naturally occurring opioids. ${ }^{36}$ In depressed patients, lower salivary cortisol, epinephrine, and urinary cortisol levels were documented immediately after 30-minute massage sessions. ${ }^{18}$ 
Patients who had received hand massages prior to cataract surgery under local anesthesia exhibited lower psychological anxiety levels, systolic and diastolic blood pressure, and pulse rates following massage therapy. Epinephrine and norepinephrine levels decreased in the experimental group, whereas these levels increased in the control group. ${ }^{38}$ The control group continued to release stress hormones, whereas the stress hormone levels decreased in the experimental group.

In hospice patients, slow-stroke back massage decreased heart rate and blood pressure and led to an increase in skin temperature. The changes in vital signs were indicative of relaxation. ${ }^{47}$ In 24 women with premenstrual syndrome, 5-week sessions of massage therapy reduced pain and water retention as well as overall menstrual distress. ${ }^{32}$ In comparing the effectiveness of acupuncture, therapeutic massage, and self-care education for chronic low-back pain, researchers found therapeutic massage more effective in providing long-lasting benefits than Chinese medical acupuncture and self care. ${ }^{9}$ Eight 30 -minute massages of the cranial and cervical muscles by a trained massage therapist over a 4-week period led to a reduction in headache frequency and duration in patients with chronic tension headaches, although headache intensity was not affected. ${ }^{61}$ Hospitalized patients reported increased relaxation, well-being, and mood, which led to enhanced mobility, increased energy, increased treatment participation, and shortened recovery times. ${ }^{67}$

\section{Massage in Critically Ill Patients}

Massage improved the quality of sleep in critically ill older men with 6-minute nighttime back rubs provided by nurses. ${ }^{63}$ Intensive care unit patients between the ages of 
19 and 81 had significant transient decreases in heart rate, blood pressure, and respirations during 5-minute foot massages. ${ }^{27}$

\section{Social Support and Isolation for Patients Undergoing ASCT}

Perceived social support is important in this patient population. One of the most important factors in proceeding well through the ASCT procedure is the support of family and friends. ${ }^{65}$ Patients who report greater positive social support from family and friends may exhibit less treatment-related distress and better QoL as well as superior cardiovascular and immune function. ${ }^{37,74}$

Patients receiving ASCT experience social and physical isolation due to treatment regimens. Physical touch in the seriously ill patient has been poorly addressed by traditional medical interventions. ${ }^{40}$ Comforting touch during nursing interventions is essential, especially for vulnerable patients whose care must be provided with gloves because of isolation precautions. ${ }^{6}$ However, there has been little research on patient perception of touch while in isolation or associated with glove use by healthcare providers. Likewise, no research has been conducted on massage therapists' perceptions or difficulty with technique while using gloves.

\section{Conclusion}

The purpose of this manuscript was to explore the use of massage therapy in cancer patients undergoing ASCT, a highly stressful cancer treatment. These patients experience anxiety, depression, pain, nausea, vomiting, stress, and a poor health-related QoL during the ASCT process. Often they do not respond to conventional pharmacological/medical approaches to treat their symptoms, making them highly 
vulnerable to short- and long-term threats to QoL.

Massage has been recommended to assist patients with cancer- and treatmentrelated symptoms, ${ }^{1}$ although only four clinical trials have been focused on the effects of massage on outcomes in patients undergoing ASCT. Given the need for further research on adjunctive supportive care and complementary medical interventions with the potential to assist these patients, further studies are needed to address the efficacy of massage therapy. Additionally, further research is needed on patient perceptions of massage and touch with barrier protection (gloves) as massage can decrease stress in patients with cancer during and after ASCT and can augment their QoL. 


\section{References}

1. Agency for Health Care Policy and Research: Management of Cancer Pain: Clinical Practice Guideline, No. 9. Silver Spring, MD, AHCPR Clearinghouse, DHHS Pub. No. 94-0592, 1994

2. Ahlberg K, Elkman T, Gaston-Johansson F, et al: Assessment and management of cancer-related fatigue in adults. Lancet 362:640-650, 2003

3. Ahles TA, Tope DM, Pinkson B, et al: Massage therapy for patients undergoing autologous bone marrow transplantation. J Pain Symptom Manage 18:157-163, 1999

4. Anderson BL, Kiecolt-Glaser JK, Glaser R: A biobehavioral model of cancer stress and disease course. Am Psychol 49:389-404, 1994

5. Buchsel PC, Whedon MB (eds): Bone Marrow Transplantation: Administration and Clinical Strategies, Boston, MA, Jones \& Bartlett, 1995

6. Butts JB, Janes S: Transcending the latex barrier: the therapeutics of comfort touch in patients with acquired immunodeficiency syndrome. Holist Nurs Pract $10: 61-67,1995$

7. Cameron CI, Cella D, Herndon JE, et al: Persistent symptoms among survivors of Hodgkin's disease: an explanatory model based on classical conditioning. Health Psychol 20:71-75, 2001

8. Chan YM, Ngan HY, Li BY, et al: A longitudinal study on quality of life after gynecological cancer treatment. Gynecol Oncol 83:10-19, 2001

9. Cherkin DC, Eisenberg D, Sherman KJ, et al: Randomized trial comparing 
traditional Chinese medical acupuncture, therapeutic massage, and self-care education for chronic low back pain. Arch Intern Med 161:1081-1088, 2001

10. Churchill AQ: Massage, its physiologic effects. Am J Nurs 15:635-636, 1915

11. Crocetti E, Crotti N, Feltrin A, et al: The use of complementary therapies by breast cancer patients attending conventional treatments. Eur J Cancer 34:324328,1998

12. Felhendler D, Björn L: Pressure on accupoints decreases postoperative pain. Clin J Pain 12:326-329, 1996

13. Fellowes D, Barnes K, Wilkinson S: Aromatherapy and massage for symptom relief in patients with cancer. Cochrane Database of Systematic Reviews, Issue 3, Art No: CD002287, 2004, DOI: 10.1002/14651858.CD002287.pub2

14. Ferrell-Torry AT, Glick OJ: The use of therapeutic massage as a nursing intervention to modify anxiety and the perception of cancer pain. Cancer Nurs 16:93-101, 1993

15. Field T: Massage therapy. Med Clin North Am 86:163-171, 2002

16. Field T, Grizzle N, Scafidi F, et al: Massage and relaxation therapies' effects on depressed adolescent mothers. Adolescence 31:903-911, 1996

17. Field T, Hernandez-Reif M, Diego M, et al: Cortisol decreases and serotonin and dopamine increase following massage therapy. Int J Neurosci 11:1397-1413, 2005

18. Field T, Quintino O, Henteleff T, et al: Job stress reduction therapies. Alt Ther Health Med 3:54-56, 1997 
19. Field TM: Massage therapy effects. Am Psychol 53:1270-1281, 1998

20. Flechtner H, Bottomley A: Fatigue and quality of life: lessons from the real world. Oncologist 8:5-9, 2003 (suppl 1)

21. Fritz S: Mosby's Fundamentals of Therapeutic Massage, St. Louis, MO, Mosby, 2000

22. Fung HC, Nademanee AP: Approach to Hodgkin's lymphoma in the new millennium. Hematol Oncol 20:1-15, 2002

23. Gaston-Johansson F, Fall-Dickson JM, Nanda JP, et al: The effectiveness of the Comprehensive Coping Strategy Program on clinical outcomes in breast cancer autologous bone marrow transplantation. Cancer Nurs 23:277-285, 2000

24. Gaston-Johansson F, Foxall M: Psychological correlates of quality of life across the autologous bone marrow transplant experiences. Cancer Nurs 19:170-176, 1996

25. Grealish L, Lomasney A, Whiteman B: Foot massage: a nursing intervention to modify the distressing symptoms of pain and nausea in patients hospitalized with cancer. Cancer Nurs 23:237-243, 2000

26. Gruber U, Fegg M, Buchamann M, et al: The long-term psychological effects of haematopoetic stem cell transplantation. Eur J Cancer Care 12:249-256, 2003

27. Hayes J, Cox C: Immediate effects of a five-minute foot massage on patients in critical care. Intensive Crit Care Nurs 15:77-82, 1999

28. Herbert TB, Cohen S: Depression and immunity in humans: a meta-analytic review. Psychol Bull 113:472-486, 1993 
29. Herbert TB, Cohen S: Stress and immunity in humans: a meta-analytic review. Psychosom Med 55:364-379, 1993

30. Hernandez M, Field T, Largie S, et al: Parkinson's disease symptoms are differentially affected by massage therapy vs. progressive muscle relaxation: a pilot study. J Bodywork Mov Ther 6:177-182, 2002

31. Hernandez-Reif M, Field T, Krasnegor J, et al: Low back pain is reduced and range of motion increased after massage therapy. Int J Neurosci 106:131-145, 2001

32. Hernandez-Reif M, Martinez A, Field T, et al: Premenstrual symptoms are relieved by massage therapy. J Psychosom Obstet Gynecol 21:9-15, 2000

33. Hulme J, Waterman H, Hillier VF: The effect of foot massage on patients' perception of care following laparoscopic sterilization as day case patients. $J A d v$ Nurs 30:460-468, 1999

34. Imrie K, Esmail R, Meyer RM, et al: The role of high-dose chemotherapy and stem-cell transplantation in patients with multiple myeloma: a practice guideline of the Cancer Care Ontario Practice Guidelines Initiative. Ann Intern Med $136: 619-629,2002$

35. Jassak PF, Riley MB: Autologous stem cell transplant. Cancer Pract 2:141-145, 1994

36. Kaada B, Torsteinbo O: Increase of plasma $\beta$-endorphins in connective tissue massage. Gen Pharmacol 20:487-489, 1989

37. Kamarck TW, Peterman AH, Raynor DA: The effects of the social environment 
on stress-related cardiovascular activation: current findings, prospects, and implications. Ann Behav Med 20:247-256, 1998

38. Kim MS, Cho KS, Woo HM, et al: Effects of hand massage on anxiety in cataract surgery using local anesthetic. J Cataract Refract Surg 27:884-890, 2001

39. Kotani N, Hashimoto H, Sato Y, et al: Preoperative intradermal acupuncture reduces postoperative pain, nausea, vomiting, analgesic requirement, and sympathoadrenal responses. Anesthesiol 95:349-356, 2001

40. Lafferty WE, Downey L, McCarty RL, et al: Evaluating CAM treatment at the end of life: a review of clinical trials for massage and meditation. Complement Ther Med 14:100-112, 2006

41. Larsen J, Nordström G, Björkstrand B, et al: Symptom distress, functional status and health-related quality of life before high-dose chemotherapy with stem-cell transplantation. Eur J Cancer Care 12:71-80, 2003

42. Leukemia and Lymphoma Society: Blood and marrow stem cell transplantation. http://www.leukemia-lymphoma.org/all_page?item_id=5965

43. Lovas JM, Craig AR, Raison RL, et al: The effects of massage therapy on the human immune response in healthy adults. J Bodywork Mov Ther 3:143-150, 2002

44. McGuire DB, Yeager KA, Dudley WN, et al: Acute oral pain and mucositis in bone marrow transplant and leukemia patients: data from a pilot study. Cancer Nurs 21:385-393, 1998

45. McNamara ME, Burnham DC, Smith C, et al: The effects of back massage before 
diagnostic cardiac catheterization. Alt Ther Health Med 9:50-57, 2003

46. McQuellon RP, Russell GB, Cella DF, et al: Quality of life measurement in bone marrow transplantation: development of the Functional Assessment of Cancer Therapy-Bone Marrow Transplant (FACT-BMT) scale. Bone Marrow Transplant 19:357-368, 1997

47. Meek SS: Effects of slow stroke back massage on relaxation in hospice clients. Image J Nurs Scho 25:17-21, 1993

48. Molassiotis A, van den Akker OB, Milligan DW, et al: Symptom distress, coping style and biological variables as predictors of survival after bone marrow transplantation. J Psychosom Res 42:275-285, 1997

49. Molassiotis A, Yung HP, Yam BM, et al: The effectiveness of progressive muscle relaxation training in managing chemotherapy-induced nausea and vomiting in Chinese breast cancer patients: a randomized controlled trial. Support Care Cancer 10:237-246, 2002

50. Morris KT, Johnson N, Homer L, et al: A comparison of complementary therapy use between breast cancer patients and patients with other primary tumor sites. Am J Surg 179:407-411, 2000

51. National Institutes of Health Technology Assessment Panel on Integration of Behavioral and Relaxation Approaches into the Treatment of Chronic Pain and Insomnia: Integration of behavioral and relaxation approaches into the treatment of chronic pain and insomnia. JAMA 276:313-318, 1996

52. Neitzert CS, Ritvo P, Dancey J, et al: The psychosocial impact of bone marrow 
transplantation: a review of the literature. Bone Marrow Transplant 22:409-422, 1998

53. Ni H, Simile C, Hardy AM: Utilization of complementary and alternative medicine by United States adults: result from the 1999 National Health Interview Survey. Med Care 40:353-358, 2002

54. Palinkas L, Kabongo M: The use of complementary and alternative medicine by primary care patients: a SURF*NET study. J Fam Pract 49:1121-1130, 2000

55. Pan CX, Morrison S, Ness J, et al: Complementary and alternative medicine in the management of pain, dyspnea, and nausea and vomiting near the end of life: a systematic review. J Pain Symptom Manage 20:374-382, 2000

56. Phipps S: Reduction of distress associated with paediatric bone marrow transplant: complementary health promotion interventions. Pediatr Rehabil 5:223243, 2002

57. Pico JL, Avila-Garavito A, Naccache P: Mucositis: its occurrence, consequences, and treatment in the oncology setting. Oncologist 3:446-451, 1998

58. Podestà M: Transplantation hematopoiesis. Curr Opin Hematol 8:331-336, 2001

59. Portenoy RK, Itri LM: Cancer-related fatigue: guidelines for evaluation and management. Oncologist 1:1-10, 1999

60. Preyde M: Effectiveness of massage therapy for subacute low-back pain: a randomized controlled trial. Can Med Assoc J 162:1815-1820, 2000

61. Quinn C, Chandler C, Moraska A: Massage therapy and frequency of chronic tension headaches. Am J Public Health 92:1657-1661, 2002 
62. Redd WH, Montgomery GH, DuHamel KN: Behavioral interventions for cancer treatment side effects. J Natl Cancer Inst 93:810-823, 2001

63. Richards K: Effect of a back massage and relaxation intervention on sleep in critically ill patients. Am J Crit Care 7:288-299, 1998

64. Richards KC, Gibson R, Overton-McCoy AL: Effects of massage in acute and critical care. Advanced Pract Acute Crit Care 11:77-96, 2000

65. Rodeheaver PF, Taylor AG, Lyon DE: Incorporating patients' perspectives in clinical trial design. J Alt Complement Medicine 9:859-967, 2003

66. Smith MC, Reeder F, Daniel L, et al: Outcomes of touch therapies during bone marrow transplant. Alt Ther Health Med 9:40-49, 2003

67. Smith MC, Stallings MA, Mariner S, et al: Benefits of massage therapy for hospitalized patients: a descriptive and qualitative evaluation. Alt Ther Health Med 5:64-71, 1999

68. Stelfox HT, Bates DW, Redelmeier DA: Safety of patients isolated for infection control. JAMA 290:1899-905, 2003

69. Stephenson NL, Weinrich S, Tavakoli AS: The effects of foot reflexology on anxiety and pain in patients with breast and lung cancer. Oncol Nurs Forum 27:67-72, 2000

70. Taylor AG, Galper DI, D’Huyvetter K, et al: Pain, in Spencer JW, Jacobs JJ (eds): Complementary and Alternative Medicine: An Evidence-Based Approach, 2nd ed, St. Louis, MO, Mosby, 2003, pp 311-408

71. Taylor AG, Galper DI, Taylor P, et al: Effects of adjunctive Swedish massage and 
vibration therapy on short-term postoperative outcomes: a randomized, controlled trial. J Alt Complement Med 9:77-89, 2003

72. Testa MA, Simonson DC: Assessment of quality-of-life outcomes. $N$ Engl J Med 334:835-840, 1996

73. Thompson PB, Lambert JV: Touch sensitivity through latex gloves. J Gen Psychol 122:47-58, 1995

74. Uchino BN, Cacioppo JT, Kiecolt-Glaser JK: The relationship between social support and physiological processes: a review with emphasis on underlying mechanisms and implications for health. Psychol Bull 119:488-531, 1996

75. Walker LG, Walker K, Ogston K, et al: Psychological, clinical and pathological effects of relaxation training and guided imagery during primary chemotherapy. Br J Cancer 80:262-268, 1999

76. Ward D: Infection control: reducing the psychological effects of isolation. $\mathrm{Br} J$ Nurs 9:162-170, 2000

77. Watson M, Meyer L, Thomson L, et al: Psychological factors predicting nausea and vomiting in breast cancer patients on chemotherapy. Eur J Cancer 34:831837,1998

78. Weinrich SP, Weinrich MC: The effect of massage on pain in cancer patient. Appl Nursing Res 3:140-145, 1990

79. Wilkie DJ, Kampbell J, Cutshall S, et al: Effects of massage on pain intensity, analgesics and quality of life in patients with cancer pain: a pilot study of a randomized clinical trial conducted within hospice care delivery. Hosp J 15:31- 
53, 2000 


\author{
Manuscript 3 \\ Effects of Massage Therapy on Quality of Life Outcomes \\ for Autologous Stem Cell Transplant Patients
}

Proposed submission to:

Complementary Therapies in Medicine

Impact factor for this journal is 1.362 . 
Effects of Massage Therapy on Quality of Life Outcomes for Autologous Stem Cell Transplant Patients

Audrey Snyder, PhD(c), RN, MSN, ACNP, CMT

University of Virginia

Charlottesville, Virginia 


\section{Abstract}

Background: Patients with cancer undergoing autologous stem cell transplantation (ASCT) endure a series of stressors and adverse symptoms throughout treatment, resulting in greatly impaired quality of life $(\mathrm{QoL})$.

Objectives: To investigate the immediate and cumulative effects of massage on stress, relaxation, and comfort, explore effects of massage on anxiety, pain, and QoL outcomes, and identify the benefits of and barriers to patient acceptance of massage during phases of the ASCT process in individuals undergoing ASCT for cancer.

Methods: This pilot project used a mixed methods, unmasked, prospective, randomized experimental design. Baseline demographics and history, health-related QoL, state anxiety, perceived stress, comfort, and relaxation levels, pain, and social support were assessed. Descriptive statistics and graphing techniques were used to analyze the data. Results: An immediate effect in stress reduction, increased relaxation, and increased comfort were identified post massage. Cumulative effects of massage over transplant phases were not seen in the massage group. Participants in the massage group also reported lower anxiety scores across the transplant phases and lower affective and sensory pain scores during hospitalization following transplant than those in the SMC alone group. Perceived benefits of massage for the participants included improvement in symptoms that they had been experiencing prior to undergoing ASCT as well as their current treatment-related symptoms.

Discussion: It is feasible to provide massage across the continuum of outpatient, inpatient, and home settings to patients undergoing ASCT. Supportive care massage can 
have immediate effects on stress, comfort, and relaxation and improve treatment-related symptoms for patients undergoing ASCT.

Keywords: Hematopoetic stem cell transplant (ASCT), quality of life, massage 
Effects of Massage Therapy on Quality of Life Outcomes for Autologous Stem Cell Transplant Patients

\section{Introduction}

Leukemia, myeloma, lymphoma, and breast cancer are diseases frequently treated with Autologous Stem Cell Transplant (ASCT ) (Fung, \& Nademanee, 2002; Neitzert, Ritvo, Dancey, Weiser, Murray, \& Avery, 1998). Over 9,000 stem cell transplantations occur yearly in the United States (Leukemia and Lymphoma Society, 2002) with the intent to cure the disease or prolong survival (Buchsel \& Whedon, 1995). High-dose chemotherapy and/or whole-body radiation are used to eradicate the cancer, followed by infusion of the patient's previously harvested bone marrow or peripheral blood stem cells (Imrie et al., 2002; Jassak \& Riley, 1994). Treatment-related morbidity and mortality have decreased over the past decade. Patients with cancer who undergo ASCT experience an intense treatment regimen and endure a series of stressors and adverse symptoms throughout treatment, resulting in greatly impaired quality of life (QoL) (Imrie et al., 2002; Rodeheaver, Taylor, \& Lyon 2003).

The ASCT process entails several distinct phases. Patients are hospitalized or treated daily as outpatients for stem cell collection from the bone marrow. Cell collection involves daily chemotherapy for three to five days, and supplementation with growth factors to stimulate cell proliferation. Patients then undergo several days of stem cell collection from blood and bone marrow (if necessary) followed by hospitalization approximately one week later for a one to three week period for conditioning with 
myeloablative chemotherapy and/or radiation (usually two to five days), followed by transplantation of the harvested cells. Most patients respond to transplant with repopulation of the cells within two weeks of transplant. Patients stay in-hospital for several weeks following stem cell transplant. Following discharge patients may stay in the local community for continued outpatient assessment and treatment if they live long distances from the transplant center. ASCT recipients display a prolonged period of immune dysfunction and remain vulnerable to various threats to health status, including opportunistic infections and anemia that may require blood transfusions.

The stressors and adverse symptoms experience by patients during ASCT treatment result in a greatly impaired quality of life (QoL). Patients face life-threatening medical therapies after adjustment to their diagnosis, numerous aversive procedures, travel, unemployment, financial strain, physical isolation, and separation from social support networks (Molassiotis, van den Akker, Milligan, \& Goldman, 1997; Rodeheaver, Taylor, \& Lyon, 2003). Distress, anxiety, depression, pain, nausea, and vomiting are commonly reported symptoms before ASCT (Cameron et al., 2001; Gaston-Johansson \& Foxall, 1996). Patients undergoing ASCT confront a challenging array of treatmentrelated physical, emotional, and behavioral stressors and symptoms, resulting in impaired QoL prior to and up to 12 months following ASCT (Andrykowski, et al., 2005; GastonJohansson et al., 2000; McQuellon et al., 1997; Neitzert et al., 1998). These symptoms are often difficult to manage by conventional medicine alone (Pico, Avila-Garavito, \& Naccache, 1998; Portenoy \& Itri, 1999). Patients receiving ASCT experience social and physical isolation due to treatment regimens and separation from family and significant 
others. These patients are on protective isolation for immunosuppression for 7 to 10 days following transplant. Isolation measures may be continued for opportunistic infections. Touch plays a large role in patients' perception of comfort. Comforting touch in nursing interventions is essential for patients on isolation where gloves are required to provide basic care (Butts \& Janes, 1995). Touch provided through massage has the potential to comfort patients and have a positive effect on patient outcomes.

The need for early intervention with adjunctive therapies to diminish stress reactivity and treatment-related distress has been identified (Gaston-Johansson et al., 2000). Preliminary research suggests that adjunctive massage therapy may improve adverse symptoms and QoL of patients during treatment for cancer, without the side effects associated with conventional pharmacological treatments (Ahles et al., 1999; Field, 1998, Field, 2002; Richards, Gibson, \& Overton-McCoy, 2000; Smith et al., 2003; Taylor, Galper, D’Huyvetter et al., 2003; Taylor, Galper, Taylor et al., 2003). Many patients with cancer use complementary and alternative medicine (CAM) modalities, including massage, to improve symptoms (Morris, Johnson, Homer, \& Walts, 2000). Mucositis, or disruption of the function and/or integrity of the gastrointestional mucosa resulting in oral mucositis, nausea, vomiting and diarrhea, is a common complication of the high-dose chemotherapy used in the ASCT process and has been associated with reduced survival following ASCT in patients with lymphoid malignancies (Fanning et al., 2006). Emotional distress, pain, fatigue, and nausea and vomiting are frequently reported symptoms of patients undergoing ASCT (Gaston-Johansson \& Foxall, 1996; McQuellon et al., 1997). 
Preliminary studies in patients undergoing conventional cancer care indicate that various types of massage can reduce distress (Ahles et al., 1999; Phipps, 2002; Smith et al., 2003; Taylor, Galper, D’Huyvetter et al., 2003; Taylor, Galper, Taylor et al., 2003), anxiety (Ahles et al., 1999; Fellowes, 2004, Menard, 1995), pain (Grealish, Lomasney, \& Whiteman, 2000; Weinrich \& Weinrich, 1990), fatigue (Ahles et al., 1999), and nausea (Ahles et al., 1999; Grealish et al., 2000). These findings are further supported by a growing number of controlled prospective trials demonstrating positive effects of massage on anxiety in various medical populations (Ferrell-Torry \& Glick, 1993; Menard, 1995; Stephenson, Weinrich, \& Tavakoli, 2000).

Only four studies, reported in three research articles, have examined the potential benefits of massage during ASCT (Ahles et al., 1999; Smith et al., 2003; Phipps, 2002). Two studies (Ahles et al., 1999; Smith et al., 2003) reported short-term effects of massage on distress, anxiety, fatigue, nausea, and ability to sleep in adults undergoing bone marrow transplantation. Massage was generally most effective at the beginning of treatment, when symptoms were highest. However, the intervention entailed only 20- to 30 -minute treatment sessions during the acute phase of hospitalization, and one investigator called for further research to understand fully the impact of massage therapy on QoL for these patients (Ahles et al., 1999). Pediatric patients reported decreased distress with daily 15 -minute parent provided massages post-transplant in two studies by Phipps described within the same research article (2002). Patients often experience considerable distress prior to ASCT, as well as during or after ASCT (Gaston-Johansson et al., 2000; Molassiotis, Yung, Yam, Chan, \& Mok, 2002). 


\section{Theoretical Framework}

The objectives of this study were to: (1) explore differences in anxiety, pain, and QoL outcomes in the massage group compared to the SMC group; (2) investigate the immediate and cumulative effects of massage on stress, relaxation, and comfort in the massage group; and (3) to identify the benefits of and barriers to patient acceptance of massage during phases of the ASCT process in individuals undergoing ASCT for cancer. Psychoneuroimmunology is presented as a theoretical model for the interaction between psychological process, biological factors, and health behaviors that influence QoL via processes involving neuroendocrine and immune mechanisms. The primary model used for the research intervention was adapted from the psychoneuroimmunology and health psychology integrative model by Lutgendorf and Costano (2003) (See Figure 1). The interaction between psychological process (Box A) biological factors (Box B), and health behaviors (Box C) influences QoL via processes involving neuroendocrine and immune mechanisms. Effects of life stress (e.g., ASCT) are filtered through psychosocial processes (Box A) of anxiety, social support resources and feelings of comfort, and health behaviors (Box C) such as sleep. Complementary therapies can modulate effects of psychosocial processes and health behaviors, decreasing treatment-related symptoms and influencing QoL (Box G). Complementary therapies, such as massage, can be used to alter psychosocial processes (Box A, e.g., decrease anxiety, improve social support, increase feelings of comfort) or improve health behaviors such as sleep (Box C) to improve treatment-related symptoms of pain, distress, nausea, and vomiting (Box F). 


\section{Methods}

The study investigators had proposed to use a mixed-methods, unmasked, prospective, randomized experimental design with participants assigned to a standard medical care (SMC) alone control group or a massage plus standard medical care intervention group (hereafter referred to as massage group) with repeated measures. However, the ASCT clinic in the medical center where recruitment was occurring closed unexpectedly 6 months into the study period. Travel distance to another ASCT transplant center and the complexity of the study precluded a change in setting from which to recruit potential study participants.

\section{Subjects}

Potential study participants were identified in the clinic when they presented for pre-transplant evaluation. All patients were recruited into the study 1 to 2 weeks prior to admission for mobilization chemotherapy. Potential candidates were patients who met the following criteria: (1) scheduled to undergo ASCT for the treatment of cancer at an academic medical center Stem Cell Transplant Clinic, (2) age 18 years or older, (3) able to understand the consent form (written at Grade 5-8 level) and complete the pencil and paper instruments, (4) had a platelet count $\geq 15,000 / \mathrm{mm}^{3}$, (5) could be contacted by phone, and (6) were willing to abide by the proposed protocol and complete the assessments. Criteria for exclusion were: (1) regular use of massage ( $>1$ massage/month) prior to enrollment in the study, (2) current thrombosis or phlebitis because of the potential danger of dislodging a clot that could lead to an embolism, and (3) the presence of anxiety or depression that remained uncontrolled on medication. Potential participants 
were approached by the study coordinator, who (1) checked eligibility criteria, (2) invited patients to learn about the study; and (3) obtained informed consent from those patients interested in the study. Human Subject Committee and Cancer Center Protocol Committee approvals were obtained prior to enrolling participants in the study.

Following completion of the consent form and baseline assessments, study participants were stratified by gender because of possible differences between men and women in response to massage (Altemus et al., 2001; Labyak \& Metzger, 1997). Participants were then randomly assigned by computer randomization, with probabilities in a ratio of 1:1, to one of two groups: (1) SMC alone group; or (2) massage group. Participants in both SMC alone and massage groups received $\$ 50$ compensation for the return of baseline and each weekly assessment for a total of $\$ 400$.

\section{Measurements}

Self report and objective measures of QoL symptoms were collected from participants in the massage and SMC alone groups weekly throughout the 7-week study. Briefly, participants completed and returned demographic data and medical history forms prior to group assignment. At baseline the following questionnaires were completed by all participants: the European Organization for Research and Treatment core questionnaire (QLQ-C30), State scale of the State Trait Anxiety Inventory, McGill Pain Questionnaire, and Medical Outcome Study-Social Support Survey to evaluate the constructs of QoL, anxiety, pain, and social support respectively. QoL symptom questionnaires and the social support survey were completed by all participants. The same assessments were repeated weekly by participants in the SMC group and by 
participants in the massage group on specified non-massage days weekly through the 7week intervention (see Table 1). The therapists completed the massage checklist before and after each massage session and asked the participants to identify comfort, relaxation, and stress on numeric rating scales (NRS) prior to and immediately following each massage. All medical information provided by a participant was cross-validated against the participant's medial record or with the Stem Cell Transplant Clinic staff. A therapist pre-study and post-study questionnaire evaluated the massage therapist experience.

\section{Demographic Form}

A one-page demographic form developed by the study team included: age, gender, racial category, ethnicity, years of education, and marital status. The study coordinator recorded these data upon enrollment of the participant.

\section{Medical History Form}

A medical history form was used to document type, stage, and location of cancer, prior history of cardiovascular disease, surgeries and injuries, medications, and diabetes. The form also assessed past and current use of CAM therapies and psychotherapy.

\section{Health-related Quality of Life}

The European Organization for Research and Treatment (EORTC) core questionnaire (QLQ-C30) reflects the multidimensionality of the QoL construct for patients with cancer (Aaronson et al., 1993). It was administered using procedures reported in Kiebert, Curran \& Aaronson (1998). The EORTC QLQ-C30 is one of the most widely used and validated measures of QoL for patients with cancer (Aaronson et al, 1993). The QLQ-C30 includes 30 items comprising five functional scales (physical, 
role, cognitive, emotional, and social), three symptom scales (fatigue, pain, and nausea and vomiting), a global QoL scale (two items), and six single items assessing symptoms (dyspnea, insomnia, appetite loss, constipation, diarrhea) and financial impact (difficulties). Scoring: Responses for the functional scale were "No (1)" and "Yes (2)." Higher mean scores on the global scale and the subscales represent better function and higher QoL. No time frame is referenced for these functional questions. The remaining questions ask the participant to refer to the last week. Responses for the symptom scale items are rated "Not at all (1)", "A Little Bit (2)," "Quite a Bit (3)," and "Very much (4)." Higher means on the symptoms subscales represent more symptomatology and a lower QoL. The global health status/QoL is an 8-point scale (1-7), ranging from "Very poor (1)" to "Excellent (7)." The global QoL scale is a primary measure of QoL. Other scales were also used as exploratory outcomes, as recommended by the developers (Curran et al., 2000). Higher mean scores on the QoL scales represent better function and higher QoL.

State Anxiety

The State-Trait Anxiety Inventory (STAI) (Spielberger, 1989; Spielberger, Gorsuch, \& Lushene, 1970) is the standard instrument to assess anxiety (Schwarzer, 1997). The State Anxiety Inventory (SAI) subscale measures feelings of apprehension, tension, nervousness, and worry. The SAI scale consists of 20 items, rated on a 4-point Likert scale, ranging from "Not at all (1)" to "Very much so(4)," representing low to high anxiety for how a person "feels right at this moment" or emotionally responds to a stressful situation (Spielberger, 1983). The score ranges from 20 to 80 with 20 to 39 
representing low anxiety, 40 to 59 moderate anxiety, and 60 to 80 high anxiety. Scores are reportedly higher under stress conditions (Speilberger, 1983). In this study state anxiety was measured.

\section{Perceived Stress, Comfort, and Relaxation NRS}

Stress, relaxation, and comfort were measured using an 11-point numeric rating scale (NRS). Participants were asked to rate their stress, feeling of relaxation, and comfort on a 0 to 10 scale "at this moment" immediately before and after the massage session. For example, the NRS for stress ranges from 0 (no stress) to 10 (extremely stressed).

NRS is a simple, yet sensitive measure of subjective phenomena and has been used successfully in a previous study of the effects of massage (Delaney, Leong, Watkins $\&$ Brodie, 2002). Validity and reliability of NRS as a measure of symptoms has been demonstrated with established reliability and validity (Ahles, Ruckdeschel \& Blanchard, 1984; Benotsch et al., 2000). NRS for pain strongly correlated (0.85) with visual analog scales (VAS) in patients with cancer pain and in younger adults (Herr, Spratt, Mobily \& Richardson, 2004; Paice \& Cohen, 1997). Hospitalized patients are accustomed to symptom assessment using numeric rating scales in the hospital and clinics. Pain

The McGill Pain Questionnaire, Short-Form (MPQ-SF) (Melzack, 1987) measures sensory and affective aspects of pain. It contains words describing both the sensory and affective components of pain. The sensory descriptors are throbbing, shooting, stabbing, sharp, cramping, gnawing, hot-burning, aching, heavy, tender, and 
splitting. The affective descriptors are:

tiring-exhausting, sickening, fearful, and punishing-cruel. The descriptors are ranked from 0 to 3 (none, mild, moderate, and severe) (Melzack, 1987). The measure also contains two overall measures of pain, the Present Pain Index ( 0 to 5 rating accompanied by descriptive words: no pain, mild pain, discomforting, distressing, horrible and excruciating) and an 11-point numeric rating scale for pain intensity. Verbal anchors are 0 for no pain and 10 for worst pain possible.

\section{Social Support}

The Medical Outcome Study-Social Support Survey (MOS-SSS) (Sherbourne \& Stewart, 1991) was used to assess social support. This 21-item survey has four subscales (emotional/informational support, tangible support, positive interaction, and affection) and an overall index of perceived social support. All but one item is rated on a 5-point Likert scale from "none of the time" to "all of the time." One item asks "About how many close friends and close relatives do you have (people you feel at ease with and can talk to about what is on your mind)?" A higher score indicates higher overall social support.

\section{Massage Checklist}

To evaluate the massage protocol, the investigator developed a checklist to be completed by all therapists before and after each massage administered during the study. The therapist documented the date, time of day, and length of each massage administered. The checklist was used to explore treatment adherence and integrity (deviations from the protocol, environmental barriers to massage in the hospital and 
home) over the course of the intervention. The therapist asked the participant to evaluate the level of stress, relaxation, and comfort "at this moment" using NRS scales prior to, and immediately following, each massage. On the days of the first and last massage the therapists asked participants several open ended questions to document the participant's previous experiences with massage therapy and to evaluate the participants' perceptions of massage provided during the study.

\section{Massage Intervention}

Participants in the massage intervention group were to receive three massages weekly for 7 weeks, for a potential of 21 massages for each participant. The first massage occurred prior to the placement of the participant's central line. The remaining massages were coordinated as much as possible with the participants' scheduled appointments at the Stem Cell Transplant Unit, as well as other outpatient appointments. Many of the patients traveled long distances from their home for cancer care. The massage coordinator scheduled massage sessions so that massages were not given on consecutive day. During periods when participants were at home between phases of treatment, participants received three weekly "in-home" massages to provide continuity of care during the outpatient phases of ASCT, while minimizing treatment barriers and unnecessary participant burdens (e.g., travel). Each study participant was assigned the same therapist for all "at-home" massage sessions, and the same therapist provided all massages at the medical center. Therapists talked weekly with the study coordinator. The clinic staff communicated with the study coordinator if a participant had any concerns (e.g. shingles, compression fractures) that could preclude massaging affected areas of the 
body. The therapist assessed areas of sensitivity and pain. Areas of concern were avoided and other areas of the body were massaged and documented on the massage checklist. The study coordinator communicated any concerns to the therapist. All therapists were female. A standardized massage cream was used for all massage sessions. See Box 1 for the massage protocol.

All participants living within a 30-mile radius of the Cancer Center received massages from a massage therapist affiliated with the Center for the Study of Complementary and Alternative Therapies. The community therapists were recruited in geographic locations throughout the Commonwealth of Virginia.

Following informed consent and randomization, if the participant was randomized to the massage group, a local community massage therapist was identified in the participant's home area so that scheduling and preparations could begin for home massages. The first massage was administered by a therapist prior to central line placement for mobilization chemotherapy in the outpatient environment. Massages were deferred if the participant had a platelet count less than $15,000 / \mathrm{mm}^{3}$. The massage was rescheduled if possible, following platelet transfusion and documentation of an acceptable platelet count to minimize potential bruising or bleeding.

\section{Staff Training}

Two hospital-based and three community-based massage therapists completed the training to participate in providing massage in the study. Three of the therapists were nurse-massage therapists. All were nationally certified by the National Certification Board for Therapeutic Massage and Bodywork and certified by the Virginia Board of 
Nursing, the governing body for massage therapy in the Commonwealth of Virginia. Four of the five therapists $(80 \%)$ were members of the American Massage Therapy Association. The average years of experience with massage therapy was 4.5 years at the start of the study. Four of the five therapists $(80 \%)$ had worked previously with patients with medical conditions; three of the five $(60 \%)$ previously had provided massage to patients in-hospital and had worked on patients who were in hospital beds; all therapists had provided in-home massages. Four of the five therapists $(80 \%)$ previously had worked with patients with cancer. None of the therapists previously had experience working with patients who were receiving bone marrow transplant or stem cell transplant. Two of the five therapists (40\%) previously had provided massages wearing gloves and one $(20 \%)$ previously had provided massage while wearing a mask. None of the therapists previously had provided massages wearing isolation gowns. A common concern of the therapists prior to the study was the need to have sufficient information regarding the participants to safely work with them. All therapists completed the Institutional Review Board online training for protection against research risks, reviewed study information, and completed a 3-hour training session specific to the massage protocol, hospital environment, and cancer treatment. The therapists were reimbursed $\$ 50$ an hour for providing massages and the current state mileage rate when traveling to participants' homes.

The therapists completed the massage checklist before and after each massage administered during the study. Community-based therapists were instructed to mail their 
forms on a weekly basis to the study coordinator who reviewed the measures and clarified any points in a scheduled weekly telephone call with each therapist.

\section{Data Analysis}

Data were entered, cleaned, and verified using Statistical Package for the Social Sciences $\left(\operatorname{SPSS}^{\circledR}\right)$, version 15.0. Data entry and cleaning were conducted as the data were collected. Descriptive statistics were calculated on demographic and study variables. Frequencies were calculated for categorical variables and means were reported for continuous variables.

Data analyses were conducted in accordance with the instrument scoring guidelines. The mean scores for anxiety, pain, and QoL scales were averaged over each ASCT treatment phase (at baseline, cell collection, chemotherapy, ASCT transplant, post transplant hospitalization, and following discharge to the home environment) for each group (massage and SMC). In the massage group, pre- and post-massage scores for stress, relaxation and comfort were averaged over each phase, beginning with the first massage. Data were analyzed using descriptive statistics with graphing of the data to make comparisons.

To describe ASCT patient acceptance of supportive care massage therapy in the hospital and in home settings, a qualitative analysis was performed on the participants' responses to open-ended questions asked before the first massage and following the final massage sessions. The therapists' comments recorded following the massage sessions were also analyzed. Responses were categorized using "perceived benefits of massage" 
and "perception of barriers to providing massage" as categories for participants and therapists, respectively.

\section{Results}

\section{Demographics}

A total of nine participants were enrolled in the study. After the study had started, the ASCT transplant center closed within six months with no plans to reopen. Eight participants completed the study, and one dropped out when he decided to continue treatment at another transplant center. Of the 8 participants who completed the study, 3 were randomized to the SMC group, and 5 to the massage group. One of the 5 participants in the massage group had disease recurrence during hospitalization and did not receive ASCT. Data from this participant were not included in the analysis of the mean scores; however, qualitative analysis of questionnaires and the massage therapy checklists were included for this participant.

Of those who completed the study, 3 were males and 5 were females ( 1 male and 2 females in the SMC group and 2 males and 3 females in the massage group (see Table 2). There were 2 African-Americans, 1 in each group. The remaining participants were Caucasian. All participants were non-Hispanic or non-Latino in ethnic origin. All participants were married, except for one widow in the SMC group. The participants ranged in age from 51 to 69 years (mean 60). The mean age in each study group was also 60 years. The average years of participant education was 12.8 years (13.3 years in the SMC group and 12.6 years in the massage group). In the SMC group 1 participant had multiple myeloma and 1 participant had Non-Hodgkin's lymphoma. In the massage 
group 2 participants had multiple myeloma and 3 participants had Non-Hodgkin's lymphoma.

Of the patients presenting for potential stem cell transplant during the enrollment period, there were 11 who did not enrolled in this study. Of these 11 patients, 7 were male and 4 were female. There were 2 African-Americans ( 1 male and 1 female), and the remaining patients were Caucasian. Two of these patients could not be recruited for the study because of scheduling issues with 1 having had collection of stem cells prior to the study coordinator being able to approach the patient. Of the remaining 9 potential study participants, 1 patient died prior to enrollment, 1 was ineligible due to active deep vein thrombosis, and 7 declined to participate in the study. Reasons for decline included no previous or limited experience with massage therapy, a preference not to be touched, and concern for being a participant in a study.

\section{Prior Massage Experiences}

Of the participants completing the study, one in the SMC group and two in the massage group had had previous experience with massage. The participant from the SMC group reported five previous massages, and the 2 participants from the massage group reported two and five previous massages. All 3 participants stated that their previous massage sessions had been comfortable experiences. Family members who were present while the study was discussed encouraged the patient to participate in the study. While the majority of massages that participants received during the study were administered at the medical center, approximately six massages for each participant were administered by a community-based therapist. However, the number of massages administered in each 
setting varied depending upon the participants' needs and availability of a therapist within commuting distance to the participants' home.

\section{Implementation of the Massage Intervention}

Participants received 12 to 18 (average 16) of the planned 21 massages over the course of the 7-week study. When platelets were below $15,000 / \mathrm{mm}^{3}$, massages were not done and were rescheduled, if possible. For 1 participant even the slightest movement during the cell collection phase caused the collection machine to alarm, deferring the massage. Three participants received no in-home massages. One participant refused all in-home massages but accepted the in-hospital massages. There was difficulty locating a therapist in one participant's rural community to deliver the in-home massages, and 1 participant did not return to his home over the course of the 7-week study because of travel distance, resulting in his massages being provided locally as an outpatient.

Participant refusal of a massage was rare. One participant refused one massage before the cell collection phase and one after this phase, and another participant refused a massage because vomiting and diarrhea were a concern as a result of chemotherapy.

Glove Use. Glove use was required for all in-hospital massages. More lotion than is usually needed for massage was required to increase the glide capacity of the gloves, as the gloves tended to produce a drag on the skin without sufficient lotion. No gloves were required for any of the massages in the home environment. The therapist documented skin assessment with each massage and avoided areas of central line placement, bruising, or skin markings for radiation therapy. The survey completed by each therapist at the end 
of the study indicated the therapists did not believe that glove use interfered with their ability to provide comforting massage.

Barriers to Massage. In post-study assessments, the therapists reported that there had been occasional interruptions in the massage sessions provided to participants in the hospital to permit other patient care activities. The therapists also noted that abdominal massage was deferred because of bruising of the abdomen caused by subcutaneous injections as part of the participants' medical regimens. At the same time, the therapists noted on the assessment forms that abdominal distention was present. The therapists did not report any difficulties in providing massage in the home environment. However, scheduling of in-home massages was complicated by difficulty finding a communitybased therapist in several rural areas, as well as coordinating the in-home massage with a time that was best for the participant.

\section{Differences between Massage and SMC Groups on Study Outcomes}

\section{Anxiety}

Although initial and final state anxiety mean scores were similar for both the SMC alone and massage groups, at all other phases of treatment the massage group had lower anxiety scores than the SMC group (see Figure 1). Mean averages for the massage group remained in the low anxiety range (20-39) except during the post-transplant hospital phase when there was a slight increase in the mean score to 40 . The SMC group had mean scores initially at 39 , peaking at 58 post-transplant (moderate anxiety range). Pain 
The SMC group began the study with higher mean pain scores on the 11-point pain NRS compared to the massage group (see Figure 2). Three participants in the SMC group had chronic pain conditions (bone pain, hip pain, and fibromyalgia) contributing to the elevation of their pain scores. NRS pain scores were collected on days when massages were not given. At the cell collection phase and at final assessment following discharge to home, the pain scores were similar for both groups. Although the NRS pain scores for the massage group were consistently lower than SMC group, the massage group started the study with a lower rating for pain and, in general, did not have further reductions in pain across the phases.

The McGill sensory and affective pain scales scores were similar between groups until post-transplant hospitalization, at which time the SMC group reported an increase in pain while the massage group reported a decrease (see Figures 3 and 4). The mean sensory pain rating for the SMC group was 10.3 on the 11-point scale compared to 1.2 for the massage group, and 6.7 on the affective pain scale compared to 1.8 for the massage group.

Social Support

All participants reported moderately high social support. See Figures 5, 6, 7, and 8 for the mean scores for the tangible, emotional, affective, and positive interaction subscales, respectively. All participants had a significant other physically present during their transplant phases. For 6 of the participants, the significant other was their spouse. For 1 participant it was a daughter, and for another participant it was a friend who had previously received treatment for cancer and was currently unemployed. The massage 
group reported higher emotional and tangible support during chemotherapy and transplant compared to the SMC group, while the group scores were similar on other phases of treatment. The groups appear similar on the subscales of affective and positive interaction support.

\section{Quality of Life}

At the beginning of the 7-week study, the massage group had higher mean scores for overall QoL and maintained a score over 50 except for the transplant phase, which was 48 (see Figure 12). The SMC alone group initially had a lower mean score of 36 and maintained a score below 50 until the final assessment at home. Although the QoL scores for the massage group were consistently higher than SMC group, the massage group started the study with a higher rating for QoL and, in general, did not have further increases in QoL across the phases. For all participants regardless of group, QoL subscales for role functioning decreased at both the stem cell collection phase and at transplant. QoL subscales for nausea/vomiting and for diarrhea decreased at the chemotherapy phase for both groups during hospitalization.

Differences in Pre-and Post-Massage Ratings on Stress, Relaxation, and Comfort in the Massage Group

An immediate effect in the stress NRS was seen following massage, with lower post-massage stress ratings compared to the pre-massage. The largest differences were seen in the phases of chemotherapy, transplant, hospitalization post-transplant, and at home, with the smallest change occurring at cell collection (see Figure 9). Cumulative effects of massage were not demonstrated in the pre-massage stress scores over the 
transplant phases except in one participant who had low pre-massage stress levels over the course of five massages. In this participant, the pre-massage stress rating was 0 before the last in-hospital massage and was maintained at 0 for the following four in-home massages.

An immediate effect in the relaxation NRS score was seen following massage, with higher post-massage relaxation ratings compared to the pre-massage relaxation ratings. The largest differences were seen in the phases of transplant and in-hospital post transplant, with the smallest change occurring following discharge to home (see Figure 10). However, no cumulative effects of massage were found on pre-massage relaxation scores over the ASCT treatment phases.

An immediate effect in the comfort NRS score was seen following massage, with higher post-massage comfort ratings compared to the pre-massage NRS scores. The largest differences were seen in the phases of chemotherapy, transplant, and in-hospital post transplant, with the smallest change occurring at cell collection (see Figure 11). No cumulative effects of massage were seen in the pre-massage comfort levels over time.

\section{Participants Perceived Benefits of Massage}

Therapists documented comments by the participants on their study forms. One participant, who had received previous chemotherapy and had reported problems with peripheral neuropathies that impaired his ability to hold items and walk, reported following his second massage, "The tingling is all gone from my hands." After another massage, the same participant reported, "I love my hands not shaking and tingling." This sentiment persisted throughout the study period. On another day the same participant 
reported, "I feel whole again. This morning my knees were a little shaky...now they feel like they're solid." For this participant, improvement in his peripheral neuropathy symptoms was a benefit of the massage sessions.

Although patients are cared for in highly specialized transplant centers, most do not required general intensive care unit admission. One participant became critically ill and had to be transferred to the intensive care unit and intubated. He remained overnight in the intensive care unit. Upon extubation and the participant's ability to speak, his first request to the nursing staff was to ask whether or not he could get a massage. The physician and nursing staff in the intensive care unit agreed and massage was provided. The participant's request was for what he thought would benefit him the most at this stressful time.

One therapist documented prior to a massage session edema of a participant's extremities to the extent that it made the blood bank typing band too tight around the participant's wrist. Prior to beginning the massage, the therapist suggested a phone call to the clinic staff after the massage to ask if the participant should return to the clinic for the staff to replace the restricting band. Upon completion of the massage the arm band slipped off the participant's wrist and a return visit to the clinic was not necessary. Although the massage protocol was a Swedish massage technique, it mobilized a large amount of fluid for this participant, which proved to be a benefit.

Nausea, vomiting, and diarrhea are expected side effects of chemotherapy that have an impact on QoL for patients undergoing ASCT. For 1 participant, nausea that had persisted for two days during the cell collection phase was reported to be immediately 
improved after the massage session.

At the completion of the final massage, the therapist asked the participants several open-ended questions regarding benefits and barriers to massage for the participant. All participants in the massage intervention group reported massage had benefited them by increasing relaxation. Four of the 5 participants $(80 \%)$ reported stress reduction and increased comfort as benefits following the final massage. One reported that massage made him "feel looser." Two participants stated that they looked forward to their massage sessions. The nursing staff frequently greeted the therapists' arrival on the nursing unit to let the therapists know that the participant was waiting for them or had been talking about the benefits of the massage sessions.

Although family members were not surveyed during the study, they frequently commented on how beneficial they believed that the massage sessions were for their family member. One participant's wife, who was present during the oral questions, stated, "He's more relaxed and patient. Also, massage has helped with his prior shoulder and neck pain that he's had since before he started this ordeal. He has increased range of motion in his shoulder and less pain."

Participant responses to the question about the phase of the transplant process they thought massage had most helped varied. For several, it was the cell collection phase or after transplantation of the stem cells. One stated, “...following the transplant, massage helped the most with nausea and stress." Another participant stated that massage was most helpful "after returning home and not being able to work in the garden.

Working outside is where I get relief from stress and comfort, and not being able to do so 
is stressful." Another participant interpreted this question to mean, "What part of the body benefited most?" stating it was his "legs and shoulder." He had left shoulder pain with limited range of motion before the study began and noted the pain was gone and there was much greater range of motion of the shoulder. He could now move his arm over his head, which he could not do prior to the study. He had also reported restless leg syndrome when sleeping, but with the regular massages he had noted much less of a problem and was not awakened at night. He stated that he liked the last three weeks the best, when he had been able to receive all three massage in a week.

Only 1 participant commented that there was a difference in the way she experienced massages when the therapist used gloves. She stated, "Yes, you could tell that the therapist's hands were rougher. It interfered some."

No participants expressed problems receiving massage in-hospital or in their home environments. Participants did ask if their significant others could receive massage as well. One participant expressed that getting massage for his wife would have improved the process for him, as well. He stated, "It was very helpful [to me] in relieving stress during this transplant process." Another stated that he had asked about a year prior to his ASCT process whether or not massage was available and it was not. So, he was very happy massage was offered when he went through the transplant process.

Perceived benefits of massage for the participants included improvement in improvement in symptoms that they had been experiencing prior to undergoing ASCT as well as their current treatment-related symptoms. Increased relaxation and comfort and stress reduction were participant perceived benefits of the massage sessions. Family 
members and nursing staff noted improvement of symptoms and that participants looked forward to the massage sessions. The use of gloves for massage was identified by only one participant as interfering with the massage experience, and no difficulties were identified in receiving massage. A perceived potential benefit of massage for participants' social support persons was identified, too.

\section{Discussion}

The ASCT process involves a multitude of stressors and adverse symptoms for patients throughout treatment. The descriptive analysis of this study supports the use of massage therapy in patients throughout the ASCT process.

\section{Anxiety}

Participants in the massage group maintained lower mean scores on anxiety during cell collection, chemotherapy, transplant, and post transplant hospitalization phases than the SMC group which reported moderate anxiety post-transplant. This finding is similar to the short term effects of massage on anxiety reported by Ahles and colleagues (1999) and end of study effects reported by Smith and colleagues (2003) comparing massage to standard care for the ASCT population and in patients with cancer (Fellowes, 2004).

\section{Pain}

Compared to the massage group, the SMC group began the study with higher mean pain scores, which partially may be explained by the presence of chronic pain syndromes unrelated to the cancer disease process in the SMC group. At the cell collection phase and at final assessment following discharge to home, the pain scores 
were similar for both groups. Although the NRS pain scores for the massage group were consistently lower than SMC group, the massage group started the study with a lower rating for pain and did not reduce pain across most of the phases, except for a small reduction at the chemotherapy phase. The highest mean pain rating was 2.7 on the 11point NRS at cell collection. With such a low mean peak score, massage may not have been able to reduce the pain further. A previous study of 10 minute back massages in 28 patients with cancer that were randomly assigned to massage or a control group demonstrated significant reductions in pain immediately following the back massages for male patients only. There was not a significant difference for females and there were no differences between pain at 1 hour and 2 hours post-massage.

The massage group reported decreased sensory and affective pain at posttransplant hospitalization while the SMC group reported an increase in pain. This was at a phase when all of the participants were on isolation and perhaps receiving less interaction with healthcare providers than when not isolated (Stelfox, 2003). However, the massage group may have perceived more interaction from the massage therapist during isolation, and rated their NRS for pain less than the SMC group.

Although there was improvement in other symptoms, this study supports the findings of the two previous studies in adult patients undergoing ASCT, which did not report significant immediate reductions (Ahles et al., 1999) or over treatment period reductions (two weeks) in pain with massage (Smith et al., 2003). Perhaps the timing of pain ratings may have affected the results. In the current study, pain ratings were done on non-massage days, indicating that massage did not have long-term effects on pain. 
Because most cancer patients receiving ASCT experience pain that is multifactoral (Gaston-Johansson et al., 2000), massage alone may be insufficient to reduce pain on non-massage days. Therefore, other pain management strategies in addition to massage are necessary, especially on non-massage days.

\section{Social Support}

Both emotional and tangible support scores were higher for the massage group during chemotherapy and transplant compared to the SMC group. A support person was present throughout all the phases of ASCT for participants in both groups. Adding the support of massage may have provided additional social support during these two stressful phases of ASCT (chemotherapy phase and transplant phase). Perceived social support has been identified as one of the most important factors for persons going through the ASCT process (Rodeheaver et al., 2003) although no prior studies of massage effects in ASCT or cancer patients have evaluated the impact of social support on outcomes.

\section{Quality of Life}

The massage group had a higher QoL mean score at baseline and did not demonstrate further increases in QoL over the treatment phases. In fact the massage group had a slight decreased in QoL at transplant and again at discharge to home, while the SMC group had a slight increase at discharge. Although nausea, vomiting, and diarrhea are expected side effects of chemotherapy (Watson, Meyer, Thomson, \& Osofsky, 1998), these symptoms have a major influence on QoL for patients undergoing ASCT. QoL decreased at the chemotherapy phase due to nausea, vomiting, and diarrhea; 
role functioning decreased during both the stem cell collection phase and the transplant phase for both groups. The results of this study are similar to the findings of another study of cancer patients receiving massage where there were only small differences seen in the effect of massage on quality of life using a different QoL instrument; and the authors suggested that the QoL instrument they used (Gaham's QoL) may not be sensitive to the effects of massage therapy in the context of excellent pain control (Wilkie et al., 2000). The participants in the massage group had low mean pain scores throughout the transplant phases (peak 2.7). Although a different QoL score was used, it may not have been sensitive to the effects of massage considering the low pain scores.

\section{Perceived Stress, Comfort, and Relaxation}

In the current study, the massage group had improvements in stress, relaxation, and comfort immediately after massage. These findings are consistent with other studies of patients undergoing ASCT who received massage (Ahles et al., 1999; Smith et al., 2003). Even though no cumulative effects of massage were seen in the pre-massage scores for stress, relaxation, and comfort measures over the phases, it is unclear how long the massage effects lasted for the participants, as measurements were assessed approximately every three days at the time of the massage sessions. Future research needs to measure perceived stress, comfort, and relaxation daily or at least every two days to determine if there is a cumulative effect. In another study of patients undergoing marrow transplant, $35 \%$ of the sample $(n=27)$ reported that benefits persisted for more than a day (Smith et al., 2003). Having a temporary reduction in stress may have been beneficial for the participants in the current study. 


\section{Participants Perceived Benefits of Massage}

Perceived benefits of massage for the participants included improvement in symptoms that they had been experiencing prior to undergoing ASCT as well as their current treatment-related symptoms. Increased relaxation and comfort and stress reduction were participant perceived benefits of the massage sessions. Family members and nursing staff noted improvement of symptoms and that participants looked forward to the massage sessions. The use of gloves for massage was identified by only one participant as interfering with the massage experience. Patient perception of glove use with touch has not been previously evaluated. No difficulties were identified by participants in receiving massage.

This is the first study involving community based massage therapists. Perceived benefits of massage for the participants included improvement in symptoms that they had been experiencing prior to undergoing ASCT as well as their current treatment-related symptoms.

\section{Theoretical Model}

The finding of this study support the psychoneuroimmunology and health psychology model (See Figure 1). In this study, participants in the massage group reported less treatment- related symptoms of lower affective and sensory pain scores during post-transplant hospitalization which impact QoL than did the SMC group (Box F). The massage group participants reported reduced stress (Box G), and increased comfort and less anxiety (Box A psychological processes) across the ASCT phases, as well as increased relaxation (Box E). Massage can modulate effects of psychosocial 
processes (decreased anxiety, increase comfort, increase relaxation, and decrease stress) decreasing treatment-related symptoms (Box F).

\section{Massage Acceptance}

Although only $50 \%$ of the eligible participants were recruited for this study, previous studies have reported that patients with cancer undergoing ASCT are very receptive to the use of massage therapy during hospitalization (Ahles et al., 1999; Rodeheaver et al., 2003; Smith et al., 2003). Reasons for declining to be in the study included no previous or limited experience with massage therapy, a preference not to be touched, and concern for being a participant in a study. The only drop out in the study was a participant who changed transplant centers. In another study (Smith et al., 2003) there was an approximate $30 \%$ drop out rate, half of these were before treatment began but following randomization to a group other than massage. No participants expressed problems receiving massage in-hospital or in their home environments.

\section{Massage Dose}

Participants received an average of 16 massage sessions lasting 50 minutes each over the course of the 7-week study, which is a higher massage dose than the dose provided in any other study of patients with cancer or patients undergoing ASCT. However, in spite of the higher dose, the massage dose for the participants in the current study may have been insufficient to decrease pain or increase QoL scores. Larger treatment effects generally result from longer treatment sessions and the cumulative effects of massage over longer intervention periods (Field, 1998; Taylor, Galper, Taylor et al., 2003). Even with a higher dose of massage, the pain and decrease in QoL 
associated with ASCT may be too great to be relieved by massage alone. However, there were immediate effects seen in stress reduction and increased comfort and relaxation. Another factor is the massage group started out with lower pain scores and maintained a low pain score throughout phases of transplant (peak 2.7).

\section{Massage for Persons Providing Social Support to ASCT Recipients}

A perceived potential benefit of massage for participants' social support persons was identified by one patient. One randomized control study $(n=42)$ of therapeutic back massage for spouses of patient with cancer suggest that massage may benefit spouses of patients with cancer by enhancing positive mood and reducing perceived stress (Goodfellow, 2003).

\section{Study Limitations}

This pilot study is limited by the small sample size $(N=8)$, which restricted the data analysis to descriptive techniques. Given the sample size and that an average of 16 of the 21 planned massages were provided, the investigators were not able to conduct an analysis of the effect of massage dose on study outcomes. Stress, relaxation, and comfort were not assessed over time in the SMC group; therefore, comparison between the 2 groups on these variables could not be evaluated. Also, the massage therapists providing the massages were the same individuals who collected the pre- and post-NRS scores for stress, comfort, and relaxation which could have potentially biased participants' selfreport on these variables. However, hospitalized patients are accustomed to having the same healthcare provider who administers care to also assess its outcome. 


\section{Future Research}

This descriptive pilot study is a first step in evaluating the effectiveness of massage as an intervention to improve symptoms and QoL in individuals with cancer who undergo ASCT. This study as designed should be replicated in a setting where a larger sample size can be recruited. Measures of stress, relaxation and comfort should be assessed in all participants. Pain measurement needs to be done more frequently in both groups. Protocols should optimize the massage group participants receiving three massages a week. This may be facilitated by a hospital-based massage therapist. Future studies should also consider adding assessments of the stressors experienced by the persons providing social support to the transplant recipients. The effect of massage on stressors in persons providing support to ASCT recipients should be studied to evaluate the effect for both the person providing support and the ASCT recipient.

\section{Conclusions}

This study investigated the effects of massage on symptoms and QoL in individuals undergoing ASCT for cancer, and the benefits and barriers to patient acceptance of massage during phases of the ASCT process. The most important descriptive findings for participants in the massage group were reduced stress, and increased relaxation and comfort immediately following massage compared to premassage ratings. Participants in the massage group also reported lower anxiety scores across the ASCT phases and lower affective and sensory pain scores during posttransplant hospitalization than participants in the SMC group. The massage group had a higher global QoL mean score at baseline and did not demonstrate further increases in 
QoL over the ASCT phases. In fact, the massage group had a slight decrease in QoL at transplant and again at discharge to home, while the SMC group had a slight increase at discharge. Although nausea, vomiting, and diarrhea are expected side effects of chemotherapy, these symptoms have a major influence on QoL for patients undergoing ASCT. Both groups reported a decrease in QoL at the chemotherapy phase related to nausea, vomiting, and diarrhea, as well as a decrease in role functioning during the stem cell collection phase and the transplant phase.

Perceived benefits of massage for the participants in the massage group included improvement in symptoms that they had been experiencing prior to undergoing ASCT as well as their current treatment-related symptoms. While the massage therapists needed to wear gloves for all in-hospital massages, only one participant reported that the gloves interfered with the massage experience. Massage therapy training should include the use of barrier protection (gloves) in medical massage courses to ensure that therapists are prepared to work with patients on isolation. It is feasible to provide massage to patients undergoing ASCT across the continuum of outpatient, inpatient, and home settings, although locating massage therapists in some rural areas provides the same challenges as accessing health care for residents of rural communities. Supportive care massage can have immediate effects on stress, comfort, and relaxation and improve treatment-related symptoms for patients undergoing ASCT. 


\section{References}

Aaronson, N. K., Ahmedzai, S., Bergman, B., Bullinger, M., Cull, A., Duez, N. J., et al. (1993). The European Organization for Research and Treatment of Cancer QLQC30: A quality-of-life instrument for use in international clinical trials in oncology. Journal of the National Cancer Institute, 85, 365-376.

Ahles, T. A., Tope, D. M., Pinkson, B., Walch, S., Hann, D., Whedon, M., et al. (1999). Massage therapy for patients undergoing autologous bone marrow transplantation. Journal of Pain and Symptom Management, 18, 157-163.

Ahles, T.A., Ruckdeschel, J.C., \& Blanchard, E.B. (1984). Cancer-related pain: II. Assessment with Visual Analogue Scales. J Psychosom Res, 28, 121-124.

Altemus, M., Redwine, L. S., Leong, Y.-M., Freye, C. A., Porges, S. W., \& Carter, C. S. (2001). Responses to laboratory psychosocial stress in postpartum women. Psychosomatic Medicine, 63, 814-821.

Andrykowski, M. A., Greiner, C. B., Altmaier, E. M., Burish, T. G., Antin, J. H., Gingrich, R., et al. (1995). Quality of life following bone marrow transplantation: Findings from a multicenter study. British Journal of Cancer, 71, 1322-1329.

Benotsch, E. G., Lutgensorf, S.K., Watson, D., Fick, L.J., \& Lang, E.V. (2000). Rapid anxiety assessment in medical patients: Evidence for the validity of verbal anxiety ratings. Ann Behav Med, 22, 199-203.

Buchsel, P. C., \& Whedon, M. B. (Eds.). (1995). Bone marrow transplantation: Administration and clinical strategies. Boston: Jones \& Bartlett.

Butts, J. B., \& Janes, S. (1995). Transcending the latex barrier: The therapeutics of 
comfort touch in patients with acquired immunodeficiency syndrome, Holistic Nursing Practice, 10, 61-67.

Cameron, C. I., Cella, D., Herndon, J. E., Kornblith, A. B., Zuckerman, E., Henderson, E., et al. (2001). Persistent symptoms among survivors of Hodgkin's disease: An explanatory model based on classical conditioning. Health Psychology, 20, 71-75.

Delaney, J. P., Leong, K. S., Watkins, A., \& Brodie, D. (2002). The short-term effects of myofascial trigger point massage therapy on cardiac autonomic tone in healthy subjects. Journal of Advanced Nursing, 37, 364-371.

Fanning, S.R., Rybicki, L., Kalaycio, M., Andresen, S., Kuczkowski, E., Pohlman, B., Sobecks, R., Sweetenham, J. \& Bolwell, B. Severe mucositis is associated with reduced survival after autologous stem cell transplantation for lymphoid malignances. British Journal of Haemotology, 135, 374-381.

Fellowes, D., Barnes, K., \& Wilkinson, S. (2004). Aromatherapy and massage for symptom relief in patients with cancer. The Cochrane Library, 2, CD002287.

Field, T. (2002). Massage therapy. Medical Clinics of North America, 86, 163-171.

Field, T. M. (1998). Massage therapy effects. American Psychologist, 53, 1270-1281.

Fung, H. C., \& Nademanee, A. P. (2002). Approach to Hodgkin's lymphoma in the new Millennium. Hematological Oncology, 20, 1-15.

Gaston-Johansson, F., Fall-Dickson, J. M., Nanda, J. P., Ohly, K., Stillman, S., Krumm, S., et al. (2000). The effectiveness of the Comprehensive Coping Strategy Program on clinical outcomes in breast cancer autologous bone marrow transplantation. Cancer Nursing, 23, 277-285. 
Gaston-Johansson, F., \& Foxall, M. (1996). Psychological correlates of quality of life across the autologous bone marrow transplant experiences. Cancer Nursing, 19, 170-176.

Grealish, L., Lomasney, A., \& Whiteman, B. (2000). Foot massage: A nursing intervention to modify the distressing symptoms of pain and nausea in patients hospitalized with cancer. Cancer Nursing, 23, 237-243.

Herr, K., Spratt, K., Mobily, P.R., \& Richardson, G. (2004). Pain Intensity in older adults: Use of experimental pain to compare psychometric properties and usability of selected pain scales with younger adults. Clinical Journal of Pain, 20 (4), 207219.

Jassak, P. F., \& Riley, M. B. (1994). Autologous stem cell transplant. Cancer Practice, 2, 141-145. Kiebert, G. M., Curran, D., \& Aaronson, N. K. (1998). Quality of life as an endpoint in EORTC clinical trials. Statistics in Medicine, 17, 561-569.

Kiebert, G. M., Curran, D., \& Aaronson, N. K. (1998). Quality of life as an endpoint in EORTC clinical trials. Statistics in Medicine, 17, 561-569.

Labyak, S. E., \& Metzger, B. L. (1997). The effects of effleurage backrub on the physiological components of relaxation: A meta-analysis. Nursing Research, 46, 59-62.

Leukemia and Lymphoma Society. (May, 2002). Bone Marrow and Stem Cell Transplantation. http://www.leukemia-lymphoma.org/all_page?item_id=5965, retrieved October 7, 2004.

Lutgendorf, S.K. and Costanzo E. S. (2003) Psychoneuroimmunology and health 
psychology: an integrateive model. Brain, Behavior, and Immunity 17, 225-232.

McQuellon, R. P., Russell, G. B., Cella, D. F., Craven, B. L., Brady, A., Bonomi, A., et al. (1997). Quality of life measurement in bone marrow transplantation:

Development of the Functional Assessment of Cancer Therapy-Bone Marrow Transplant (FACT-BMT) scale. Bone Marrow Transplantation, 19, 357-368.

Melzack, R. (1987). The Short-Form McGill Pain Questionnaire. Pain, 30, 191-197.

Menard, M. (1995). The effects of therapeutic massage on post-surgical outcomes. Unpublished doctoral dissertation, University of Virginia, Charlottesville.

Molassiotis, A., van den Akker, O. B., Milligan, D. W., \& Goldman, J. M. (1997). Symptom distress, coping style and biological variables as predictors of survival after bone marrow transplantation. Journal of Psychosomatic Research, 42, 275285.

Molassiotis, A., Yung, H. P., Yam, B. M., Chan, F. Y., \& Mok, T. S. (2002). The effectiveness of progressive muscle relaxation training in managing chemotherapy-induced nausea and vomiting in Chinese breast cancer patients: A randomized controlled trial. Support Care Cancer, 10, 237-246.

Morris, K. T., Johnson, N., Homer, L., \& Walts, D. (2000). A comparison of complementary therapy use between breast cancer patients and patients with other primary tumor sites. The American Journal of Surgery, 179, 407-411.

Neitzert, C. S., Ritvo, P., Dancey, J., Weiser, K., Murray, C., \& Avery, J. (1998). The psychosocial impact of bone marrow transplantation: A review of the literature. Bone Marrow Transplantation, 22, 409-422. 
Paice, J.A. \& Cohen, F.L. (1997). Validity of a verbally administered numeric rating scale to measure cancer pain intensity. Cancer Nurse, 20, 88-93.

Phipps, S. (2002) Reduction of distress associated with paediatric bone marrow transplant: complementary health promotion interventions. Pediatric Rehabilitation, 5, 223-243.

Pico, J-L., Avila-Garavito, A., \& Naccache, P. (1998). Mucositis: Its occurrence, consequences, and treatment in the oncology setting. The Oncologist, 3, 446-451.

Portenoy, R. K., \& Itri, L. M. (1999). Cancer-related fatigue: Guidelines for evaluation and management. Oncologist, 1, 1-10.

Richards, K. C., Gibson, R., \& Overton-McCoy, A. L. (2000). Effects of massage in acute and critical care. Advanced Practice in Acute \& Critical Care, 11, 77-96.

Rodeheaver, P. F., Taylor, A. G., \& Lyon, D.E. (2003). Incorporating patients' perspectives in clinical trial design. Journal of Alternative and Complementary Medicine, 9, 859-967.

Sherbourne, C. D., \& Stewart, A. L. (1991). The MOS social support survey. Social Sciences and Medicine, 32, 705-714.

Smith, M. C., Reeder, F., Daniel, L., Baramee, J., \& Hagman, J. (2003.) Outcomes of touch therapies during bone marrow transplant. Alternative Therapies in Health and Medicine, 9(1), 40-49.

Spielberger, C. D., Gorsuch, R. L., \& Lushene, R. E. (1970). State-Trait Anxiety Inventory. Palo Alto, CA: Consulting Psychologists Press.

Speilberger, C. (1983). Manual for the State-Trait Anxiety Inventory: STAI (Form Y). 
Palo Alto, CA: Consulting Psychological Press, Inc.

Spielberger, C. (1989). State-Trait Anxiety Inventory: A comprehensive bibliography. Palo Alto, CA: Consulting Psychologists Press, Inc.

Stelfox, H.T., Bates, D.W. \& Redelmeier D. A. (2003) Safety of patients isolated for infection control. JAMA, 290, 1899-905.

Stephenson, N. L., Weinrich, S., \& Tavakoli, A. S. (2000). The effects of foot reflexology on anxiety and pain in patients with breast and lung cancer. Oncology Nursing Forum, 27, 67-72.

Taylor, A. G., Galper, D. I., D’Huyvetter, K., Bourguignon, C., \& Lyon, D. E. (2003). Pain. In J. W. Spencer, \& J. J. Jacobs (Eds.), Complementary and alternative medicine: An evidence-based approach (2nd ed.), pp. 311-408. St. Louis, MO: Mosby.

Taylor, A. G., Galper, D. I., Taylor, P., Rice, L. W., Andersen, W., Irvin, W., et al. (2003). Effects of adjunctive Swedish massage and vibration therapy on shortterm postoperative outcomes: A randomized, controlled trial. The Journal of Alternative and Complementary Medicine, 9(1), 77-89.

Watson, M., Meyer, L., Thomson, L., \& Osofsky, S. (1998). Psychological factors predicting nausea and vomiting in breast cancer patients on chemotherapy. European Journal of Cancer, 34, 831-837.

Weinrich, S. P., \& Weinrich, M. C. (1990). The effect of massage on pain in cancer patient. Applied Nursing Research, 3, 140-145. 
Table 1

Flow Chart of Measures by Timepoints (Bolded measures were completed by study participants)

\begin{tabular}{|l|c|c|c|c|c|c|c|}
\hline Instruments & Baseline & Week 2 & Week 3 & Week 4 & Week 5 & Week 6 & Week 7 \\
\hline Demographic Data Form & $\mathrm{X}$ & & & & & & \\
\hline Medical History Form & $\mathrm{X}$ & & & & & & \\
\hline QLQ-C30 & $\mathrm{X}$ & $\mathrm{X}$ & $\mathrm{X}$ & $\mathrm{X}$ & $\mathrm{X}$ & $\mathrm{X}$ & $\mathrm{X}$ \\
\hline STAI Y Form & $\mathrm{X}$ & $\mathrm{X}$ & $\mathrm{X}$ & $\mathrm{X}$ & $\mathrm{X}$ & $\mathrm{X}$ & $\mathrm{X}$ \\
\hline $\begin{array}{l}\text { Perceived stress, comfort and } \\
\text { relaxation NRS }\end{array}$ & $\mathrm{X}$ & $\mathrm{X}$ & $\mathrm{X}$ & $\mathrm{X}$ & $\mathrm{X}$ & $\mathrm{X}$ & $\mathrm{X}$ \\
\hline MPQ-SF & $\mathrm{X}$ & $\mathrm{X}$ & $\mathrm{X}$ & $\mathrm{X}$ & $\mathrm{X}$ & $\mathrm{X}$ & $\mathrm{X}$ \\
\hline MOS-SSS & $\mathrm{X}$ & $\mathrm{X}$ & $\mathrm{X}$ & $\mathrm{X}$ & $\mathrm{X}$ & $\mathrm{X}$ & $\mathrm{X}$ \\
\hline $\begin{array}{l}\text { Massage Therapy Checklist } \\
\text { (3 per week) }\end{array}$ & $\mathrm{X}$ & $\mathrm{X}$ & $\mathrm{X}$ & $\mathrm{X}$ & $\mathrm{X}$ & $\mathrm{X}$ & $\mathrm{X}$ \\
\hline
\end{tabular}

${ }^{1}$ NRS completed before and after each massage in the intervention group only. 
Table 2 Sample Characteristics

\begin{tabular}{|c|c|c|c|}
\hline Demographics & $\begin{array}{c}\text { Total sample } \\
\qquad N=8\end{array}$ & $\begin{array}{c}\text { Massage Group } \\
\qquad n=5\end{array}$ & $\begin{array}{c}\text { SMC Group } \\
n=3\end{array}$ \\
\hline & $\begin{array}{c}\text { Mean }(S D) \\
\text { Range }\end{array}$ & $\begin{array}{l}\text { Mean }(S D) \\
\text { Range }\end{array}$ & $\begin{array}{l}\text { Mean }(S D) \\
\text { Range }\end{array}$ \\
\hline Age (years) & $\begin{array}{c}60(6) \\
51-69\end{array}$ & $\begin{array}{c}60(6) \\
51-69\end{array}$ & $\begin{array}{c}60(7) \\
53-67\end{array}$ \\
\hline Education (years) & $\begin{array}{l}12.8(2) \\
10-17\end{array}$ & $\begin{array}{l}12.6(3) \\
10-17\end{array}$ & $\begin{array}{l}13.3(2) \\
12-16\end{array}$ \\
\hline & $N(\%)$ & $n(\%)$ & $n(\%)$ \\
\hline $\begin{array}{l}\text { Gender } \\
\text { Males } \\
\text { Females }\end{array}$ & $\begin{array}{l}3(38) \\
5(62)\end{array}$ & $\begin{array}{l}2(40) \\
3(60)\end{array}$ & $\begin{array}{l}1(33) \\
2(67)\end{array}$ \\
\hline Race & & & \\
\hline $\begin{array}{l}\text { African-American } \\
\text { Caucasian }\end{array}$ & $\begin{array}{l}2(33) \\
6(67)\end{array}$ & $\begin{array}{l}1(20) \\
4(80)\end{array}$ & $\begin{array}{l}1(33) \\
2(67)\end{array}$ \\
\hline $\begin{array}{c}\text { Marital Status } \\
\text { Married } \\
\text { Widowed }\end{array}$ & $\begin{array}{l}7(88) \\
1(12)\end{array}$ & $\begin{array}{l}5(100) \\
0(\quad 0)\end{array}$ & $\begin{array}{l}2(67) \\
1(33)\end{array}$ \\
\hline
\end{tabular}


Box 1

Massage protocol

1. The massage table and any items brought into the patients' homes or hospital rooms were cleaned and treated with a germicide. The massage therapist followed infection control policies and procedures pertinent to each patient to ensure that they were not exposed to potential pathogens. If a participant was placed on contact isolation, the massage therapist used surgical latex (or non-latex if the patient or massage therapist is allergic to latex) gloves to comply with hospital policy.

2. The therapist entered the participant's room, greeted the participant and assured his/her privacy. After obtaining feedback about massage and completing hand washing, the therapist assessed the patient's skin integrity for skin breaks, lesions, or intravenous sites. Areas of sensitivity and pain were assessed and these areas of concern avoided and documented on the massage checklist. If a participant reported being "too ill" to receive a scheduled massage on a given day, or had developed a complication, the massage session was reschedule as soon as feasible.

3. Participants were assisted in transferring to a massage table when possible. However, participants with major impediments to movement or those who preferred not to move onto the massage table received massages in their hospital bed.

4. Therapists avoided initiating any conversation other than to ascertain comfort level and feedback on massage technique, but responded to direct questions asked of them. This conversational behavior is considered standard for professional therapists during a massage. 
Box 1 cont.'d

Massage protocol, cont'd.

5. The therapist provided massage to the head, neck, shoulders (avoiding the central line site), back, abdomen (except on the first session because abdominal massage is initially aversive to many persons), feet, legs, hands and arms as intravenous lines permit. Participants chose areas where the massage therapist might spend a greater proportion of time, but an effort was made to provide each participant with a full-body massage each session. The massage protocol was based on the Swedish techniques of effleurage and petrissage, applied with very gentle pressure, and hand-over-hand continuous stroking of the back, arms and legs. No deep tissue work was included.

The massage tempo was relatively slow. A standardized non-fragrant cream was used. The duration of massage was standardized to 50 minutes, unless a participant request stopping the session early.

6. At the end of each session, the therapist completed a massage therapy checklist, to document areas that were massaged, massage duration, and any comments or feedback. 
Figure 1 Psychoneuroimmunology and Health Psychology Model

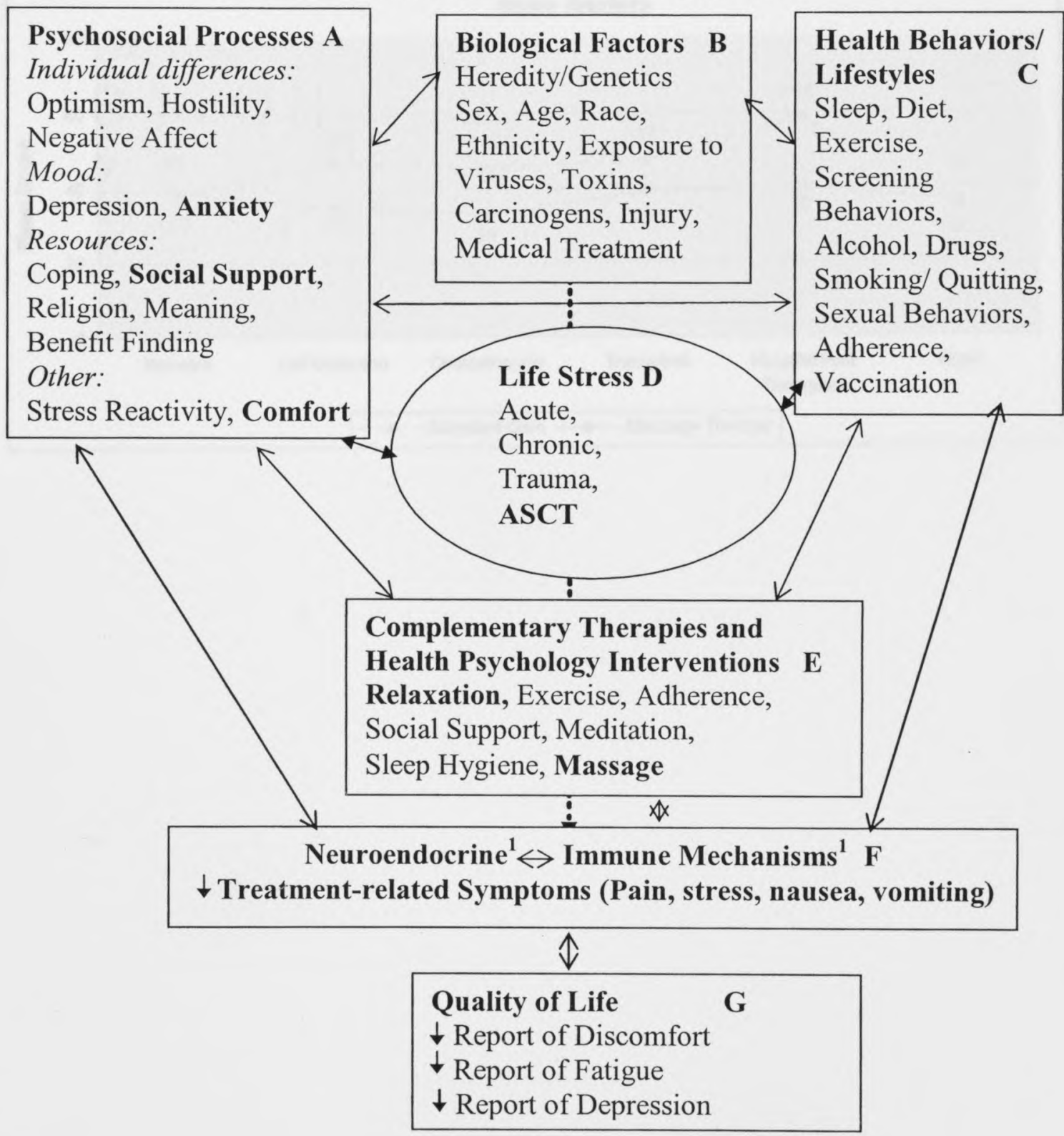


Figure 2 Differences in State Anxiety Between Massage and SMC Groups

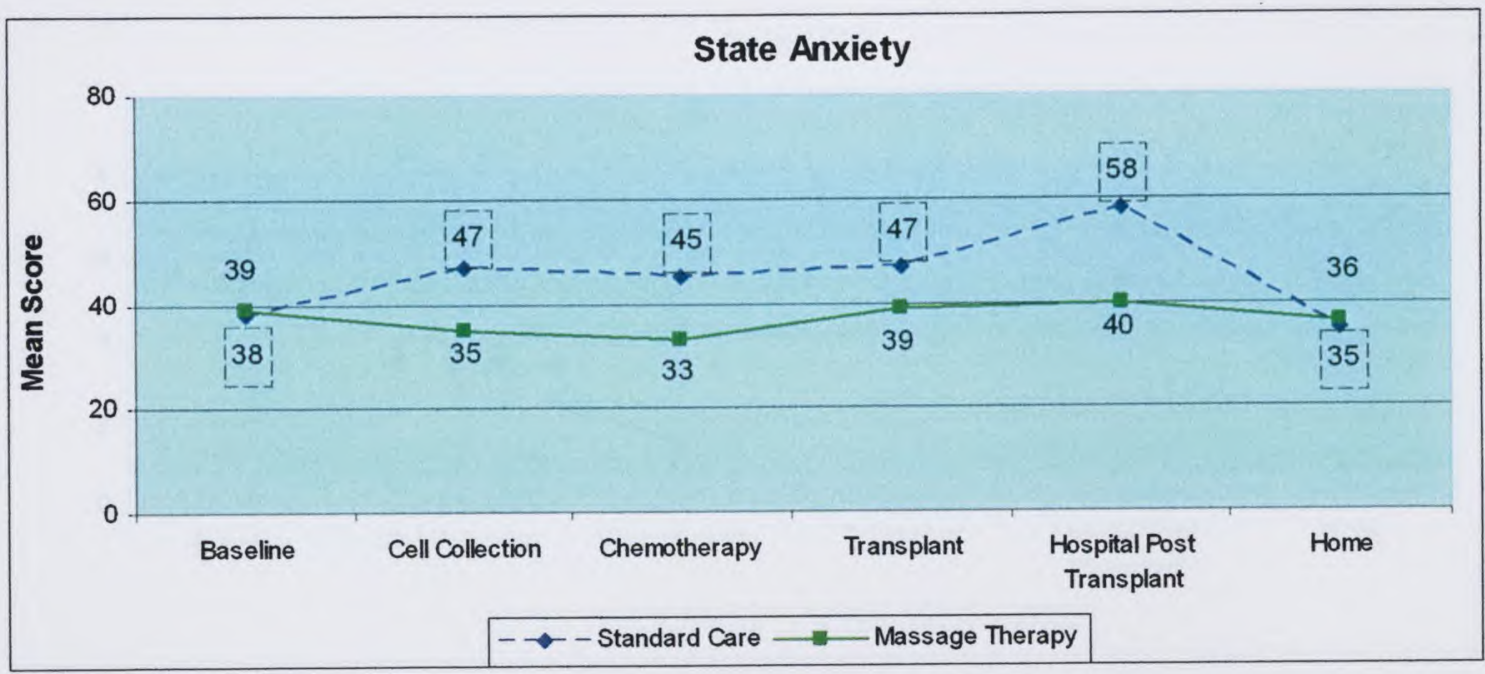


Figure 3 Differences in Pain NRS Between Massage and SMC Groups

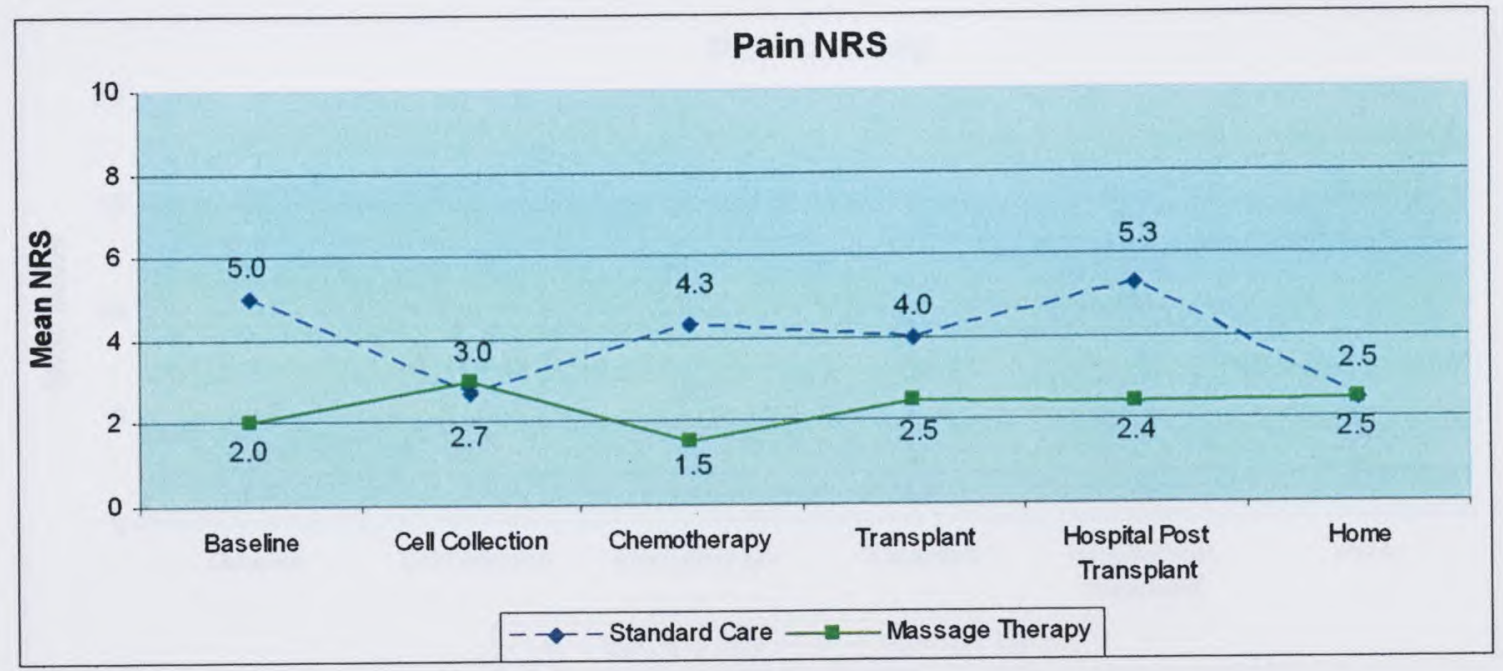


Figure 4 Differences in Sensory Pain Rating Between Massage and SMC Groups

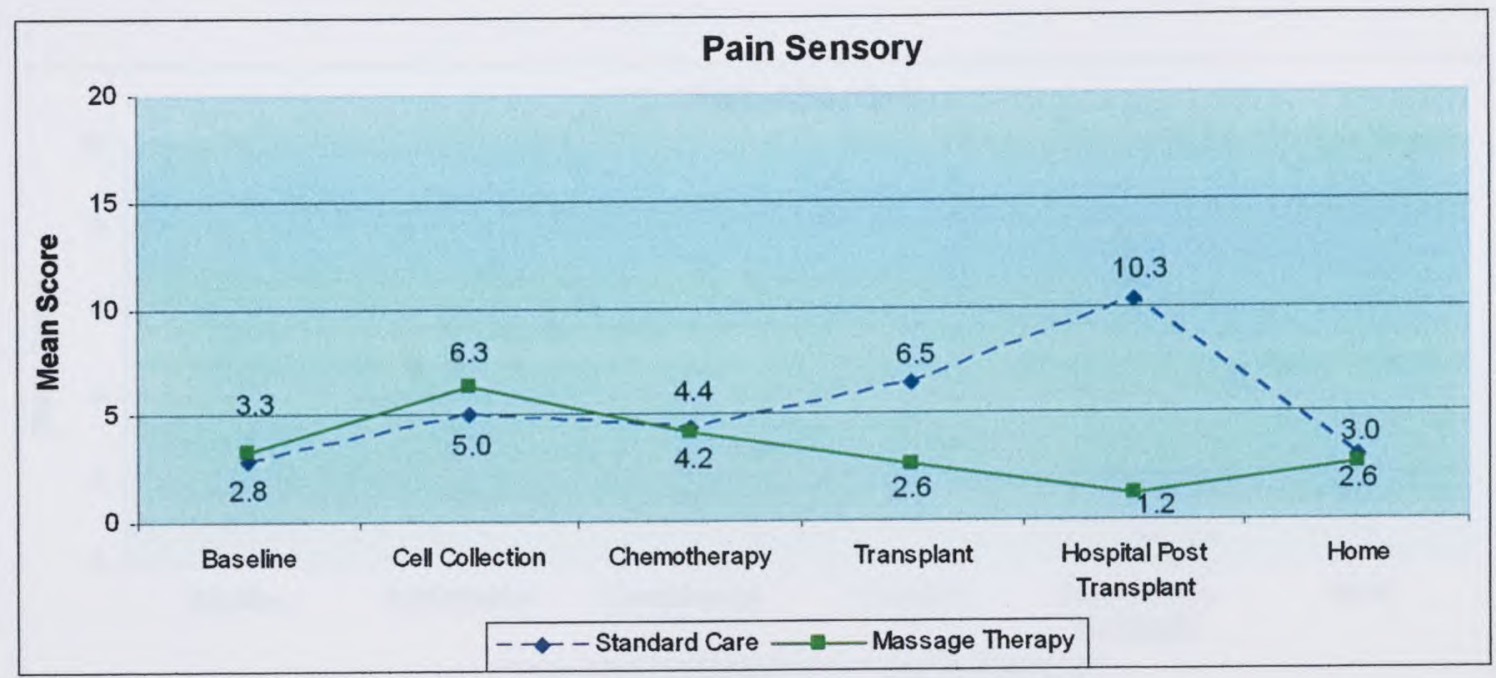


Figure 5 Difference sin Affective Pain Ratings Between Massage and SMC Groups

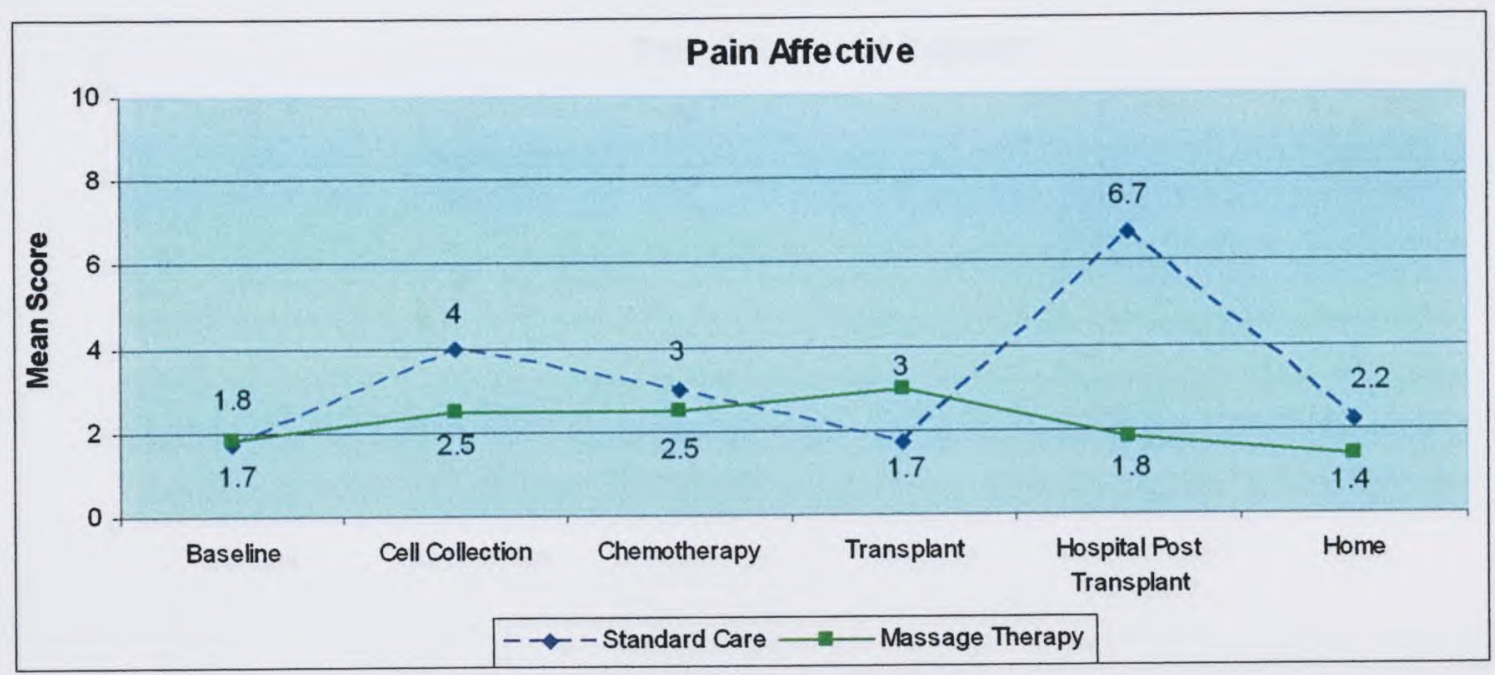


Figure 6 Differences in Tangible Social Support Between Massage and SMC Groups

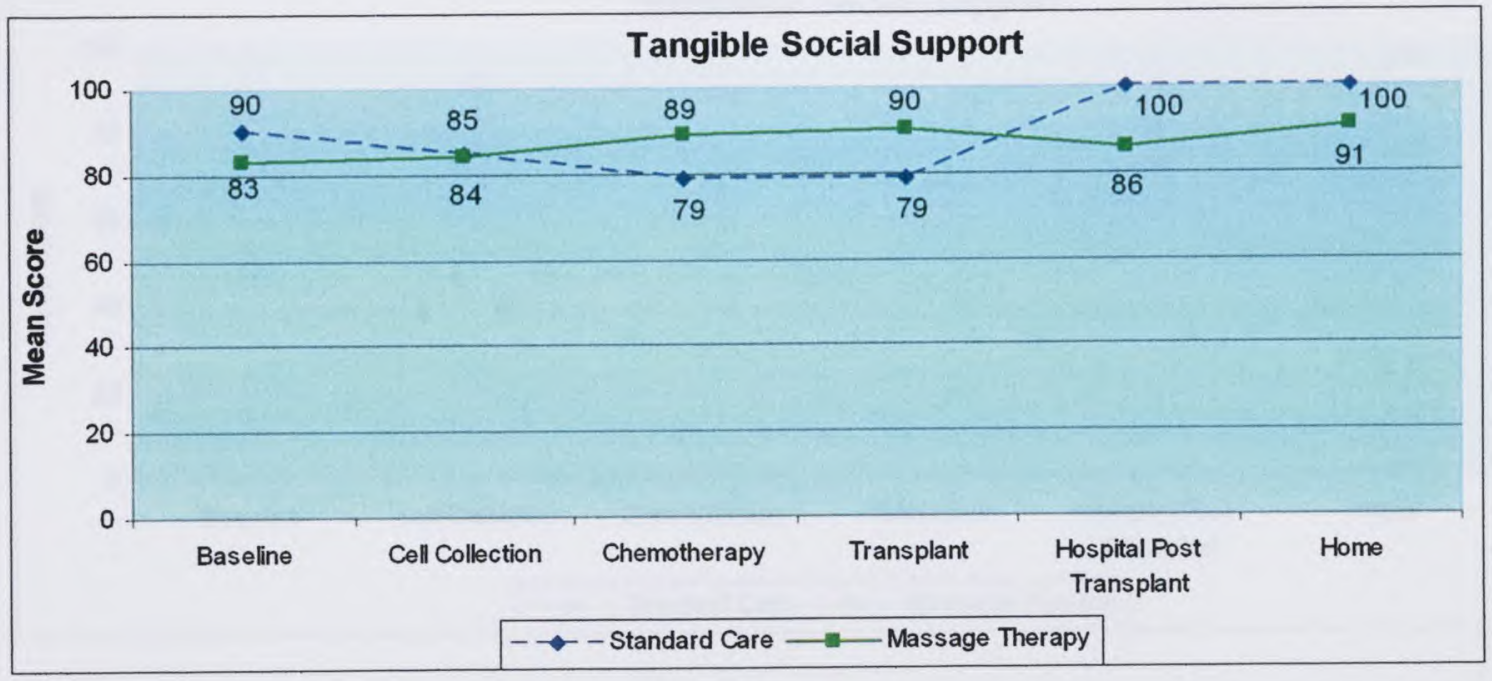


Figure 7 Differences in Emotional Social Support Between Massage and SMC Groups

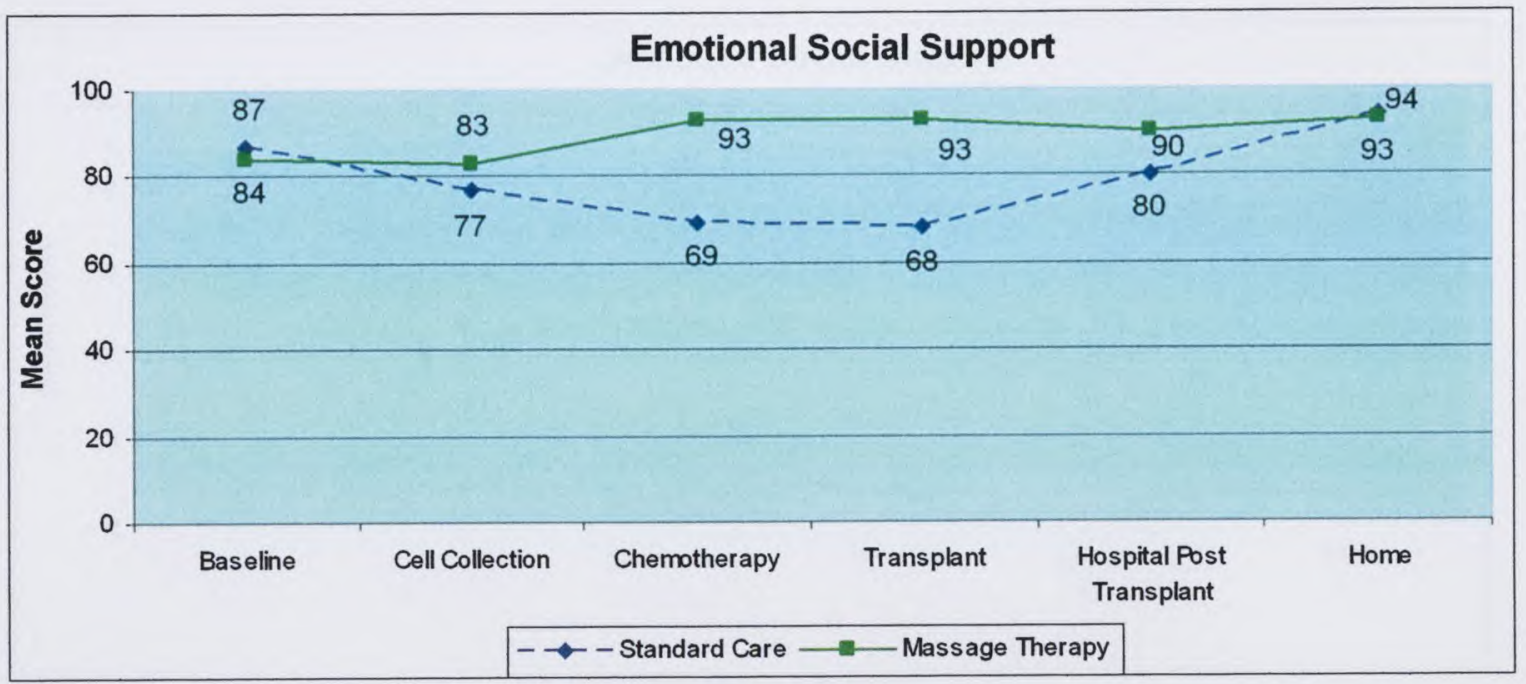


Figure 8 Differences in Affective Social Support Between Massage and SMC Groups

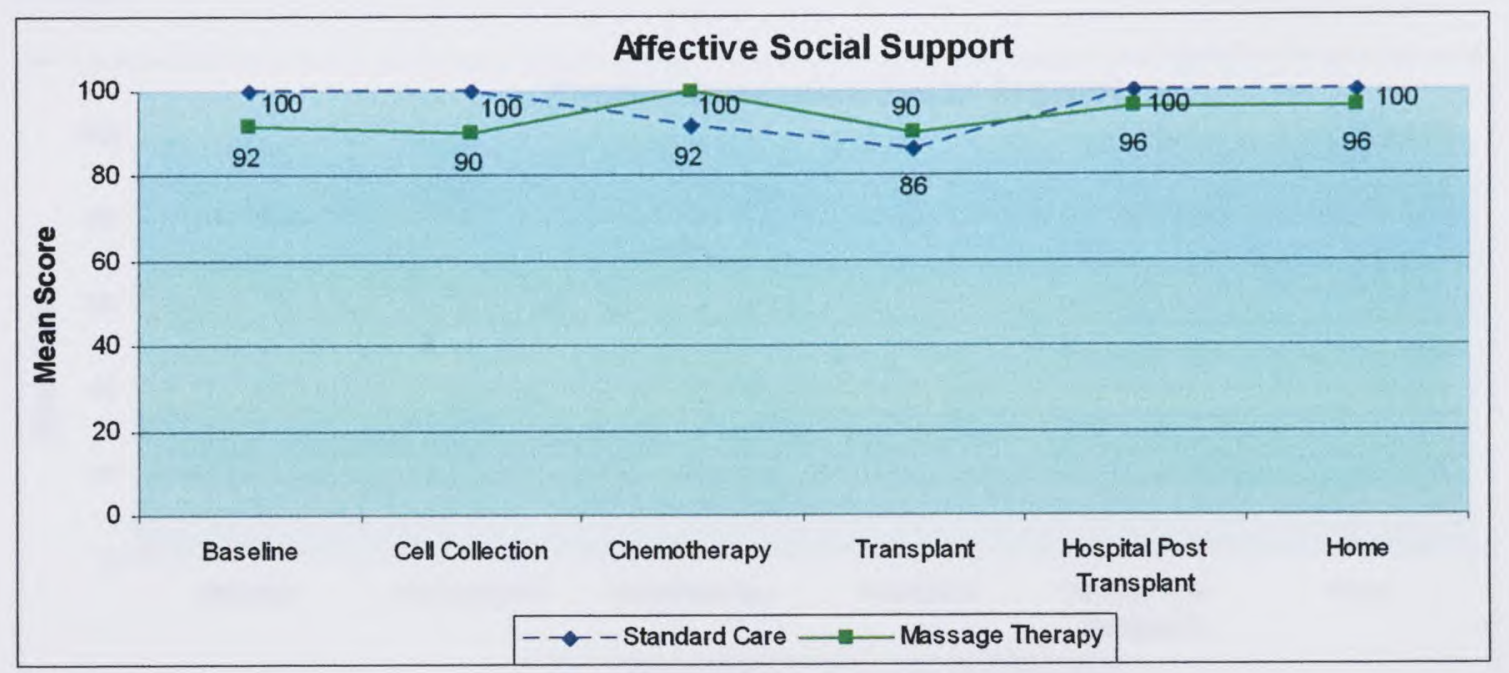


Figure 9 Differences in Positive Interaction Social Support Between Massage and SMC Groups

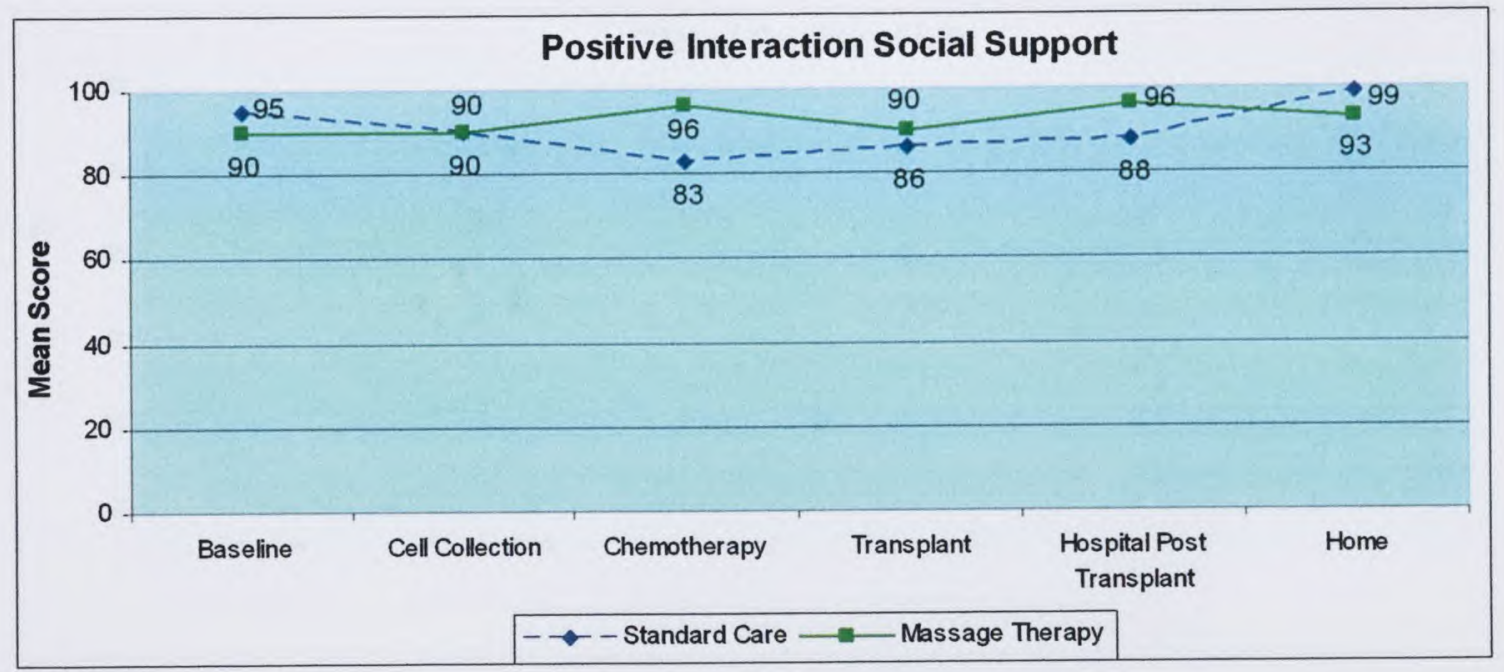


Figure 10 Differences in Global QoL Scores Between Massage and SMC Groups

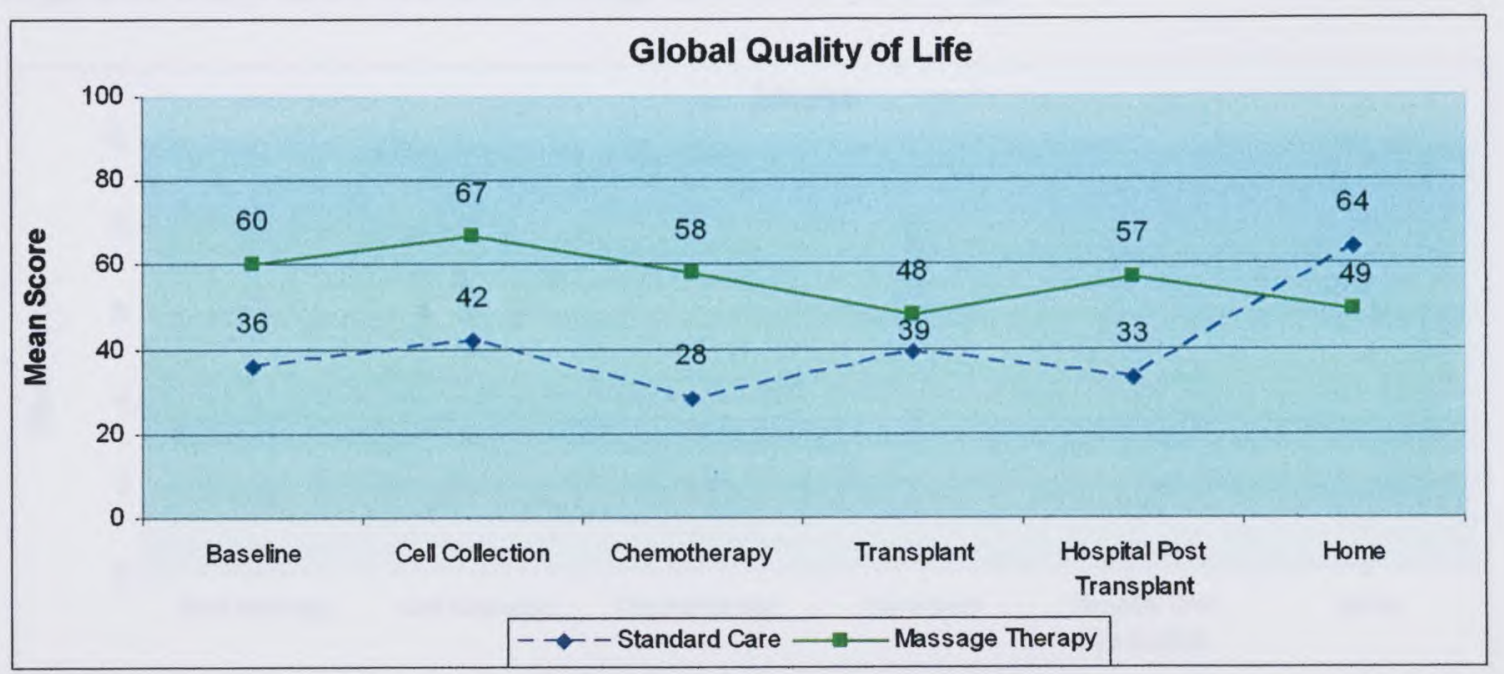


Figure 11 Differences in Stress Ratings Pre- to Post-Massage

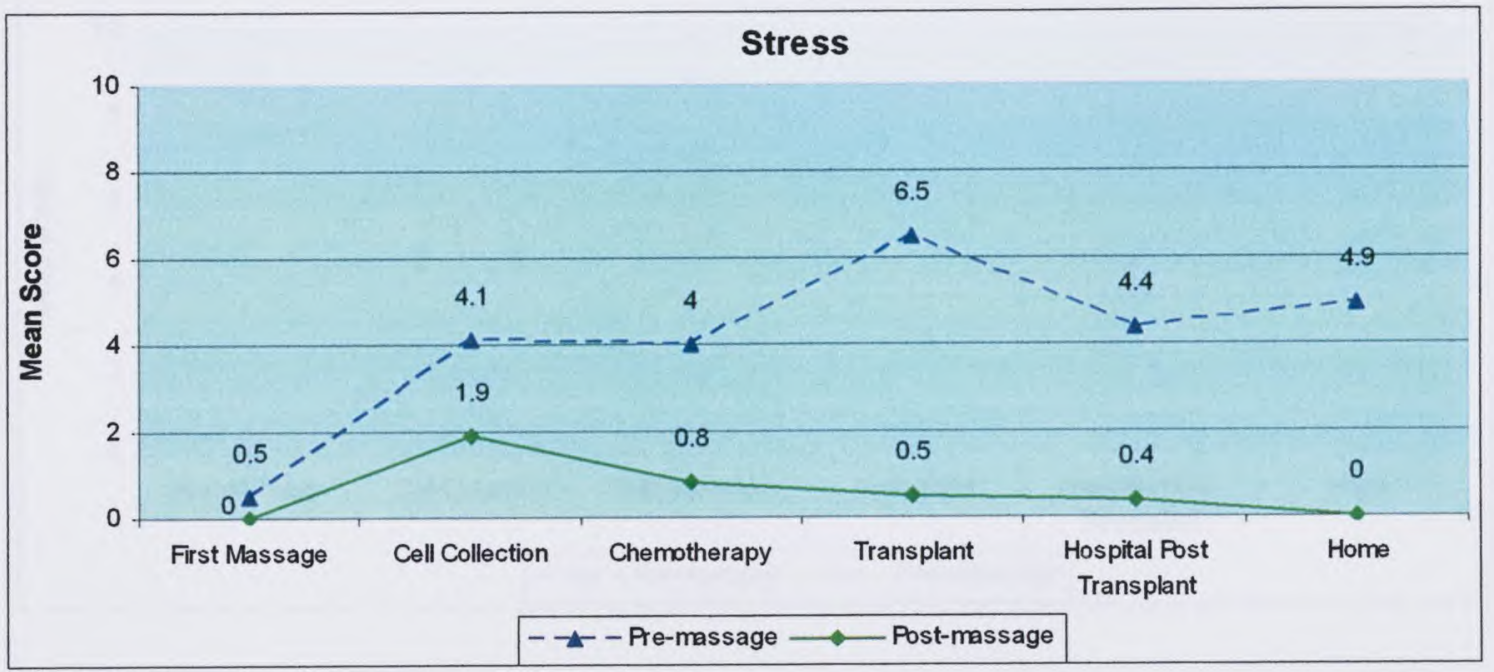


Figure 12 Differences in Relaxation Ratings Pre- to Post-Massage

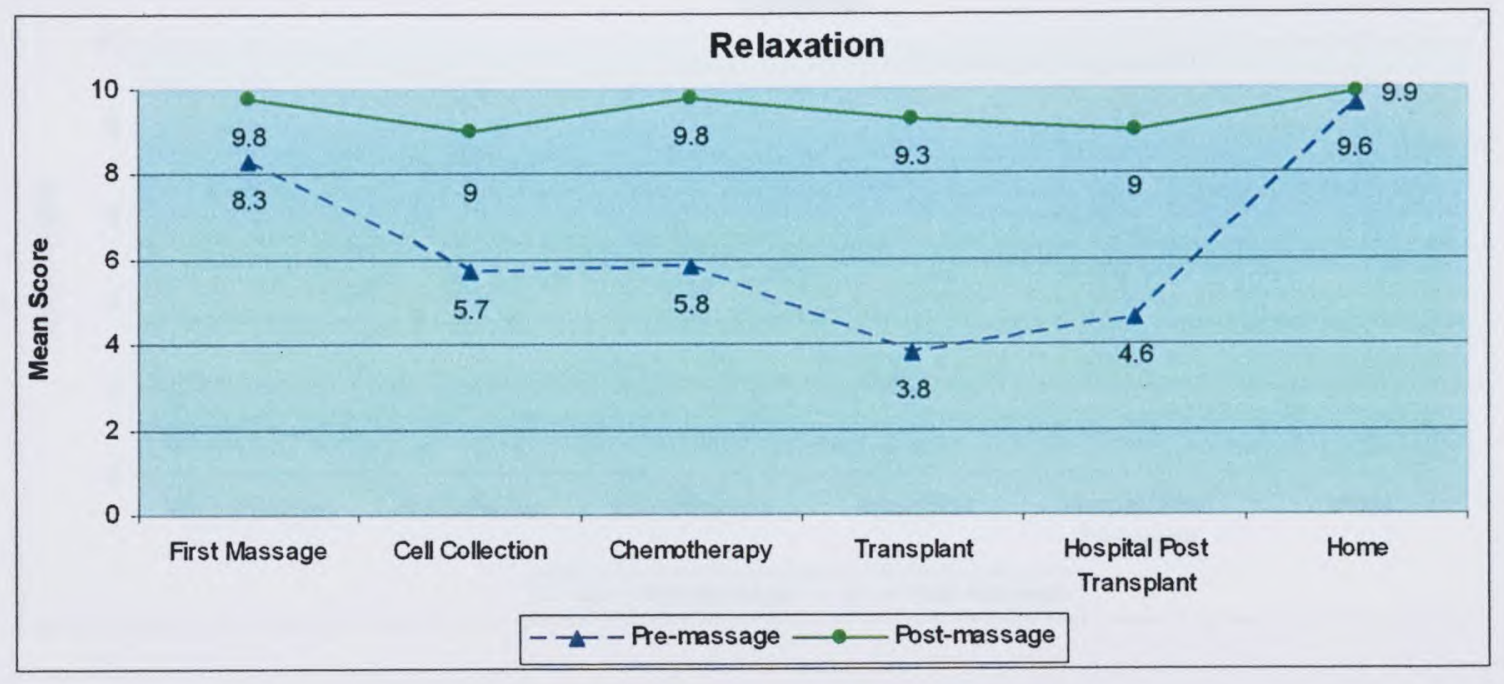


Figure 13 Differences in Comfort Ratings Pre- to Post-Massage

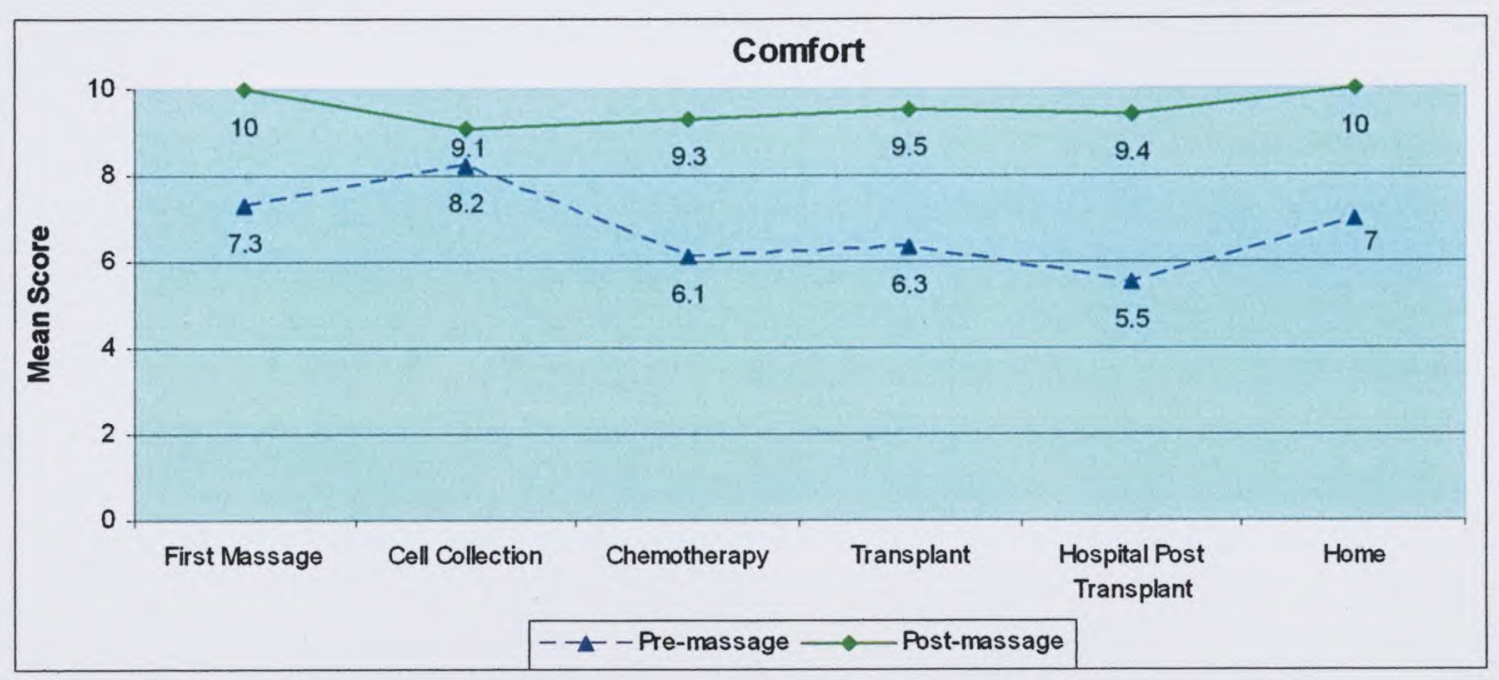

